Portland State University

PDXScholar

1984

\title{
Incest : a study in networking in Multnomah County, Oregon
}

Joanne McClarty

Portland State University

Follow this and additional works at: https://pdxscholar.library.pdx.edu/open_access_etds

Part of the Social and Cultural Anthropology Commons, and the Work, Economy and Organizations Commons

Let us know how access to this document benefits you.

\section{Recommended Citation}

McClarty, Joanne, "Incest : a study in networking in Multnomah County, Oregon" (1984). Dissertations and Theses. Paper 3384.

https://doi.org/10.15760/etd.5249

This Thesis is brought to you for free and open access. It has been accepted for inclusion in Dissertations and Theses by an authorized administrator of PDXScholar. Please contact us if we can make this document more accessible: pdxscholar@pdx.edu. 
AN ABSTRACT OF THE THESIS OF Joanne MCClarty for the Master of Arts in Anthropology presented 15 May 1984.

Title: Incest: A Study in Networking in Multnomah County, Oregon.

APPROVED BY MEMBERS OF THE THESIS COMMITTEE:
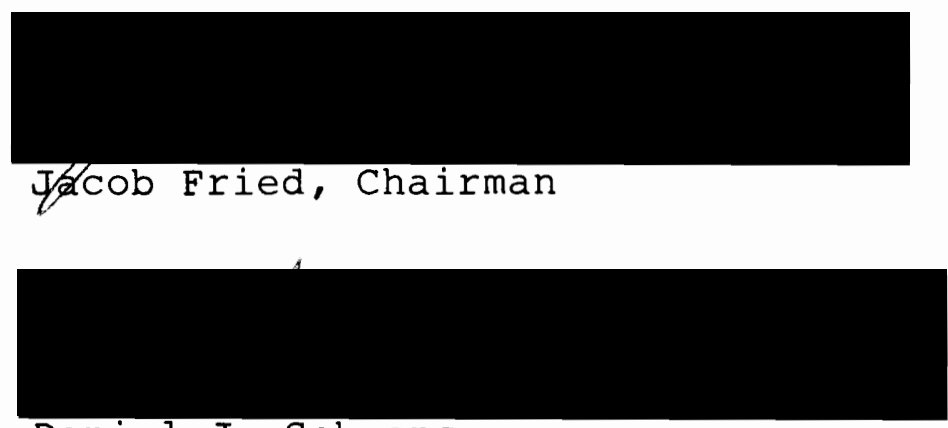

Daniel J. Scheans

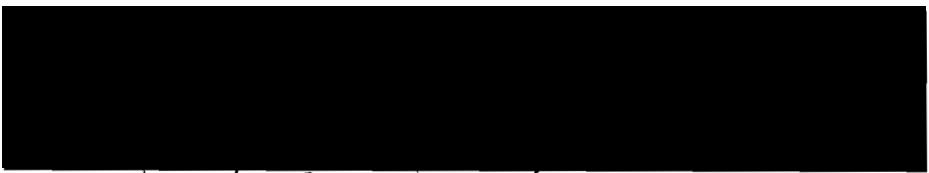

Hugo Mayphard

Reported cases of incest in Multnomah County, Oregon, as in the rest of the country, are increasing yearly. Effective networking between agencies is important in order to successfully work with the problem. The research problem of this study was to determine the effectiveness of the present network of agencies working with incest in Multnomah County. In order to evaluate network effectiveness the 
following objectives were established: to provide a "cultural" description of the major components of the Multnomah County network; to determine whether a common definition of incest among practitioners exists and to compare the networking system in this county with others throughout the country.

The data for this study dealt with how practitioners working with incest viewed the problem. It was obtained through the ethnographic research cycle designed by James $P$. Spradley. First, four task areas composed of different agencies, were established to form the core of the study. They are: Childrens Protective Services; Parents United; Criminal Justice System and Multnomah County Child Abuse Coalition. The first data gathering techniques used was participant observation which involved observing and recording the activities of others in a task area while also being engaged in those same activities. 'This study included over 100 hours of participant observation. The second data gathering technique, the ethnographic interview, is a nonjudgmental approach which allowed information to be acquired from the perspective of each of the eleven key informants interviewed. The thirty-six questions which formed the basis of the interviews were formulated from data acquired in the participant observation research. Once the data was gathered, it was evaluated by means of a taxonomic analysis, i.e., information was compiled into complete or partial 
classifications in order to compare the data for their similarities and differences. Lastly, the data was translated into an ethnographic description of each of the four task areas.

The results of the study were threefold. First, the compilation of an extensive ethnographic description of the four task areas of the network present a view as seen from the practitioners standpoint within the system. Second, an analysis of the practitioner's use of a formal or informal working definition of incest showed that a common systemwide definition does not exist. The study proposed the use of "culture themes" as an alternative to working toward a single common definition. Third, based on the theoretical models proposed by Kee MacFarlane and Josephine Bulkley, the study determined that the incest network in Multnomah County most closely resembles the Systems Modification - Independent Model. Although this model is being applied more effectively than it has been in the past, the increase in funding cutbacks which have resulted in layoffs, "burnout" and career changes among practitioners has seriously threatened viability of the network in Multnomah County.

The study concluded with recommendations on how to improve network effectiveness in order to meet the increasing need for working with incest in Multnomah County. 


\title{
INCEST: A STUDY IN NETWORKING IN
}

MULTNOMAH COUNTY, OREGON

by

JOANNE MCCLARTY

A thesis submitted in partial fulfillment of the requirements for the degree of

\author{
MASTER OF ARTS \\ in \\ ANTHROPOLOGY
}

Portland State University

1984 
TO THE OFEICE OF GRADUATE STUDIES AND RESEARCH:

The members of the committee approve the thesis of Joanne McClarty presented 15 May 1984.
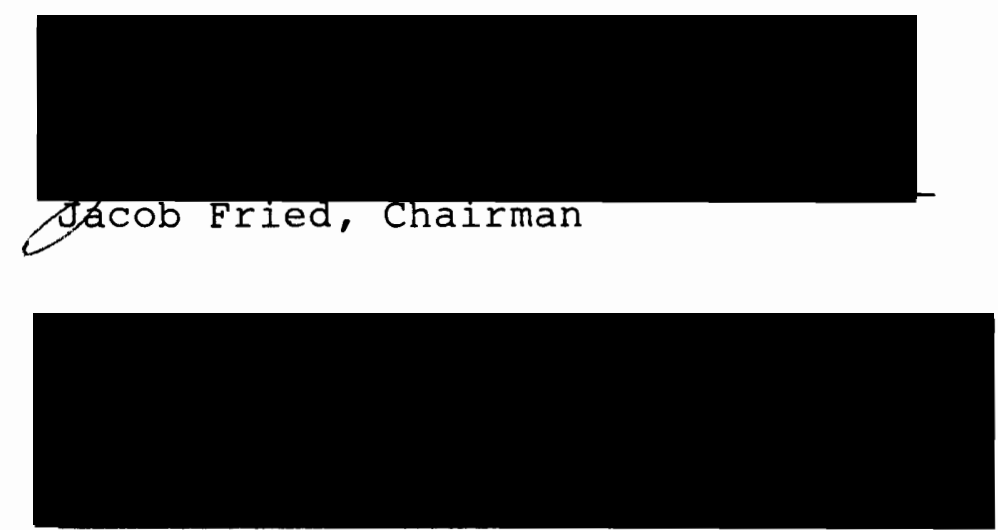

Daniel J. Scheans

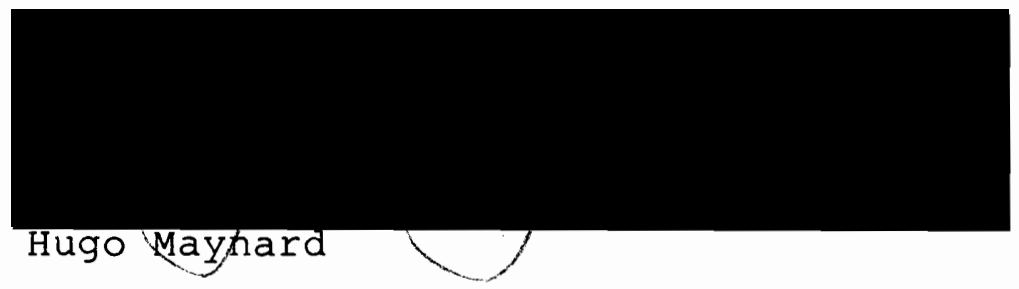

APPROVED :

Stanley Rglich, Dean, Graduate Studies and Research

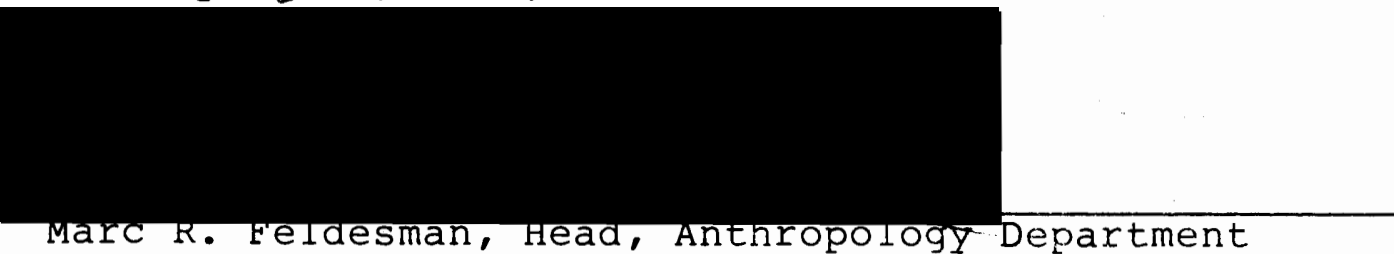




\section{DEDICATION}

To my father

who taught me never to give up but did not live to see the fruits of his teaching. Thank you for believing in me.... 
TABLE OF CONTENTS

PAGE

DEDICATION.

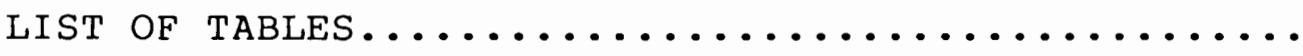

vii

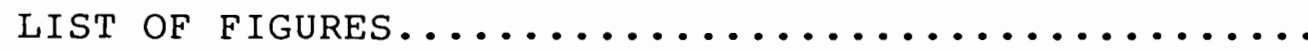
ix

CHAPTER

I INTRODUCTION................... 1

1. Coping with the Problem........... 2

2. Purpose and Thesis of the study...... 2

3. Methodology ................... 4

Research Problem.............. 5

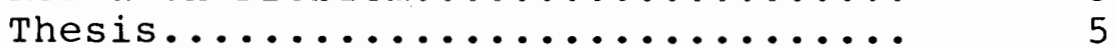

Operational Definitions.......... 5

Research Instrument............. 7

Data Analysis............... 18

Ethnography................. 19

4. Variations on Spadley's Research Model...................... 19

5. Chapter Outline............... 21

I I HISTORY AND DEFINITION............. 23

1. Anthropological Perspective....... 24

2. Historical Perspective.......... 25

3. Present Day Statutes............. 27

4. The Working Definition........... 28

5. summary................. 37 
II MODELS OF NETWORKING............. 40

1. Child Sex Abuse Networks.......... 40

2. The Model in Multnomah County...... 47

IV PRACTITIONERS.................. 52

CLASSIFYING ROLE CATEGORIES.......... 52

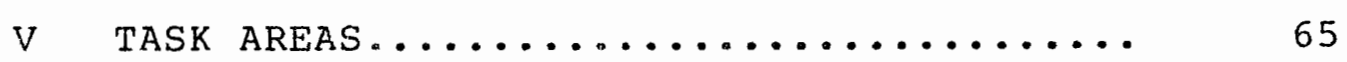

1. Task Area I................. 67

Childrens Protective Services...... 67

A. Hotline Operator........... 67

B. Child AbuseAfter Hours Hotline. $\quad 72$

C. Case Assignment............. 73

D. Ongoing Caseworker........... 75

E. Incest Treatment Program...... 79

2. Task Area II................. 84

Parents United............... 84

3. Task Area III................ 93

Criminal Justice system.......... 93

A. Special Services - Sheriff's

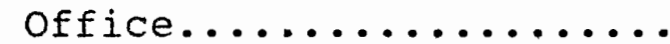

B. Special Services - Portland Police Bureau.......... 98

C. District Attorney - Juvenile

D. District Attorney - Adult

4. Task Area IV.................. 108

Multnomah County Child Abuse

Coalition...............

A. Present Fucntions of MCCAC.....

B. Child Sex AbuseResponse

Project..............

C. Child Abuse and Neglect Team...

D. Legislative Committee......... 
V ENDNOTES.......................

VI THE TOTAL NETWORK.................

1. Density in Networking............

2. Problems in the Network...........

3. This Network: Its organizational

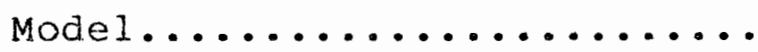

VII SUMMARY RESULTS AND RECOMMENDATIONS.....

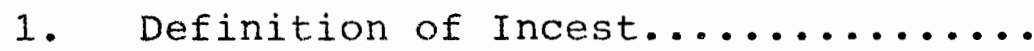

2. Culture Themes - An Alternative to

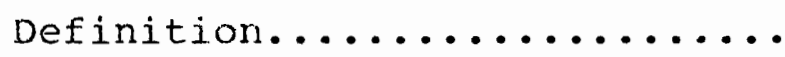

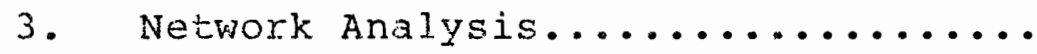

4. Recommendations.

REFERENCES CITED.......................

\section{BIBLIOGRAPHY}

INCEST - - THE ANTHROPOLOGICAL PERSPECTIVE.....

APPENDIX A - CHILD ABUSE REPORTING LAW..........

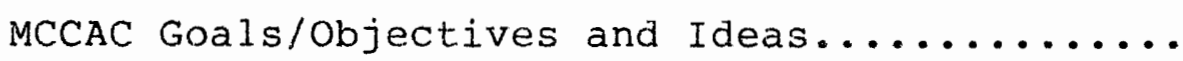

Child Sexual Abuse Response Project..........

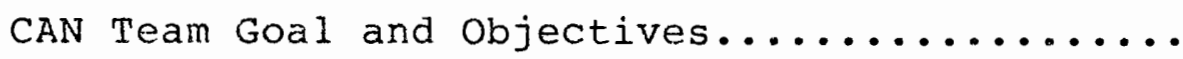


LIST OF TABLES

TABIE

PAGE

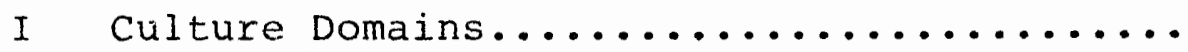

I Ethnographic Interview Questions.........

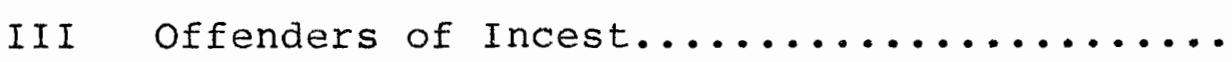

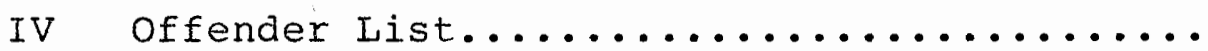

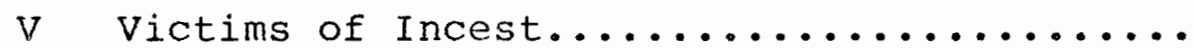

VI Attributes of Incest............... 36

VII Taxonomy of Models................ 45

VIII Incest Should be Treated As............ 50

IX Taxonomic Definitions of Practitioners.....

$x \quad$ Dimensions of Contrast for Practitioners...

XI Componential Definitions of Practitioners..

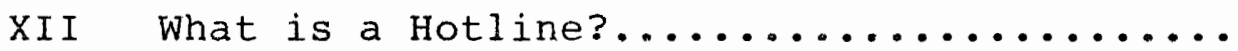

XIII Ongoing Caseworker "A Typical Day"........

XIV Responsibilities at Parents United........

XV The Investigation of the offender........

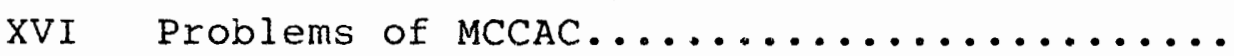

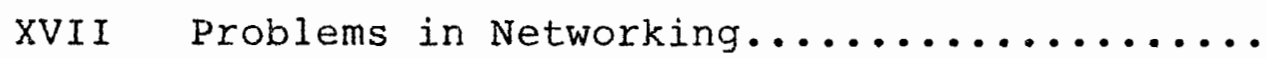

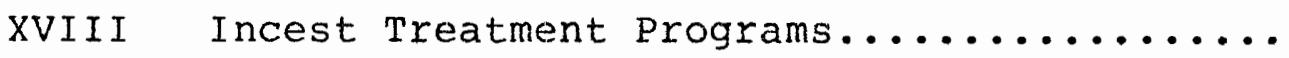

XIX Dimensions of Contrast - Incest preatment..

$\mathrm{XX}$ Componential Definitions of Incest 
TABLE

XXI Culture Themes Among Practitioners.........

XXII Sexual Molestation by Age and

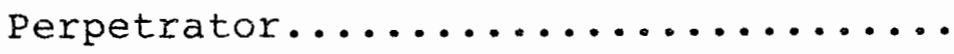




\section{IIST OF FIGURES}

FIGURE

PAGE

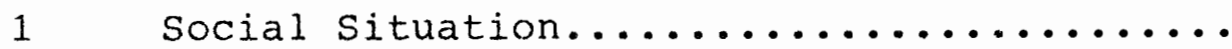

$2 \quad \# 1$ - Hotline Informant.

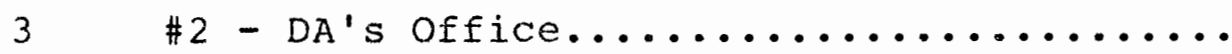

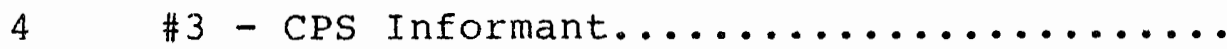

$5 \quad \# 4-$ MCCAC Informant...............

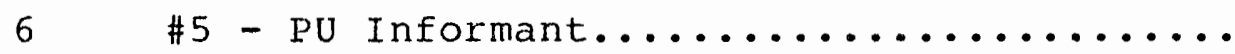

7 \#6 - Juvenile Court - DA Informant.......

$8 \quad \# 7$ - CPS Management Informant.........

$9 \#$ $\$ 8$ - CPS Treatment Informant..........

10 Child Abuse Victims of Sexual Molestation

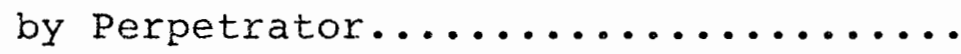


CHAPTER I

\section{INTRODUCTION}

Incest is a crime in all fifty states in this country. According to \#163.525 of the oregon statutes, anyone who "marries or engages in sexual intercourse with a person known to be related, legitimately or illegitimately as an ancestor, descendant or brother or sister either whole or half blood" (Oregon Statutes 1953-1983:1593) is involved in the act of incest and has by law committed a felony. Although the law refers to adult intermarriage as well as intra-familial child sex abuse, this study is concerned only with the latter.

In addition to the criminal aspect, incest is also a social problem which interferes with or breaks down the family system. In parent-child sexual activity, incest changes the parenting role from that of a protector and caretaker to a violator of one of their childrens' basic rights and fundamental possessions, i.e., their bodies. Thus, incestuous behavior produces multiple victims both intra-generationally (children of the same generation) as well as inter-generationally (one generation affecting the next) within family systems. 


\section{COPING WITH THE PROBLEM}

A great number of established agencies or systems are involved in dealing with incest both as a crime and as a social problem, i.e., law enforcement, child protection, legal, religious, educational, judicial and treatment services. Networking between these agencies is essential in order to prosecute the crime and provide the incest family with adequate help. According to Rueveni, networking "conveys interdependence, flow, linkage, interactions and meshing of structure - a system" (1979:17). A much better chance of success in working with incest is possible if the linkage between the agencies is strong. The analysis of the network of agencies concerned with incest in Multnomah County, oregon is the central issue of this study.

\section{PURPOSE AND THESIS OF THE STUDY}

For the past ten years there have been repeated attempts to develop a strong institutional network to deal with incest in Multnomah County with the number of reported cases of incest in this country doubling since 1980. The need for a more effective system of interacting agencies to work with the problem has become critical.

The purpose of this study is threefold. First, to observe the key agencies involved in the network and provide a current description of the networking system. An analy- 
sis of the incest network is particularly important during this time of cutbacks and funding problems in order to acquire information to be used in combining resources which will strengthen the system and insure its survival. Second, to determine to what degree a common definition of incest is possible and/or necessary to insure unity within the network. The study will also propose alternative approaches to a common definition which could provide the needed continuity for the network to operate effectively. Third, since theoretical models provide a pattern of unity for systems, this study will compare the incest network in Multnomah County with other existing systems throughout the country in order to determine if the latter contains the components necessary on which to build an effective network.

Since most of the agencies being observed serve the entire county, the boundary lines for this study will be the broader political unit, Multnomah County, instead of the City of Portland. Conversely, even though most of the agencies involved deal with all aspects of child sex abuse, this study will focus only on incest except when it is important to consider the problem in a broader context.

The research design used to gather information and evaluate the data for this study is an anthropological model developed by James P. Spradley (1979). An application of Spradley's specialized field work technqiues will 
provide the tools to assess the strengths as well as the weaknesses in the Multnomah County network as revealed by the practitioners who work within the network.

To summarize: the objectives of the study are to provide a "cultural" description of the major components of the Multnomah County network; to determine whether there exists a commonly agreed upon definition of incest; and to compare the networking model in this county with others throughout the country. These results will provide information which can be useful in strengthening the network in Multnomah county and, thus, providing better service to incest families.

\section{METHODOLOGY}

This study, focusing on incest, follows the ethnographic research cycle outlined by James P. Spradley (1980:27). The steps in his procedure are:

1) Define a research problem;

2) Formulate hypothesis;

3) Make operational definitions;

4) Design a research instrument, define the social situation, use participant observation, establish culture domains, do ethographic interviews;

5) Analyze the data; and

6) Write an ethno,raphy. 
Research Problem

The principal research problem is to determine the effectiveness of the present network design consisting of those key agencies working with incest in Multnomah County with the intention of offering recommendations for improvement.

Thesis

Networks are comprised of many components. Each component contributes certain activities or services to a network. Some activities are shared, others are unique to a particular component of the network. However, all components with their similarities and differences must work together in order for the network to function effectively. I assert the following thesis: changes in the network in Multnomah County, Oregon are necessary to unify the system so that it will function more effectively in working with the problems of incest.

Operational Definitions

The following definitions are critical to this study:
1) Network

a) "an interconnected or interrelated group or system"

b) "coordinated services dealing with specific aspects of the problem" (Merriam 1978:353). 
According to social networking theory "a network determines the flow of messages back and forth from one member (group) to one or more other members of significant others outside the family (system)" (Brommel, Bernard and Galvin 1972:17). The type of networks include chain, $Y$ network, wheel and all channel (see Brommel and Galvin for descriptions of each). For purposes of this study it will be necessary to consider only the "chain" type. In the "chain" network the flow of messages begin at a point and arrive at an end point. The links in the chain provide message flow and feedback. The chain operates both horizontally and vertically with the feedback regulating the "directions of messages up, down, or across the Iines of the network" (Brommel et al 1982:18). The network to be analyzed in this study is the chain type.

2) Practitioner

"one that practices a profession" (Merriam and Merriam 1978:414). The word "practitioner" has wider implications as it relates to this research. It includes all who work with incest problems, either directly with clients or indirectly in administrative or committee member roles.

3) Problem

"dealing with human conduct or social relationship" (Merriam and 
Merriam 1978:421).

Incest qualifies as a problem because in this culture it is a breach of human conduct and a disrupter of social relationships.

Research Instrument

The Development Research Sequence (DRS) of James P. spradley was the instrument chosen for this study. This particular research instrument guards against ethnographer's bias and provides the tools for achieving a subjective, non-judgmental perspective. It allows the ethnographer to observe each of the task areas through the eyes of those who work within the network.

The DRS model of Spradley utilizes both the ethnographic interview and the participant observation as the data gathering techniques. His procedure follows:

Define the Social Situation. All social situations involve three primary components: place, actors and activities. This study focuses on the activity: working with incest (see Figure 1). The actors and places that form the cluster around this activity are combined into four task areas: Childrens Protective Services (CPS); Parents United (PU); Criminal Justice System (CJS); and Multnomah County Child Abuse Coalition (MCCAC). The above task areas represent the main types of agencies working with incest, i.e., government service agency; legal agency; private 
SOCIAL SITUATION

Report, Investigate, Treat
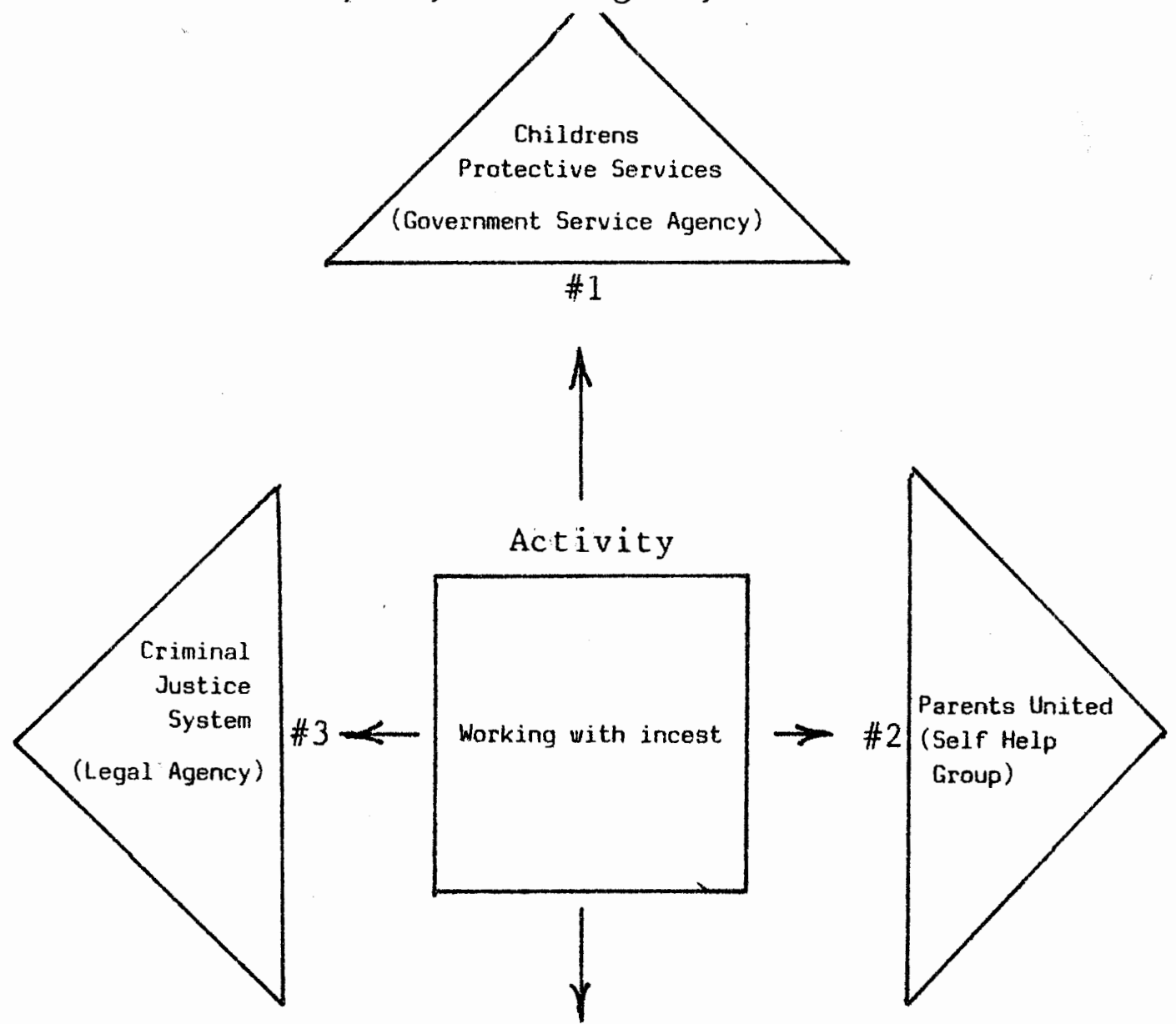

Investigation

Prosecution

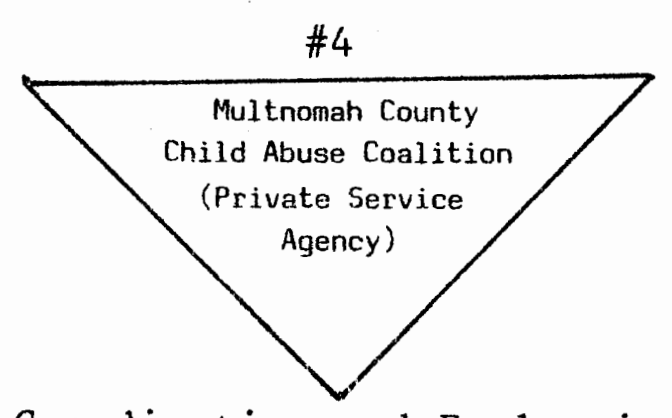

Treatment

Coordination and Evaluation

of Network

Figure 1. Task areas with designated activities. 
service agency and self-help group (see Chapter $V$ for specifics).

Use Participant Observation. The use of participant observation as the first field work technique in this study, provided me with a suitable instrument to observe the activities within each of the four task areas and determine the strengths and weaknesses from the viewpoint of the practitioners working within the network.

According to Spradley, the participant observer "comes to a social situation with three purposes: first, to engage in activities appropriate to the situation; second, to observe the activities, people and physical aspects of the situation". The observer will experience "being insider and outsider simultaneously" (Spradley 1980:54). Lastly, to be involved in record keeping, i.e., "keep a detailed record of both objective observations and subjective feelings" (Spradley 1980:58).

In order to accomplish this type of observation, the participant observer must combine a "heightened sense of awareness with the ability to take in a much broader spectrum of information than the average observer" (Spradley 1980:56). According to Spradley, the participant observer must also increase his/her introspectiveness while requiring an acute awareness of what is going on around him/her. "In a real sense you will learn to use yourself as a research instrument" (Spradley 1980:57). 
Spradley distinguishes different levels of participation: non-participation, passive participation, moderate participation, active participation and complete participation. Because I am involved in the network as a practitioner in the treatment of incest, I chose to use "complete participation" in my research approach. This is the highest level of involvement for ethnographers. According to spradley complete participation is accomplished when the ethnographer studies "a situation in which they are already ordinary participants" (Spradley 1980:61).

All my observations in this study were recorded first in condensed notes taken in each task area and these were later transcribed into detailed notes.

Establish Culture Domains. After extensive participant observation in each of the four task areas, I set up thirty-two culture domains (see Table 1). A culture domain is "a category of cultural meaning that includes other smaller categories" (Spradley 1980:88). Each cultural domain contains a cover term (the name of the domain); included terms (those terms that fall under the cover term) and a semantic relationship (the linking together of two categories). I established culture domains by first determining the semantic relationship between the cover term and those included terms acquired in my participant observations (see Table 1). After I established the semantic relationship, I then expanded my list of included terms 


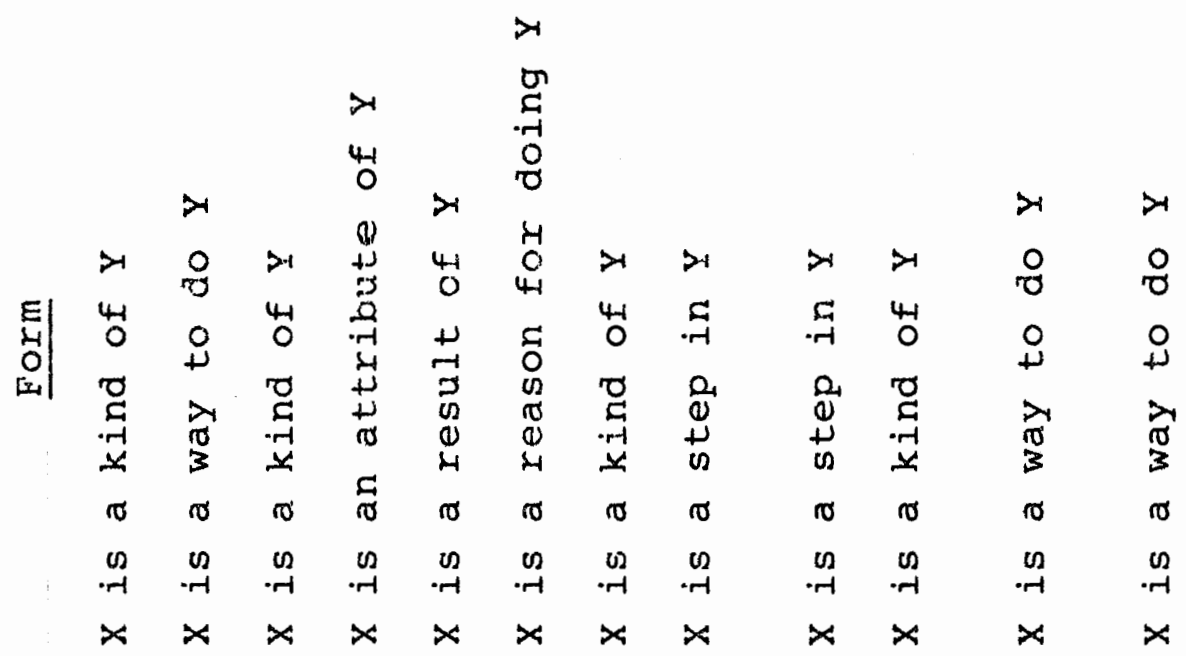

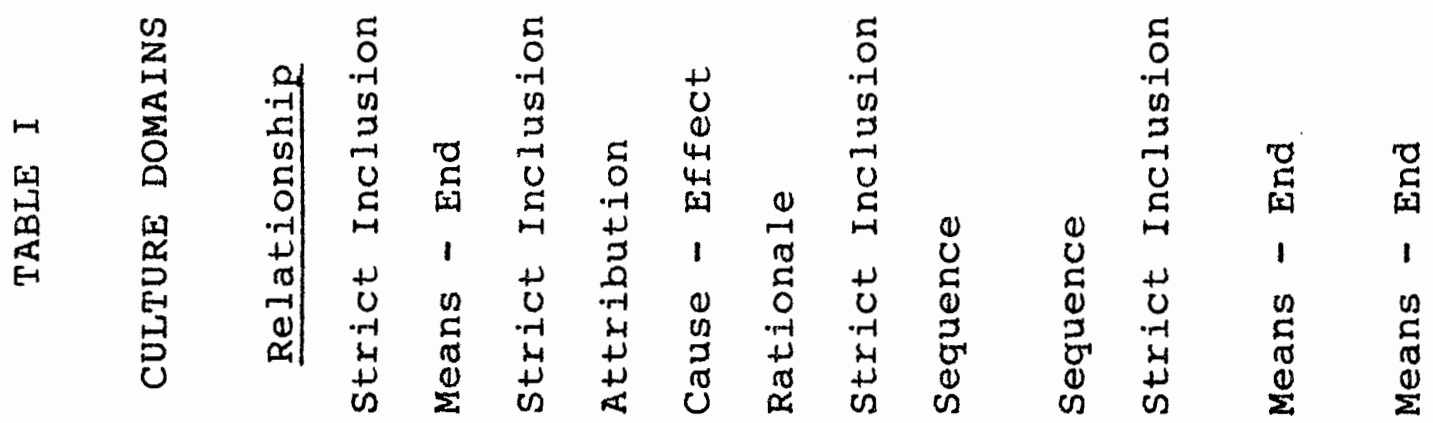

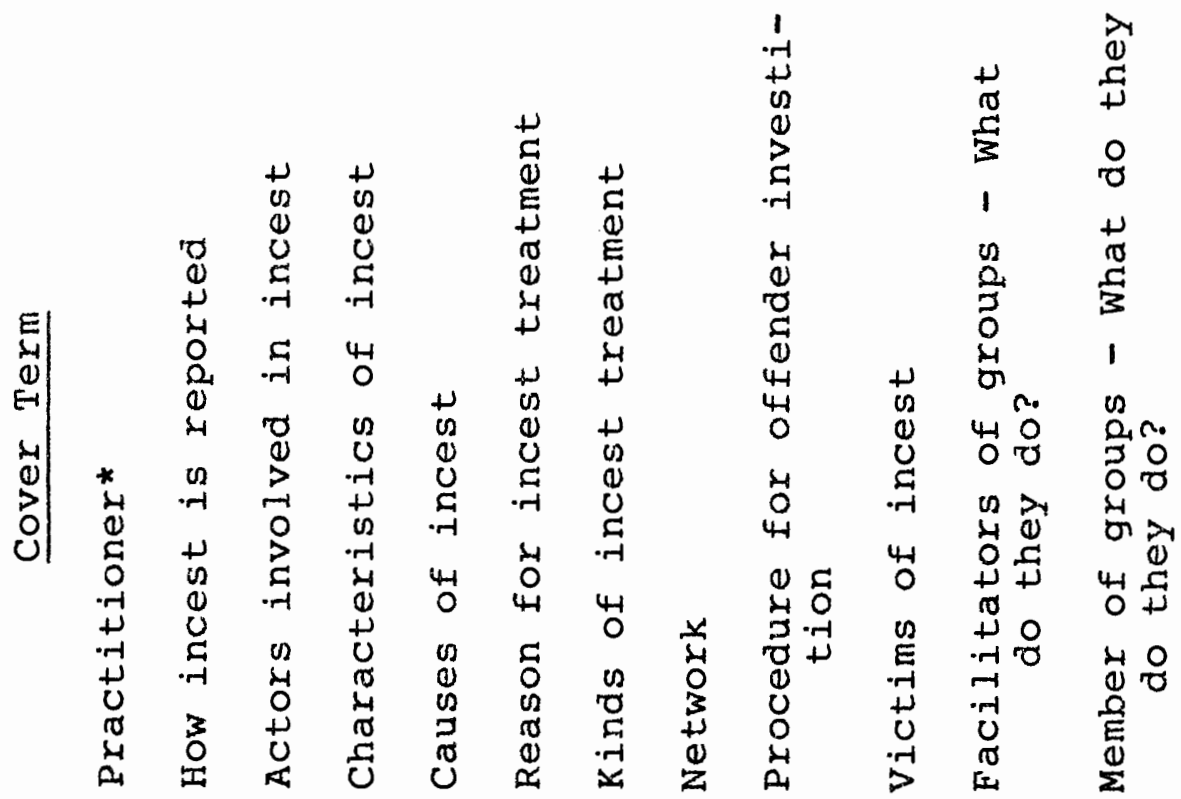




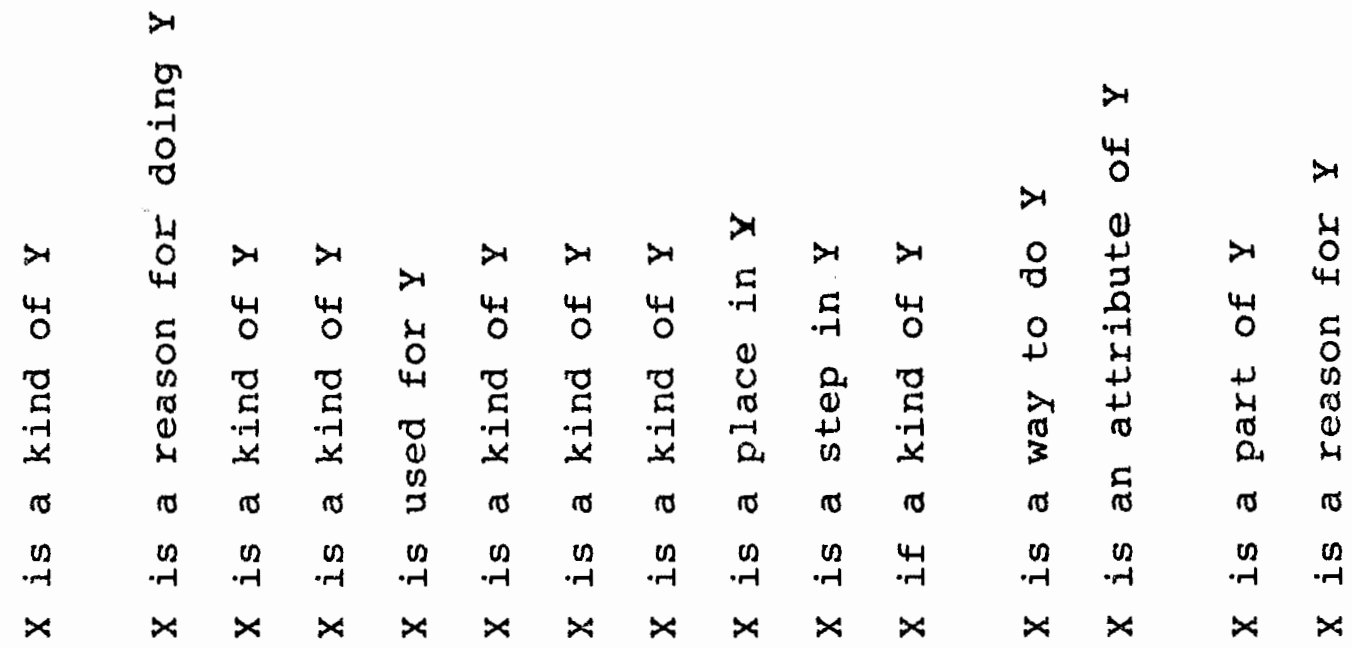

产

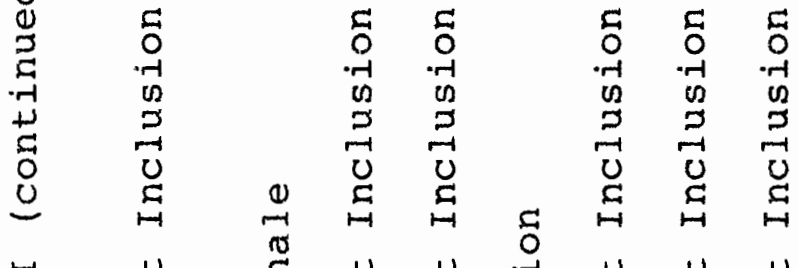

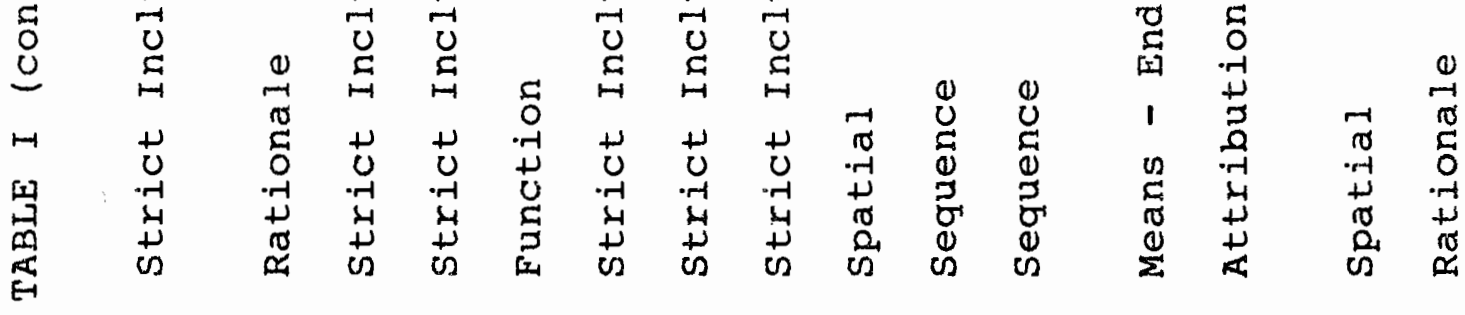

0

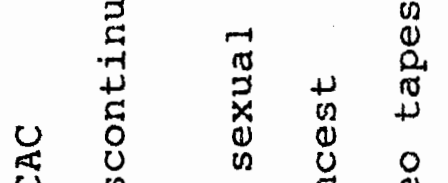

导

出 पु

¿

$\begin{array}{ll}-1 & 0 \\ 0 & \text { in } \\ 0 & 0\end{array}$

प्र $\begin{array}{cc}0 & 0 \\ 0 & 0 \\ 0 & 0 \\ -1 & 0\end{array}$

त)

岂

$\begin{array}{ll}5 & \pi \\ 0 & 0 \\ 0 & 0 \\ 0 & 0\end{array}$

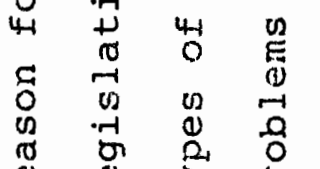

出

U 5

究

$\stackrel{+}{\stackrel{N}{ \pm}}$

a 4 


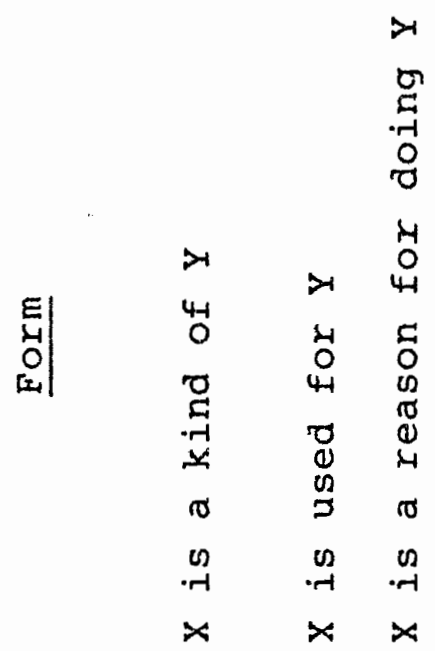

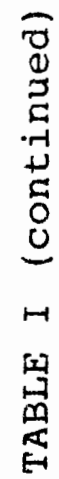

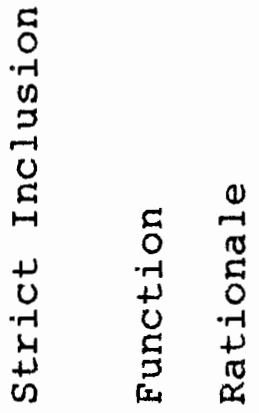

$\stackrel{1}{2}$

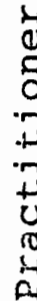

㟧

苂

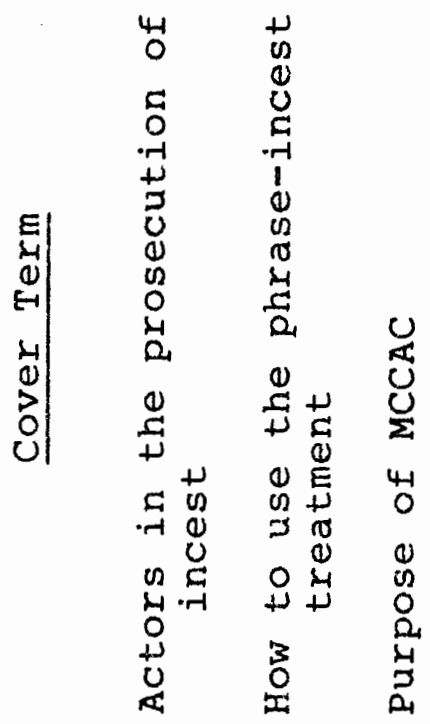

$\sigma$

0

$x$

4
0
0
0
0
0

$\pi$

í 
through further participant observation and later through ethnographic interviews.

Do Ethnographic Interviews. Once the culture domains were established, I formulated thirty-six questions based on the semantic relationships in the culture domains. These questions formed the basis of my second field work technique; the ethnographic interview (see Table II). Based on their role in the network, the eleven informants interviewed were selected from the four task areas. Twelve of the thirty-six questions were asked of all informants in order to compare responses across the network, e.g., Who are incest offenders? Other questions (fifteen) that were specific to a task area or a particular role were asked only of informants who practice in that area, e.g., What is the procedure for investigation of an offender? The remainder of the questions (eight) while not relevant to all informants, did cross over task areas, e.g., Who provides incest treatment?

According to spradley, the three most important components of an ethnographic interview are: explicit purpose, ethnographic explanation and ethnographic question. First, explicit purpose requires the ethnographer and informant to realize the objectives of the interview. It is the responsibility of the ethnographer to make the purpose clear to the informant. Secondly, ethnographic explanations are essential to produce accurate information. 
TABLE II

ETHNOGRAPHIC INTERVIEW QUESTIONS

General Questions -- Asked of all informants

1) Who do you think are included as practitioners in incest?

2) What are the different ways incest can be reported?

3) Who are all the people involved in an incestuous situation?

4) What do you think causes incest? Should it be treated as a crime, mental illness or family dysfunction?

5) Give me as many characteristics of incest as you can think of.

6) What are the steps in the network dealing with incest in Multnomah County?

7) What are the different problems that hinder networking as you see it?

8) Who are the victims of incest?

9) What is the difference between incest and stranger molestation? Is there any other kind of child sex abuse?

10) Who are incest offenders?

11) What is the purpose of MCCAC as you see it? What are the problems at MCCAC?

12) What is the question to which the answer is incest? 
TABLE II (continued)

Crossover Questions -- Asked of all informants dealing in the issue

1) What activities might you carry out in a typical day?

2) What are your duties as they relate to incest? What other responsibilities are carried out by the department?

3) Has your unit been affected by cutbacks and loss of personnel?

4) What are the kinds of incest treatment?

5) Who provides incest treatment?

6) What are the reasons for providing incest treatment?

7) How do you use the phrase "incest treatment"?

8) Who should coordinate an incest family from report through treatment?

Specific Questions -- Asked only in one task area

1) Is the present unit the same as a few years ago? How has it changed? -- (Portland Police Bureau)

2) What is the difference between your unit and the same unit of the Sheriff's office? -- (Portland Police Bureau)

3) In incest treatment what do facilitators do? (PU?)

4) What is the criteria for being a member? Who gets turned down? (PU and CPS?) 
TABLE II (continued)

5) What are the different kinds of groups offered? (PU and CPS)

6) What is a group like? Take me through a typical group. (PU and CPS)

7) What is the difference between groups at PU and those at CPS or juvenile court? (PU and CPS)

8) What is the difference between your groups and those provided by private agencies? (PU and CPS)

9) How did MCCAC develop? How did CSARP develop? (MCCAC)

10) What are the bills now in the Legislature that relate to incest? (MCCAC)

11) What is the procedure for investigation of an offender? (Portland Police Bureau)

12) What is the procedure for prosecution? (CJS)

13) Could you take me on a tour of the Grand Jury Room? (CJS)

14) What do you use video tapes for? (CPS)

15) How do you refer to cases of incest as a prosecutor? (CJS) 
1) Project explanations (general statements explaining the project);

2) Recording explanations (explain why things are being written down or tape recorded);

3) Native language explanations (encouraging informants to talk as they would in their own culture area);

4) Interview explanations (offer information as to the type of interview that will take place); and

5) Question explanations (explaining what kind of question is going to be asked the informant).

Thirdly, ethnographic questions must be carefully planned. Spradley lists three main types:

1) Descriptive questions, e.g., Could you tell me what you do in a typical day?

2) Structural questions, e.g., What are all the characteristics of incest?

3) Contrast questions, e.g., What is the difference be tween incest and stranger molest? (Spradley 1979:59)

\section{Data Analysis}

Once the participant observation and ethnographic interviewing were completed, it was necessary to determine which culture domains should be selected for taxonomic analysis. Those selected were developed into either complete or partial taxonomies (classifications) in order to compare their similarities. Then a componential analysis was 
completed on those taxonomies which demanded a further breakdown in order to compare contrasts as well as similarities. Spradley describes componential analysis as "looking for the units of meaning that people have assigned to their cultural categories" (Spradley 1980:131). These units of meaning were then compiled and a paradigm (chart) was created (see Chapter IV, Table XI for example). The paradigm included the culture domain and the dimensions of contrast. Once the domains had been selected and analyzed, I then grouped together those culture domains that related directly to my thesis and those which were necessary for explanation and clarification.

\section{Ethnography}

Lastly, I transcribed my field notes and tape recordings into an ethnographic description of each of the four task areas: Childsens Protective Services, Parents United, Criminal Justice System, and Multnomah County Child Abuse Coalition (see Chapter V). These notes and tapes were the result of over one hundred hours of participant observation and ethnographic interviews.

4. VARIATIONS ON SPRADLEY'S RESEARCH MODEL

While the DSR Model provided the basis of this study, I found it necessary to omit some parts and adapt others to my particular needs. One adaptation involved participant 
observation. Since I was dealing with such a large number of activities in the four task areas, and because I was quite familiar with the workings of most of these areas, I eliminated the preliminary observations which deal with "establishing the atmosphere". Rather, I spent the observation time asking questions and observing aspects specific to my activity area, i.e., working with incest, At other times, when I was present in the role of a practitioner, I would acquire information on more general attitudes and working relationships.

Since my activity area was so large and diverse, it was important to know the reactions of practitioners across the entire area. Therefore, I interviewed eleven informants in one or two sessions. This is a variation from Spradley's model in which he typically conducts in-depth interviews with one or two informants. I also wanted to discover likeness and difference in philosophy and approach to the network. Dealing with eleven informants instead of one or two gave me a contrasting perspective.

Utilizing specific, pre-planned questions was a diversion from the more informal, free floating approach of the Spradley model. This procedure gave me information that provided a better basis of comparison and helped me to determine where the overlap areas in the network were. While the predesigned questions were always asked, each informant 
was also asked spontaneous questions as the interview progressed.

When discussing "complete participation" Spradley warns that being too familiar with the activity area can be a liability in terms of acquiring unbiased information. I found this to be true. However, the tape recorded format in my ethnographic interviews increased my credibility as an "ethnographer who was also a practitioner". The more formal tape recorded sessions seemed to place informants in the role of giving information "to someone else". The result was more candor and accuracy in the information they provided.

These variations, i.e., eliminating the preliminary observations; using a larger number of informants; using specific, pre-planned questions; using complete participation; gave more structure to my research and seemed to improve the validity of practitioners' responses. More importantly, it was possible with this format to test the research for contrasts which was critical in order to make comparisons in specific areas like common definition.

\section{CHAPTER OUTLINE}

Chapter I introduces the issues that make incest a crime and a social problem; states a thesis; and indicates how research using ethnographic field work techniques were carried out. 
Chapter II presents a historical and legal history of how English and American societies have treated incest and indicates how and why the definition of incest is a critical issue for the study.

Chapter III analyzes the social organizational aspects of dealing with incest using network models to compare with the network in this study.

Chapter IV deals with the personnel of the "incest network", their statuses and roles, and reveals how practitioners conceptualize incest as a problem.

Chapter $\mathrm{V}$ examines the incest network through observations of the four task areas, analyzes their involvement in four distinctive aspects - reporting, investigating, prosecution and treatment.

Chapter VI provides an overall evaluation of how the network is organzied and shows which of several network models (as ideal types) the Multnomah county incest network most closely resembles.

Chapter VII summarizes findings and concludes with recommendations and guidelines for improving the performance of the incest network. 
CHAPTER II

\section{HISTORY AND DEFINITION}

The Oregon Child Abuse Reporting Law was enacted in 1971 (see Appendix A, Table I). However, it was not until its revision in 1975 that the law specified "sexual molestation" (child sex abuse) as a reportable condition of abuse. At the same time, public education programs were being developed to demonstrate the magnitude of the incest problem. The Oregon State Department of Human Resources in their "Ten Year Overview", a statistical report on child abuse in Oregon, states that reported cases of incest are on the rise. "Reports of sexual abuse increased from 86 in 1975 to 528 in 1978, a 5018 increase" (Department of Human Resources 1980:31. The reported number of cases in 1982 was 1,318 (see Appendix A, Tables II and III). While "sexual abuse" includes incest and "stranger molest", i.e., someone unknown to the victim; less than $15 \%$ of the 1982 figure involves the latter.

It is well substantiated that "reported" cases of incest have risen significantly since 1975. Does this mean that incest has increased or merely that through mandatory reporting and a better education and information system we have more cases of incest reported? It is almost impossible to answer this question since there is no way to 
determine the actual incidence of incest in our present society or to secure data on past abuse. What we do know is that incest is not a new problem, It has been prohibited in some form for as long as there have been social groupings or kinship systems.

\section{ANTHROPOLOGICAL PERSPECTIVE}

The incest "taboo" or prohibition in primitive cultures has been the subject of numerous anthropological studies. According to Margaret Mead, the incest taboo "serves to distinguish between those with whom sexual relations are forbidden and those with whom they are permitted" (Mead 1968:115).

There appears to be as many reasons proposed for the incest taboo as there are cultures practicing the prohibition. However, anthropologists would agree that all for almost all) cultures have some type of taboo or prohibition governing sexual activity and/or marriage within their family or clan. Many culturs consider "primary incest", i.e., the strongest prohibition, as relating to adult family members with only secondary concern for sexual relations between adults and children.

In our own American culture our primary concern is sexual relations between aduits and children but we have a much different view of what constitutes "family members" (see Table V). 
The extreme variations of the prohibition from one culture to the next would involve a complicated and extensive study. Therefore, a general discussion of the incest taboo and its universality will not be included in this study (see Appendix A, Figure 10 for suggested readings on this subject). The boundaries of this dissertation extend only to the conditions of prohibition as specified in the oregon state law, and their impact on practitioners working with incest in Multnomah County, oregon. Furthermore, the information acquired from practitioners working with incest must be viewed as "folk knowledge" and does not necessarily correspond with scientific literature.

\section{HISTORICAL PERSPECTIVE}

In order to understand the background of our present prohibitions on incestuous behavior and to learn how our present legal statutes came into being, it is necessary to examine briefly the events which provided the foundation of our legal history.

Laws to protect children were first developed in England in the 16th century. These laws were established to protect children from "free sexual license by adults". In 1548 a law was passed protecting boys from forced sodomy, and in 1576, a law protecting girls under 10 from forcible rape! In the $1600^{\prime}$ 's childrens' sexual innocence and naturalness were interpreted as a source of temptation for the 
child as well as for adults that he/she came in contact with. Therefore, "during this time, children were to be considered potentially sexually dangerous and consequently asexuality was to be enforced" (Schultz 1982:22-24).

Our laws in the United States were based on English law. Our early sexual abuse laws emphasized "conviction of offenders with little attention paid to victims" (Schultz 1982:25). In 1874 in New York, the first social welfare agency dealing with sexual abuse and immoral conduct, i.e., sexual behavior, was established. The period from 1900 to 1930 produced the child protection programs and a concern for rehabilitation of victims and offenders.

It was also during this period that the responsibility for dealing with the protection and rehabilitation of victims shifted from the private to the public sector. In the 1930 's the Department of Health, Education and Welfare of the United States Government created the Childrens Protective Services Department as a branch of the Childrens services Division. This department was established for the protection of children from abuse and neglect. However, understanding the scope of the problem of child sexual abuse and the need for treatment did not receive real impetus in this country until a political movement in the 1970 's. This movement was characterized by a concern for the equality of children's rights and eventually resulted in passage of the Child Abuse Prevention and Treatment Act 
of 1974. This act was followed by laws requiring professionals working with children to report any signs of abuse. Attached to the Act of 1974 were federal funds to be used for research, in-service training of personnel and treatment for incest families.

\section{PRESENT DAY STATUTES}

The National Council on Child Abuse and Neglect (NCCAN), a monitoring and policy-making organization of the federal government, was developed out of the Child Abuse Prevention and Treatment Act of 1974. This Council defines incest as:

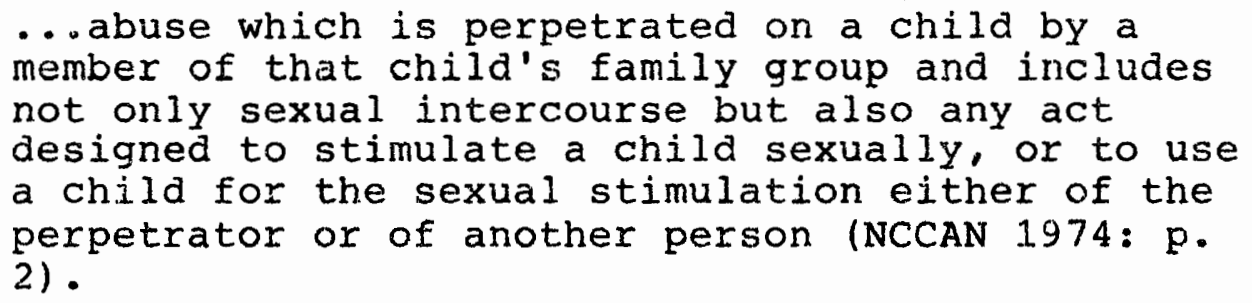

The Oregon Legislative Assembly passed the first child abuse reporting law in 1971. It was amended in 1975 and 1977 (see Appendix A, Figure 1). This 1971 legislation was followed by our present state statutes relating to incest. They are as follows:

163.525 INCEST (1977): Marries or engages in sexual intercoursewith a person known to be related, legitimately or illegitimately as an ancestor, descendant or brother or sister either whole or half blood. Class C felony: maximum 5 years, 161.605 (3).

163.375 RAPE IN THE 1ST DEGREE: Sexual intercourse when female is under 16 and is the male's sister, of the whole or half blood, his daughter, 
or his wife daughter. Class A felony; maximum 20 years, 161.505 (1).

163.425 FIRST DEGREE SEXUAL ABUSE: Sexual contact when victim is under 12 . Class C felony.

163.315 The age of consent for sexual acts is 18. (Three categories of rape and two categories of sexual abuse as well as sexual misconduct are defined in part by age of participants.) (Oregon statutes 1953-83:1595-1598).

\section{THE WORKING DEFINITION}

The statutes and definitions mentioned above are known by all practitioners working in the incest network in Multnomah county. However, are these the actual definitions practitioners use in their everyday dealings with incest? Are these definitions functional? In order to answer these questions, I divided the definitions into three major components or cultural domains: a) Who did it? (offender or perpetrator); b) Who was it done to? (victim); c) What was done? (sexual activity). Using an ethnographic interview format, I asked practitioners to discuss and describe their thoughts concerning these three components.

A. Who Did It? The offender or perpetrator ("a person guilty of performing" [Merriam and Merriam 1978:392]) in an incest situation is, according to the oregon law, "related" to the victim as an "ancestor, descendant, or brother/sister" (Oregon Statutes 1953-83:1598). The offender in the definition by NCCAN is a member of the 
"family group". In my study I asked informants to list, "Who are offenders of incest?" Table III lists their responses.

Although 508 of informants agreed that all persons on the list were indeed offenders of incest, the other $50 \mathrm{z}$ did not agree. Two informants did not think that "boy friend/ girl friend" category should be included, and four informants felt that "someone you know" was too broad to be included. One informant rejected the "stepfather/stepmother" category as not applicable.

In order to further clarify the problem of identifying offenders of incest, I asked informants the following additional questions: "What is the difference between incest and stranger molest?", and "Is there a third category of sexual abuse?". The results of these questions are described in Table IV under the headings: Incest, Stranger Molest and Other. The differences in practitioners' choices become clearer in this last table. The major distinction exists between blood ties and relationship. These informants defined "relationship" from the social aspect, i.e., a certain bonding or closeness to another person. Blood ties, on the other hand, were seen as "related through blood lineage". One informant listed "blood ties" as the only criteria for incest. She explained, "Unless they are related through blood, you get into gray areas and then it's not incest." At the other end of the continuum, 


\section{TABLE I I I}

\section{OFFENDERS OF INCEST}

Father/Mother*

Stepfather/stepmother

Brother/Sister

Uncle/Aunt

Grandfather/Grandmother

Boyfriend/Girlfriend

"Someone you know"

Cousin

Gay boyfriend/Lesbian girlfriend

*While all practitioners agreed that females are definitely offenders at times, the numbers of reported female offenders is minimal. 
six informantsdevised a third category, consisting of neighbors, babysitters, etc., persons who have an established social relationship with the victim. The "offender" category creating the most controversy among informants was the "boyfriend/girlfriend" group. While ten informants perceived incest as blood and/or relationship based, they all agreed the offender must be a family member for the sexual activity to constitute incest. However, when asked specifically about a parent's boyfriend or girlfriend as an incest offender, eight informants included them within the "family" even if they were not living in the home. This would indicate that the perception of the boundaries of "the family" are extended beyond those of the oregon Statutes; at least by these practitioners.

B. Who Was It Done to? Victims ("a person cheated, fooled or damaged by someone else.." [Webster 1978:598]) of incest are designated in \#163.525 only by the term "related". However, additional statutes add an age stipulation as well: \#163.375 states sixteen years, and \#163.425 states twelve years, while \#163.315 places the age of consent at eighteen years (Oregon Statutes 193-83:1595-1598). The definition from NCCAN uses the term "child" but does not specify age or specific relationship. Informants when asked, "Who are victims of incest?" listed many of the counterpart pairs found in the "offender" list (see Table V). As a result the same differences 

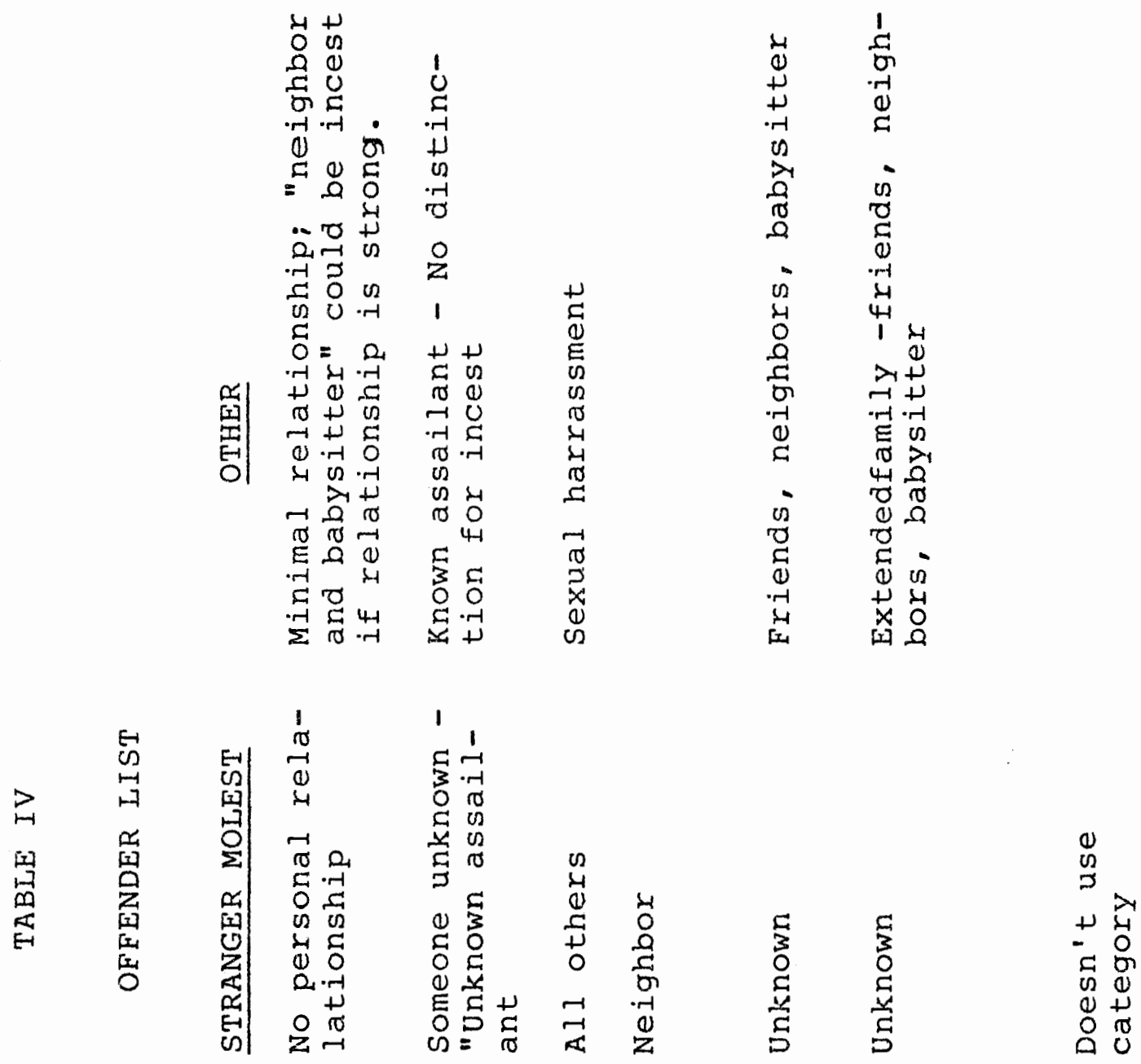

(1) 


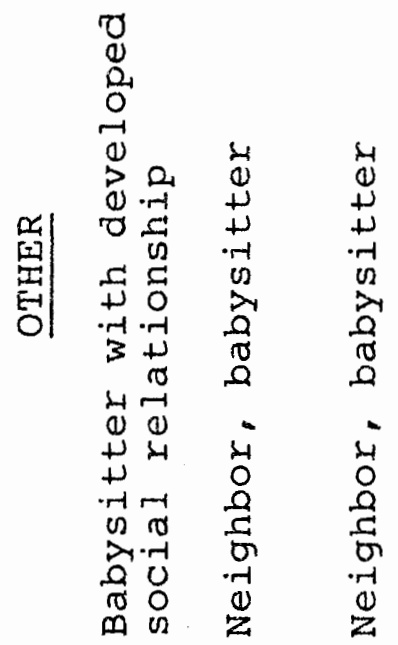

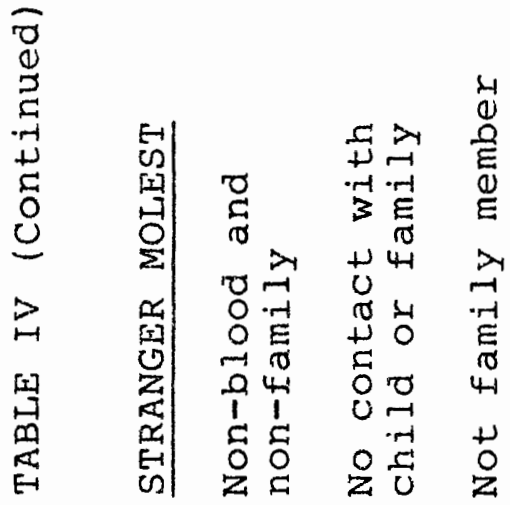

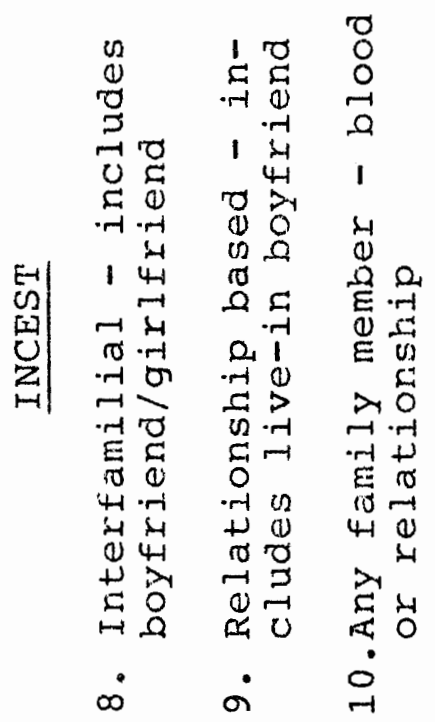


of opinion regarding "who is included in the incest family" were found to be existent in this research exercise.

c. What Was Done? Oregon Laws \#163.525 and \#163.375 specify only "intercourse" as the sexual activity. Number 163.425 does refer to "sexual contact" but does not specify what that includes. The 1971 reporting law uses "sexual molestation" when referring to the child sex abuse that is reportable.

The definition by NCCAN is somewhat more specific: ". includes not only sexual intercourse but also any act designed to stimulate a child sexually, or to use a child for the sexual stimulation either of the perpetrator or of another person" (NCCAN 1974:2).

Informants in this study were asked to list "ways to talk about incest". The partial taxonomy in Table VI is the informants' list of all the major attributes of incest as an activity. This table consists of a cover term, "molestation" with five included terms, i.e., "fondling", "intercourse", "sodomy", "kissing", and "masturbation". "Threats", "secrets", and "legal sentence" were all independent categories which informants agreed were critical to their working definition of incest. The list in Table VI is a compilation of attributes given by all informants and does not represent agreement among practitioners. More importantly, it shows that the attributes of incest are very complex and cannot be summarized in a few words. 


\section{TABLE V}

\section{VICTIMS OF INCEST}

Daughter/son

Sister/Brother

Niece/Nephew

Granddaughter/Grandson

Stepchildren

Cousins

Adopted Daughters/Sons 


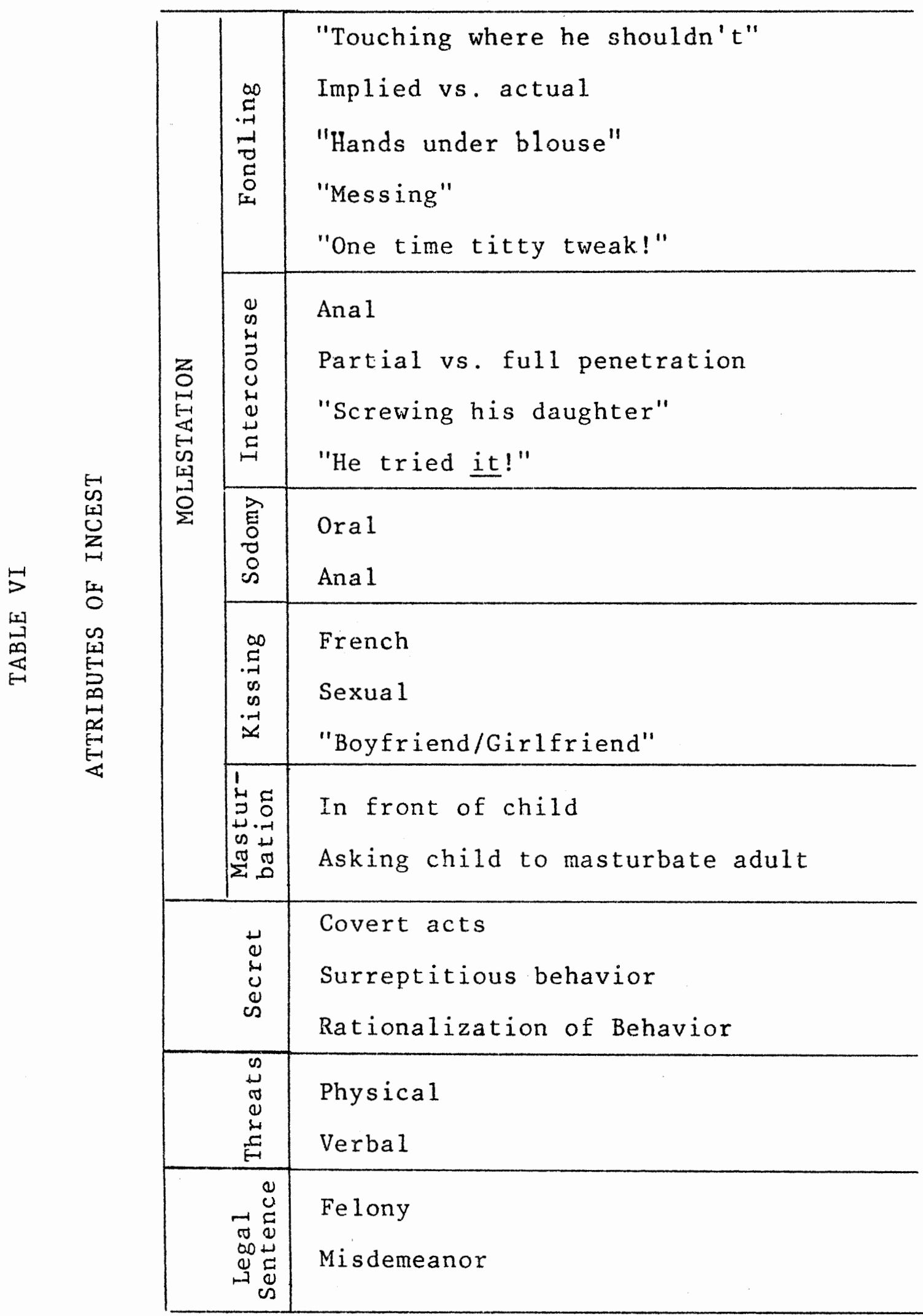




\section{SUMMARY}

From these findings it appears that practitioners agree on the major actors in "who are offenders" and "who are victims". They do not agree on incest victims and offenders in the more minor categories, e.g., "boyfriend/ girlfriend". Further, there was a great deal of disparity in the categories of incest, stranger molest and a third distinction of "other" which lies somewhere in between the first two.

Informants are in agreement as to the major attributes of incest, i.e., intercourses and sodomy. They were not in agreement in such categories as "fondling" which produced some very vague criteria, e.g., "touching where he shouldn't". In questioning informants further, I discovered a great variation among practitioners as to which characteristics of "fondling" constitute incest.

One informant representing a legal agency agreed with the "attributes of incest" but did not agree on the division between "incest" and "stranger molest". He said;

My department doesn't use these terms. I look at who is the perpetrator and the degree of risk involved in treating him in the community. I am not concerned about whether he is a family member or not.

Another informant in the legal system said that in his agency all offenders were categorized as "known assailant" and "unknown assailant". Therefore, while the "known as- 
sailant" category would include all incest cases it would also include non-familial relationships as long as the offender was known to the victim.

On the other hand, informants whose major responsibility is investigation and treatment of incest stated that they use the terms "incest" and "stranger molest" routine1y. "We need to keep the two categories distinct, since stranger molest has a different traumatic impact on the victim and, therefore, the treatment focus is different." The entire group of informants agreed that age was a critical issue to determine those who are "victims of child sex abuse". However, there was not agreement on what that age should be. the oregon Statutes use three ages: 12 (sexual abuse); 16 (rape); and 18 (consent). Each are considered in cases of legal prosecution. Many informants are less concerned about pursuing a case legally if the victim is close to adulthood. For example, one informant said:

I'm not sure all the rules apply if you are talking about a seventeen year old girl and a twentytwo year old brother or stepfather. It is definitely incest, but is it child sex abuse?

Other informants felt that until the child is at least eighteen years old, practitioners have a responsibility to act as an advocate for the victim and provide treatment if needed. 
It is interesting to note that the exogamous aspect, i.e., prohibitions on marriage within the family, is largely ignored as an issue by practitioners when discussing incest. Rather, they are concerned almost exclusively with the intrafamilial chila sex abuse aspect which is their focus of concern as practitioners.

The responses of informants clearly indicate that the Oregon statutes and the NCCAN definitions of incest are not used as the common working definition by practitioners. Further, results show that while some commonality in their working definition of incest is evident among practitioners, there are also significant differences. Do these differences benefit the network of agencies and their personnel by providing a variety of perspectives or do they limit effective communication?

In order to better understand the place of definition in the incest network we will explore the networking models used in working with incest throughout the country. This analysis should provide a comparative framework to determine the type of model which exists in Multnomah County; and hopefully shed more light on the questions concerning the differences in the working definition of incest and its impact on the network. 


\section{MODELS OF NETWORKING}

\section{CHILD SEX ABUSE NETWORKS}

One of the difficulties in the development of effective child sex abuse networks throughout the country has been inconsistency in the working relationship between actors in the system. All of the child sex abuse systems in existence today arose out of a need, $i . e .$, the upsurge in reporting of child sex abuse cases and a growing awareness by practitioners that the problem was not being dealt with effectively. In many areas the network "grew up Iike topsy". Since child sex abuse was a criminal offense, the most imminent need was the development of the investigation and prosecution aspects. Historically, the investigation of child sex abuse was simply a small part of the total investigatory process of all crimes within the criminal justice system. It became clear to practitioners working with the problem that child abuse and especially child sex abuse required a different investigatory process. Programs were developed within child protective services and the criminal justice system to meet the specific needs of investigation of child sex abuse. At the other end of the scale was the growing realization that, at least, the victim and offender 
needed treatment if either was going to be rehabilitated and the problem of cyclical reoccurrence stopped. In answer to this need, different treatment modalities sprang up within agencies, both in the public and private sectors. While both the investigatory and treatment components were essential, and many practitioners were developing effective tools, each component was working in isolation. Very shortly it became evident that linkage between each of the components was necessary in order to deal with the common problem.

Consequently, each agency became aware of the need to examine the activities of the others and explore how to develop a smoother, more effective, more complete network. In the past eight years these attempts have borne fruit in many areas, and different models of network systems have emerged.

The Child Abuse Prevention and Treatment Act of 1974 gave further impetus to the development of child sex abuse networks. Attached to this Act was the allocation of 85 million dollars for prevention and treatment (Mazek and Kempe 1981:56). Consequently many cities and counties received federal money for the purpose of developing child sex abuse networks in their area.

In 1982 Kee MacFarlane and Josephine Bulkley presented an overview of current program models dealing with child sex abuse, and particularly, with intrafamilial child sex 
abuse (incest). The authors developed a "conceptual framework" to examine and compare systems presently dealing with child sexual abuse. Their approach was to examine the relationship between treatment programs, the criminal justice system and child protective systems and determine the strength of their linkage. These models provide a basis of comparison for the network in Multnomah county. Their research produced five models which represent the orientations of all the networks existing today. However, as the authors state:

Our primary focus is on the management of intrafamilial child sex abuse cases. Although it should be recognized that the programs discussed include many overlapping avenues of comparison and do not reflect the kind of 'pure' program models that can be neatly or exclusively categorized (MacFarlane and Bulkley 1982:69).

In examining the five models of network systems, we will first analyze the form of the network, i.e., the linkage. According to Burt, (1982:23) the form in a network is measured by: 1) strength of the link; and 2) the level of joint involvement in the same activities. The models developed by MacFarlane and Bulkley are as follows: The Victim Advocacy Model. Child sex abuse is a crime. Treatment involves the strong use of legal sanctions and depends on the criminal justice system for punishment. This demonstrates to the victim that society will protect him/her. The linkage between the legal system and treatment programs is strong and interdependent. 
The Improvement Model. Treatment and the legal system are linked, but emphasis is on "sensitive intervention" and "successful prosecutions" using "multidisciplinary techniques for improving and humanizing the investigation and prosecution of child abuse cases".

Systems Modification Model. Major concern is "reducing the impact and trauma of the legal process upon the child and family...". The treatment component views the legal system as necessary only to provide an authoritative incentive for incest families to receive treatment. The linkage between the legal system and the treatment programs is weak in density (number of contacts), but necessary.

The Independent Model. Treatment operates independently of the legal system but does not take a stand for or against court involvement. There is no linkage but parallel working relations exist between treatment programs and the legal system.

The System Alternative Model. The treatment programs in this model are opposed to any legal authority for any reason. "If intervention is going to be truly psychotherapeutic, any conditions which interfere with that process must be identified and eliminated or avoided" (MacFarlane and Bulkley 1982:82). No linkage exists and the legal system and treatment programs are in conflict.

In order to analyze more closely the type of relationship, i.e., content of each network in the five models, I 
composed a partial taxonomy of the characteristics of each of the models (see Table VII). The areas of comparison are:

1) Origin - How did the program start?

2) Focus - Which family member is central to the program?

3) Philosophy - Undexlying premises form which the program operates.

4) Goal - What does the program hope to accomplish?

5) Service components - What services does the program provide to clients?

6) Disadvantages - What weaknesses do the authors see in the program?

The table shows that there is a direct relationship between the "origin" of a program and its underlying philosophy. Those models with a more political origin, i.e., Victim Advocacy Model and Improvement Model have a very strong criminal orientation and are thus linked with legal sanctions. On the other hand, the systems Modification Model, the Independent Model and especially the Systems Alternative Model, all of whose origins are from a therapeutic environment, focus strongly on the treatment component. These latter models are also concerned with the entire family rather than focusing on the victim as is the case with the earlier models. 


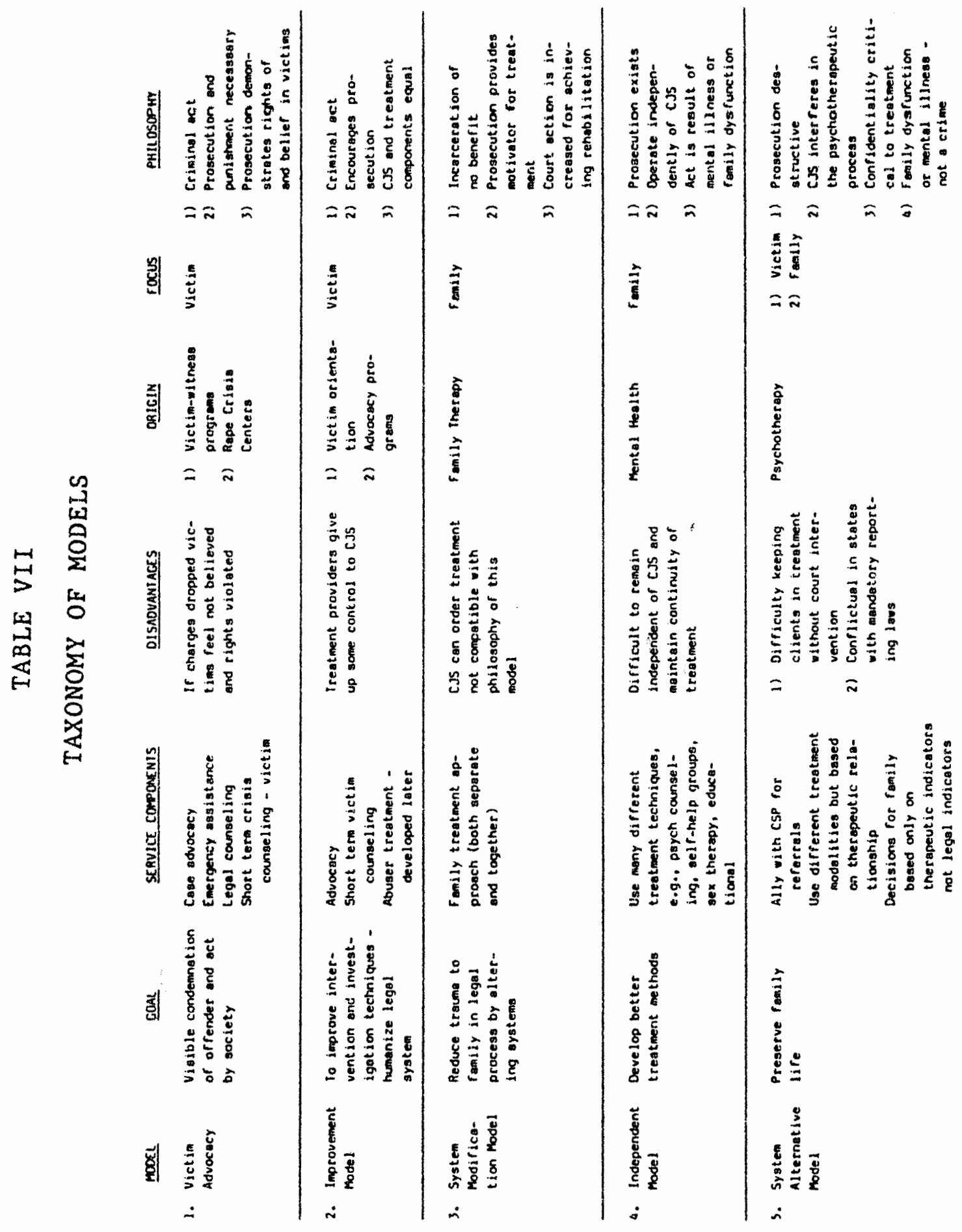


In a further comparison of "philosophy" and "goals" the issue of linkage between the treatment component of the network and the legal system is paramount. In the victim Advocacy Model the treatment component is interrelated directly with the legal aspect and is dependent on it for its effectiveness. One of the disadvantages of this model is that the prosecution of a case, which is designed to convince child victims that their rights are being upheld, can have the opposite result, i.e., if the offender is not prosecuted, it will produce the feeling in the victim that he/ she is not believed. At the opposite end of the continuum, the Systems Alternative Model, the treatment component utilized not only does not link with the criminal justice system but takes the philosophical position that the CJS disrupts treatment and keeps the therapeutic process from being effective. Since child sex abuse is a crime in all states, and a felony in some, and because all states have mandatory reporting laws, it is difficult to imagine an agency responsible for treatment operating without any linkage, and in fact, in conflict with the criminal justice system.

The "service components" of the five models are fairly self explanatory. While the first two are concerned with crisis intervention; it appears that long term, comprehensive treatment is an important aspect of the latter three models. It is important to emphasize that in any model 
there is a great deal of overlap in service components and this somewhat arbitrary breakdown is presented merely to clarify the specific service components that flow from espousing a certain philosophy.

\section{THE MODEL IN MULTNOMAH COUNTY}

Which model is developing in Multnomah County, and how strong are the linkages in this network? It is clear from this examination that even on the national level there is no ideal model to serve as a pattern for us to follow. However, according to MacFarlane and Bulkley, different models with differing philosophies "is not wholly undesirable given our current limited knowledge and understanding of the nature, causes and effects of child sex abuse and its treatment (MacFarlane and Bulkley 1982:88).

Because funding for research of this problem has gone from minimal to non-existent, it is impossible to collect the required data that would verify a possible "ideal" model based on treatment methods and outcome. At this point in time, according to the authors, it is important nevertheless to adopt some model that would be effective given the present organizational structure and based on local origins and working philosophies.

After examining the five models, MacFarlane and Bulkley present a distinction which underlies the differences in philosophy. They label it as "a fundamental dilemma" 
which centers around:

.professional and societal ambivalence about whether child sexual abuse should be regarded as a crime, a form of mental illness or (particularly in cases of incest) as a major symptom of broader family dysfunciton. The view or composite of views that one has toward child sexual abuse can constitute a major determinant in how it is dealt with in any given system. The difficulties inherent in such concepts as -prosecuting an illness', or 'treating a crime', or applying both strategies to a 'family problem' are currently being grappled with by programs throughout the country (MacFarlane and Bulkley 1982:70).

This "dilemma" of whether practitioners in Multnomah County view incest as a crime, a mental illness or a family dysfunciton is relevant for this study both to determine the strength of communication and task linkage in this network; as well as to uncover and evaluate the working definition used by practitioners. It is impossible to establish a common definition if there is no philosophical consensus. Therefore, in my interviews with informants I asked the question, "Should we treat incest as a 1) crime, 2) mental illness, or 3) a family dysfunction?" (see Table VIII). The results are interesting and somewhat distressing. Of the eleven informants interviewed, seven listed family dysfunction as the highest priority, with two of the seven listing family dysfunction and crime as equal. All eleven informants agreed that incest is a crime. This is not surprising since it is legally a crime in this state. However, nine of the informants felt that it should remain a crime, and that the legal aspect was a critical link, 
especially in the enforcement of treatment for the offender. Two informants questioned whether incest should be a crime but also stated that they did not have an effective alternative for enforcing offender treatment.

Four informants felt that incest was primarily a mental illness and two specifically labelled it as a character disorder. The results given for this category may be "contaminated" since I learned late in my interviewing that many informants were not including "character disorder" as a type of mental illness. Had I made that clear at the outset, the results might have been significantly different. Many informants told me after the interview that they define mental illness as "psychosis" and, therefore, rated it low or did not include it at all.

Eight informants did list incest in all three categories which could provide a core for determining a commonly accepted philosophical base. However, the differences in ranking among informants reflects the ambiguity referred to by MacFarlane and Bulkley and could have an impact on the feasibility of a common working definition of incest as well as on the strength of linkage in the network.

In further interviews with informants, clear consensus did emerge in some philosophical areas, i.e., treatment is more critical for the offender than incarceration, the criminal justice system must be involved at some level, victims' rights should be upheld in the investigation and 
TABLE VIII*

INCEST SHOULD BE TREATED AS

Informants

By Number

Crime

Mental Illness

Family Dysfunction

1

2

3

1

2

3

1

2

3

2

1

4

3

2

1

5

2

1

6

3

2

1

7

1

1

1

8

1

2

1

9

1

Character Disorder

1

10

Personality Disorder

11

3

1

2

1

2

3

*This is a ranking chart with \#1 as the highest priority. 
prosecution process; and all family members need some treatment to deal with the trauma that incest causes.

In order to understand better how these shared and differing philosophies impact this network, I took a closer look at who these actors are and what they do in each of their task areas. By exploring each link in the network I hope to discover commonality and difference and determine which model most closely resembles thje system operating in Multnomah County. 
CHAPTER IV

\section{PRACTITIONERS}

\section{CLASSIFYING ROLE CATEGORIES}

Incest affects our society on many levels and in complex ways. Because of this, it is difficult to determine all the categories of personnel who are involved in working with the problem of incest. Although it will be important to discuss in detail those major task areas that form the organizational core (see Chapter V), it is first necessary to consider the individual roles within those task areas and the network as a whole.

A taxonomy was compiled as a result of analyzing the data derived from interviews and observations, and includes al1 of those professionals mentioned by informants as involved in working with incest in some capacity (see Table IX). Once the list was compiled, the included terms were divided into four categories: Childrens protective Services, Parents United, Criminal Justice System and School. The cover term for this taxonomy is "practitioners" which encompasses all professionals involved, without concern for credentials, degree of involvement, direct service vs. indirect service, etc. "Practitioner" is defined here as "any professional person who works in any capacity with the 


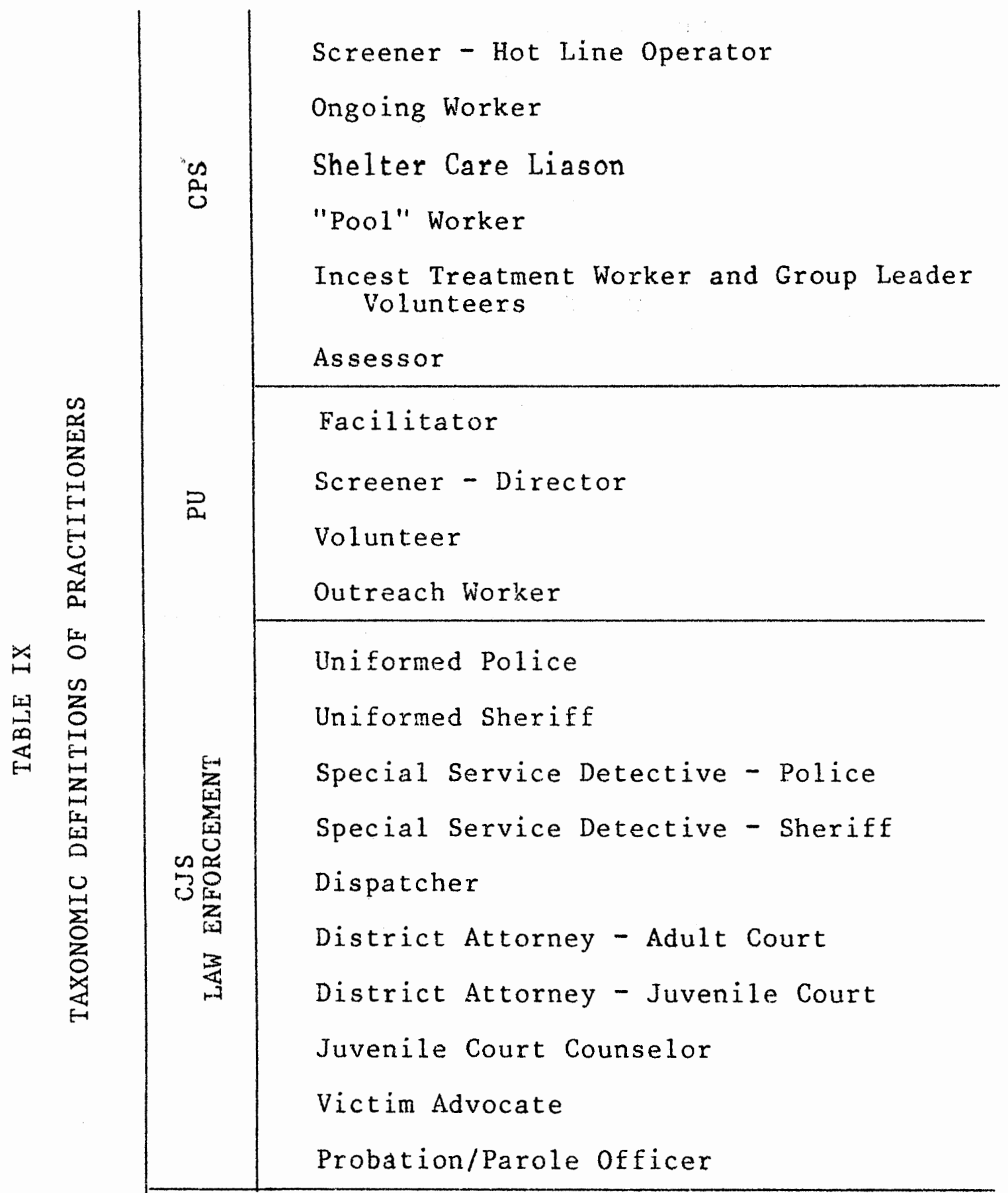

CSD Branch Office Worker

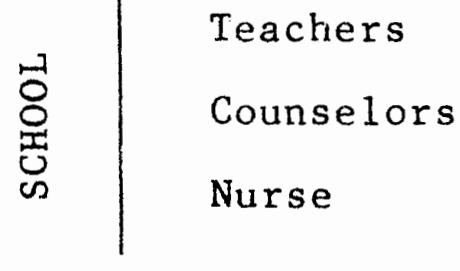




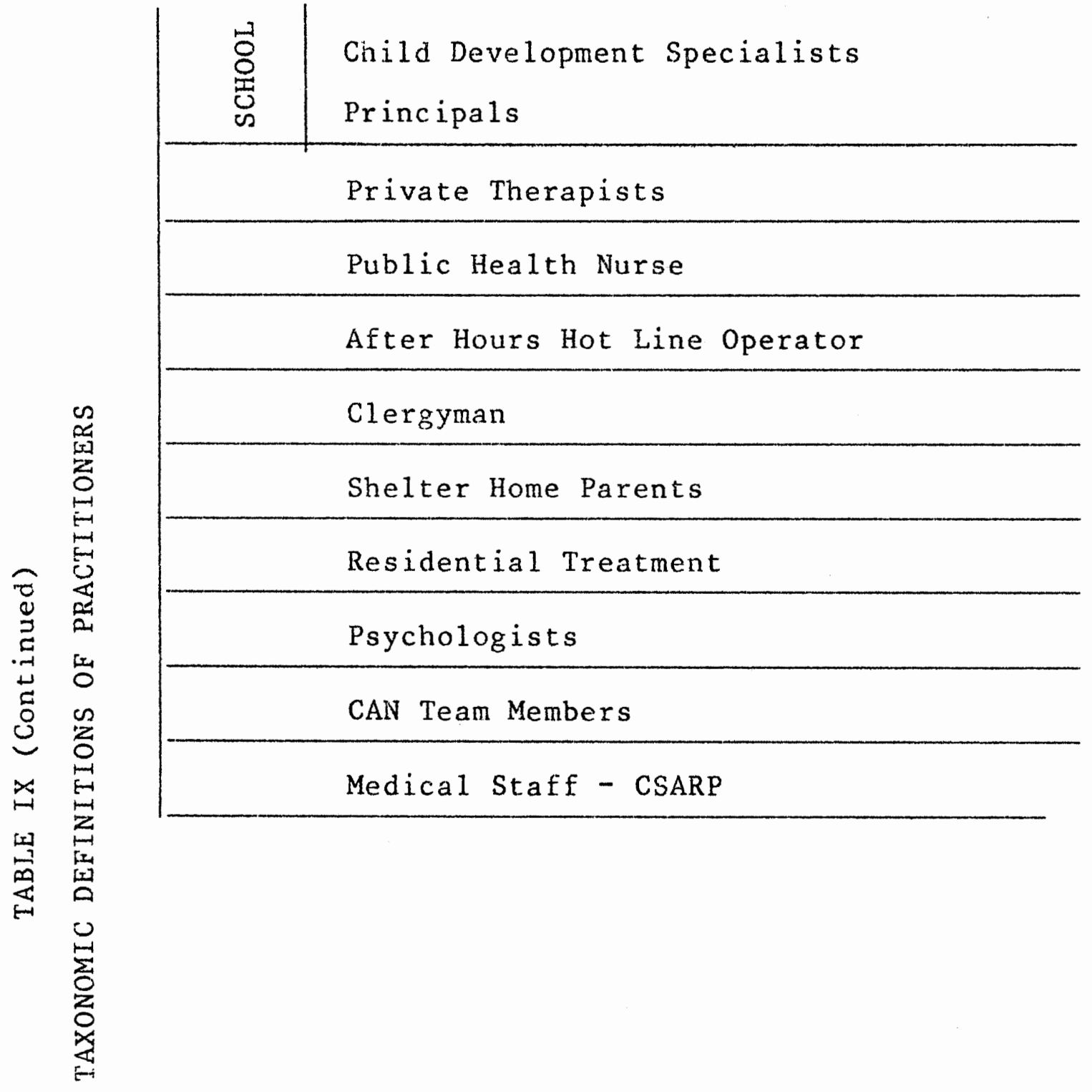


problem of incest." "Capacity" includes all the activities, i.e., reporting, investigation, prosecution and treatment, that relates to solving the problem. I did not, however, include the tasks of prevention and education which could extend the list even further.

The results of the taxonomy show a total of thirtyseven distinctive practitioner roles. Each of these roles may represent one to hundreds of individuals in the network. Of these roles, the largest number (twenty-six) are found in CPS, PU, CJS and Schools. Eleven practitioner roles are located in "independent categories" and not linked to a common agency or task area. The "School" category includes practitioners who are "reporters" of child sex abuse. Because they are mandated by law to report, they become a major focus of discovery and disclosure of incest incidents and are seen by other practitioners as critical to the function of the network even though they provide an indirect service.

Once I had determined the commonality, i.e., all those roles who work in some capacity with the problem of incest, I then developed a "dimension of contrast" (see chapter I for explanation) between practitioners. Table $\mathrm{x}$ lists five contrasting categories relating to the role of each practitioner in the network. Table XI is a componential analysis of each of those categories and their application to each practitioner. 


\section{TABLE X}

DIMENSIONS OF CONTRAST FOR PRACTITIONERS

1.0 Primary Work Load

1.1 Incest

1.2 Child sex abuse

1. 3 AlI sex crimes

1.4 A1l child abuse

1.5 other

2.0 Incest Member Focus

2.1 Victim

2.2 Offender

2.3 Entire family

2.4 One of above

2.5 Any of above

3.0 Service Delivery

3.1 Reporting

3. 2 Investigation

3.3 Prosecution

3.4 Treatment

3.5 Other

4.0 Remuneration (for work with incest)

4.1 Paid

4.2 Volunteer

5.0 Role in Network

5.1 Primary

5.2 Secondary 
TABLE XI*

COMPONENTIAL DEFINITIONS OF PRACTITIONERS

\begin{tabular}{lllll}
1.0 & 2.0 & 3.0 & 4.0 & 5.0 \\
\hline
\end{tabular}

CPS

$\begin{array}{lccccc}\text { Screener } & 1.4 & 2.1 & 3.1 & 4.1 & 5.1 \\ \text { Ongoing worker } & 1.4 & 2.1 & 3.2 & 4.1 & 5.1 \\ \text { Supervisor } & 1.5 & 2.1 & 3.2 & 4.1 & 5.1 \\ \text { Shelter Care Liason } & 1.4 & 2.1 & 3.2 & 4.1 & 5.2 \\ \text { "Pool" Worker } & 1.5 & 2.1 & 3.2 & 4.1 & 5.2 \\ \begin{array}{l}\text { Incest Treatment } \\ \text { Worker }\end{array} & 1.1 & 2.1 & 3.4 & 4.1 & 5.1 \\ \begin{array}{l}\text { Group Leaders } \\ \text { Assessor }\end{array} & 1.1 & 2.1 & 3.4 & 4.2 & 5.1 \\ & 1.4 & 2.1 & 3.2 & 4.1 & 5.1\end{array}$

PU

Facilitator

Screener

Volunteer

Outreach worker
1.12 .4

1.12 .3

1.12 .3

1.12 .1

3.4

3.4

$4.2 \quad 5.1$

3.4

4.15 .1

3.4

$4.2 \quad 5.1$

4.15 .1

LAW ENFORCEMENT
Uniformea Police
$1.5 \quad 2.2$
3.1
4.15 .2
Uniformed Sherifff
1.52 .2
3.1
4.15 .2

*Nominal scale-i.e., each number corresponds to a listing on Table $X$. 
TABLE XI (Continued)

\begin{tabular}{lllll}
1.0 & 2.0 & 3.0 & 4.0 & 5.0 \\
\hline
\end{tabular}

LAW ENFORCEMENT (Continued)

\begin{tabular}{|c|c|c|c|c|}
\hline Special Service Detail & 1.3 & 2.2 & 3.2 & 4.1 \\
\hline Special Service Detail & 1.4 & 2.2 & 3.2 & 4.1 \\
\hline Dispatcher & 1.5 & 2.4 & 3.1 & 4.1 \\
\hline $\begin{array}{l}\text { District Attorney } \\
\text { (Adult) }\end{array}$ & 1.3 & 2.2 & 3.3 & 4.1 \\
\hline $\begin{array}{l}\text { District Attorney } \\
\text { (Juvenile Court) }\end{array}$ & 1.4 & $2.1,2$ & 3.3 & 4.1 \\
\hline $\begin{array}{r}\text { Juvenile Court } \\
\text { Counselor }\end{array}$ & 1.5 & 2.4 & 3.5 & 4.1 \\
\hline Victim Advocate & 1.5 & 2.1 & 3.3 & 4.1 \\
\hline Probation Officer & 1.5 & 2.2 & 3.3 & 4.1 \\
\hline BRANCH WORKER & 1.5 & 2.1 & $3.2,5$ & 4.1 \\
\hline
\end{tabular}

CSD BRANCH WORKER

1.52 .1

$3.2,5$

$\cdot 1$

SCHOOL

$\begin{array}{lccccc}\text { Teachers } & 1.5 & 2.1 & 3.1 & 4.2 & 5.2 \\ \text { Counselors } & 1.5 & 2.1 & 3.1 & 4.2 & 5.2 \\ \text { Nurse } & 1.5 & 2.1 & 3.1 & 4.2 & 5.2 \\ \begin{array}{l}\text { Child Development } \\ \quad \begin{array}{l}\text { Specialist } \\ \text { Principal }\end{array}\end{array} & 1.5 & 2.1 & 3.1,4 & 4.1 & 5.2 \\ & 1.5 & 2.1 & 3.1 & 4.2 & 5.2\end{array}$

OTHER

$\begin{array}{llllll}\text { Private Therapists } & 1.5 & 2.5 & 3.4 & 4.1 & 5.1 \\ \text { Public Health Nurse } & 1.5 & 2.1 & 3.1 & 4.1 & 5.2\end{array}$




\section{TABLE XI (Continued)}

OTHER (Continued)

\begin{tabular}{lllll}
1.0 & 2.0 & 3.0 & 4.0 & 5.0 \\
\hline
\end{tabular}

Hot Iine Operator

$\begin{array}{lllll}1.4 & 2.1 & 3.1,2 & 4.2 & 5.1\end{array}$

clergy

1.52 .3

$3.1,44.25 .2$

Shelter Home Parent

$1.4 \quad 2.1$

3.4

$4.1 \quad 5.2$

Residential Treatment

$1.5 \quad 2.1$

3.4

$4.1 \quad 5.1$

Psychologists

$1.5 \quad 2.5$

3.4

4.15 .2

CAN Team

1.42 .1

3.4

$4.2 \quad 5.1$

Medical Staff

$1.5 \quad 2.5$

3.1

$4.1 \quad 5.2$

$3.1,2$,

CSARP Members

$1.2 \quad 2.3$

3,5

4.2

5.1 
"Primary work load" (1.0) was established to determine the practitioners' degree of involvement specifically in incest. The results show that of the thirty-seven practitioners named, only six work exclusively with incest. All. of these six practitioners are involved in the treatment. aspect of the problem. Only one other group of practitioners (CSARP) deal solely with child sex abuse, and they provide an indirect service. Therefore, thirty of the practitioners must concentrate their energies on other areas beside child sex abuse. This diversity of tasks may make it difficult to focus on child sex abuse and thus impact negatively on effective networking.

"Incest member focus" (2.0) was designed to determine which member of the incest family receives the major focus in the work of each practitioner. The entry "one of the above" (2.4) was added since many practitioners deal with all members of the incest family at different times in their work situation but do not have a specific family focus, i.e., the dispatcher who receives the call to send the police to a situation where incest has been reported, may be dealing with any one of the members of the incest family. "Any of the above" (2.5) was added to this section to include those practitioners who may focus on a particular member of the incest family at different times depending on the need. For example, private therapists may conduct "offender groups", "victim groups" or "family ther- 
apy" at different times in the therapeutic process. The results of the section on "incest member focus" were fairly predictable. Twenty-two of the practitioners focus on the victim with a secondary focus on the offender and other family members. Since many of these practitioners are involved in reporting incidents, it is understandable that the focus of the report would be the victim and concern for his/her protection. The seven practitioners whose focus is the offender are primarily involved in investigation and prosecution activities. The low number of practitioners (four) whose focus is "the entire family" may be misleading. Many practitioners are concerned with, and even work with, the entire family in some capacity. However, because of their specific job responsibilities, the focus may be directed toward a specific member of the family, i.e., victim or offender.

The category "service delivery" (3.0) was an attempt to produce an explicit breakdown of the activity areas in which practitioners work. Although five practitioners overlap in the four areas, the remainder are fairly evenly distributed in their tasks, with ten involved in reporting, seven involved in investigation, four involved in prosecution and eleven involved in treatment.

"Remuneration" (4.0) was critical in order to obtain an impression of how the problem is being viewed by the community. The issue of whether or not practitioners 
receive monetary support for their services is significant. In considering these results one must keep in mind the following questions: 1) How willing is the community to support paid positions to deal with incest? 2) Are some people so committed to working with the problem that they will become involved over and above their regular job? Both aspects are important in developing an effective incest network. Community volunteers, for example, add a point of view and a set of resources to the network that cannot be supplied by those practitioners who are paid to provide the service. On the other hand, in order to provide the expertise, energy and time needed to solve the complicated problem, it is equally important to have paid professional employees. Before analyzing the results of this category a further clarification is necessary. The category of "volunteers" includes both those practitioners who volunteer limited periods of time to work specifically with incest, e.g., Parents United group facilitators, as well as those who deal with the incest problem even though it is not a specific part of their job function, e.g., clergymen. The results of this section break down into twenty-seven paid practitioners and eleven volunteers. Again, it is important to keep in mind that these numbers represent roles and not persons.

The last category, "role in the network" (5.0) is an attempt to separate practitioners into two groups, i.e., 
those who see themselves as critical or primary to the incest network, and those who see themselves as secondary. While the results show that twenty-three practitioners see themselves as primary and fifteen secondary; all practitioners agree that a secondary involvement does not indicate lack of importance. In order for the network to operate, all practitioners whether primary or secondary are vital. For example, the incest treatment worker is involved in treatment of incest victims forty hours a week and is central to the treatment aspect of the network. On the other hand, a teacher in a classroom plays a secondary role. However, if the teacher does not remain alert to indicators of child sex abuse among her students and understand her responsibility to report suspected abuse, the incest victim may never reach the incest treatment worker for help. Because each link of the network is so critical to the next, the problem of communication and coordination in a system this large and complicated becomes immediately apparent.

As mentioned earlier, these practitioner roles can apply to individuals, groups or even departments. For example, "Parents United Outreach Workex" represents one person. On the other hand, there are several hundred uniformed police in Multnomah County. 
In order to understand the behavioral context of these roles, I will next present an ethnographic analysis of the four task areas which form the core of the incest network. 
CHAPTER V

\section{TASK AREAS}

The task areas included in this chapter are shown in Figure 1 of Chapter I (see page 8 ). They were arrived at by analysis of data collected by the fieldwork techniques of participant observation and ethnographic interviewing with practitioners working with the problem of incest in Multnomah County. The incest network functions with reference to four sub-activities which make up the central activity, "working with incest". They are: reporting, investigation, prosecution, and treatment. These four subactivities are performed within the task areas discussed below.

Because Childrens Protective Services (CPS) is the mandated agency to deal with child sex abuse and offers services in the reporting, investigating and treatment phases, its task is very broad. Parents United (PU) was included as it is the only agency that works exclusively with incest. It also provides a self-help component that is unique in the treatment phase of the network. Due to the criminal aspect of incest it is critical to include a task area that is involved in prosecution. I had initially considered using only the Special Services Division of the Sheriff's Office and the Portland Police Bureau (PPB) but I 
found that in order to obtain a core perspective of the prosecution process, it would be important to add other components. Therefore, I included the District Attorney (DA) and the Juvenile Court perspectives. The three task areas mentioned above address the direct service aspect of the activity, "working with incest". Given this complex division of labor, what remained was the need for a coordinating body which could oversee the entire process and coordinate it effectively. The Multnomah County Child Abuse Coalition is organizationally qualified to fit this role and thus is the focus of study as the fourth task area.

The following pages contain ethnographic sketches of the manner in which the major roles are perceived and carried out in each task area. This presentation is not an attempt to cover every aspect of the network or the individual task areas as a complete description. Rather, it is an "inside look" at "what practitioners do" from the viewpoint of the people who tackle many varied and difficult problems every day in working with cases of incest. It contains their actions and reactions, thir successes and failure, their views and biases, all related in the specialized languages of their professional "sub-culture", the unique product of their work situation. 


\section{TASK AREA I}

\section{CHILDRENS PROTECTIVE SERVICES}

Childrens Protective Services (CPS) is a branch of the Chilarens Services Division (CSD) of the Department of Health and Human Services. CFS has as its primary responsibility the investigation, protection and care of those who are victims or potential victims of child abuse. In child sex abuse cases, CPS is the mandated agency lordered by law) to investigate, protect and provide a rehabilitative plan for the victims of child sex abuse. Their secondary role is to provide the same services to the rest of the incest family.

While child sex abuse is not the only responsibility of this agency and while there are many roles included in their work, for purposes of this study I will focus on the roles of the hotline operator or "screener", the ongoing case worker and the incest treatment specialist.

\section{A. Hotline Operator}

The hotline operator, or screener, is involved in the first step of the network: the reporting process. As discussed in Chapter II, all professional people working directly in the "helping" professions are required by law to report suspected child sex abuse (see Appendix A, Figure 
I). Concerned citizens are encouraged to report incidents as well. Most of these reports are received by the CPS Hotline, which was established for that purpose. This hotline operates only during business hours. At other times, calls are transferred to an after-hours child abuse hotline which will be discussed later.

The CPS office is a large, open area consisting of two sections (referred to as "upstairs" and "downstairs" even though they are only separated by a hallway!). The three hotline operators sit at adjoining desks in the middle of the "upstairs" room. Other desks line the walls with "workers" involved in other duties. Because of the openness of the physical structure there is an atmosphere of support, cooperation and friendly bantering among the workers.

According to my informant, the hotline operators' responsibility is to respond to all incoming calls which come directly through the hotline. Once a call is received, they must gather information to complete a report (a "307", named for the number on the form). This report must be as detailed as possible and in many cases demands follow-up information after the hotline operator has finished the call. This "307" is the first step in the networking process. The more complete the information acquired by the hotline operator, the sooner the investigation can begin. 
A Human Resources Aid (HRA) provides backup for the operators. It is his job, basically, to take "junk calls", i.e., complaints, children in the streets, unsupervised children, etc., calls that are not directly related to child abuse. The HRA also provides transportation for clients when they need to come to the office for an interview, and operates the video equipment for child sex abuse interviews.

There is a supervisor available to assist the operators, and in one of my first observations, the operator called the supervisor over for a "quick case consultation". The operator briefly explained the details of the case and the plan she was proposing for placement of a child. "See if I'm thinking clearly," she said. The supervisor concurred with her plan but asked her to verify if the place she was considering would take this type of problem child. The operator then checked it out and found that the placement was appropriate.

The culture domain which emerged from these observations gives a good indication of the variety of issues that these operators confront (see Table XII, "What is a Hotline?").

In incest cases the procedure varies with each call. However, my informant did say that there are standard guidelines that each operator follows. After the operator has received enough information to determine the nature of 
TABLE XII

WHAT IS A HOTLINE?

Networking System

Twenty-four (24) Hour Service

Child Abuse Reports

Non-Child Abuse Reports

Loneliness

Drunk

Suicidal

Runaway

Crisis Counseling

Information source

Intervention for Protection

Report to Special Services (law enforcement)

Arrange Out-of-Home Placement (victim)

Write up "307's"

Call Backs to Callers or Police

Education

Referral to Other Agencies 
the call, she then begins asking specific questions of the caller which will give her all the details needed for a report and a follow up. "Unless we get specific details such as names, addresses, etc., we have nothing to go on once we hang up that phone and the caller is gone." While gathering information the operator makes a decision as to whether the victim is in danger. If not, she concludes the report and gives the caller the support or information needed in the particular situation. The operator writes up the report and notifies the Special Service Division of the suspected abuse. It is usually necessary to make some follow up calls to get additional information before the report can be completed. Once the report is completed, the. operator's job is finished. The report is then turned over to case assigners who will make a disposition regarding the case. If the victim is in danger and does need to be removed from the situation, the hotline operator will refer these placement needs to the Shelter Home Liason who will make arrangements for a safe placement for the child.

In observing the hotline in action it was obvious that the three operators provide a real support system for each other. "We check with each other when we need advice, for backup, or just for emotional support." There is a great deal of humor exchanged in order to alleviate anxiety and neutralize strong feelings, especially when an operator has just handled a particularly difficult call. This is a very 
stressful, demanding job and yet one of the operators told me she had been in this position for eight years!

\section{B. Child Abuse After Hours Hotline}

Once the CPS office is closed at the end of their working day, all child abuse calls are redirected to a Child Abuse After Hours Hotline which operates from Waverly Childrens' Home, a residential facility for children. This hotline, financed by a grant from the Childrens Services Division of the State of oregon continues the reporting work of the CPS Hotline from 5:00 p.m. until 8:00 a.m. and 24 hours on weekends and holidays. The After Hours Hotline is staffed by a paid coordinator and volunteer operators. These volunteers come from a wide segment of the Multnomah county community and range from housewives interested in a meaningful diversion, to students who choose the hotline as a practicum placement for their University course work.

The After Hours Hotline has the same kinds of procedural characteristics as described in Table XII. However, because of the varied nature of the calls and the time this hotline is in operation, these operators find themselves involved in more crisis counseling than the CPS hotline. All "307's" completed after hours are sent to CPS to be followed up on the next working day. All child sex abuse calls are reported directly to special services by the after hours operators. 
In responding to a call in which the child is in danger, the After Hours Hotline contacts the police to intervene. If the police are called and the child needs to be removed from the situation, the hotline operator arranges directly with a shelter home for temporary placement. There is a preliminary hearing the following day at the Juvenile court, at which time, it is determined whether temporary custody should be given to CPS, or whether the child can be returned home. The involvement of the Juvenile Court will be discussed in more detail in the task area on the Criminal Justice System.

The After Hours Hotline operators receive extensive training in child abuse, hotline procedures and crisis counseling. Their job can be frustrating and even disillusioning at times. As one informant commented, "I usually have only one chance to do my job. Once the person hangs up, I am finished and in some cases never know the outcome."

C. Case Assignment

Once all of the initial information has been gained and the report ("307") completed by the hotline operator, the case is turned over to the case assigners. Case assignment is carried out daily at $8: 30$ a.m. by the Department Head and the supervisors. Each case is considered by the group and a decision made as follows: 1) case assigned 
within CPS, or 2) case transferred to another branch of CSD. According to one informant, CPS is responsible for all child abuse cass that require investigation and intensive initial work. Branch offices are responsible for longer term cases, more variation in problems and minimal investigation.

Those cases which remain in CPS, as designated by the case assigners, are then given to each supervisor who assigns them either to an assessor, the "pool", or an ongoing worker. One of the supervisors admitted that sometimes cases are assigned based on the skill and interests of a particular worker. ("Let's give this one to Betty. The mother needs a lot of work and she can handle it!") Some cases are assigned to the assessors who do an assessment of the needs of the case and are also involved in the investigation. Since the legal investigation is the responsibility of the police, CPS assessors are more often involved in the social investigation to determine the best plan for helping the victim in the given situation.

Some cases are assigned to the "Pool". This is a newly developed group which, according to one informant, is "the peanut butter in the sandwich". Their cases are more vague in definition of problem, usually do not require an investigation, and may merely have a monitoring component required of them. The case loads (number of cases) of those working in the "pool" are large and their involvement 
minimal. And lastly, the case may be assigned to an ongo ing caseworker.

\section{Ongoing Caseworker}

The ongoing caseworker is the person who carries an assigned caseload and is responsible for management, supervision and treatment of each of his/her cases. S/he may be involved in the initial crisis, but is also the person who follows through after the crisis to make sure the case receives the services needed. Although many of the ongoing workers' cases involve responsibility for the entire family, this does not mean the family is intact as a household. Therefore, one case may require follow up on family members living in many different localities. In these cases the worker cannot make a simple one-hour "family visit" but rather may spend from three to six hours meeting with family members in different locations in the city. My informant works ten hours a day, four days a week. My observation included following her around for what she called a "typical day". Table XIII is a list of the activities of this worker during that day. At present she is carrying twenty cases, fourteen of them involve sex abuse.

One of the activities that was most interesting and relevant to this study was an alleged sexual abuse situation which included a video tape interview with a 3-1/2 year old girl. The case was assigned to my informant in 


\section{ONGOING CASEWORKER \\ "A TYPICAL DAY"}

Phone calls

Reading files

Six month narratives written on each case

Court hearings

Video tape interviews

"Special Certification"

Certifying foster home - initial visit

"Paper work"

Consult with:

Detectives

Juvenile court worker

Other Case Workers

CPS Hotline Operators

Supervisor

clerk

In-Home interview

In-Office Interview (sometimes pick up client)

Interview child in foster home 
the morning by the case assigner. The hotline operator who had taken the original report met with the ongoing worker to acquaint her with the details of the case.

The child was living with her mother who was in the middle of a divorce and a custody battle. Since the father had visiting rights, the child had spent some time with him on weekends. As the child began to show some evidence of changes in behavior the mother became concerned. All medical possibilities had been eliminated. One day the child described to her grandmother some

'games' that she and her father played which indicated that her father might be abusing her sexually. The mother was anxious to get the father's visiting rights terminated while the investigation was being completed but the court did not feel they had enough evidence to deny the father his rights.

CPS became involved in an effort to gain more information to determine if they should request temporary custody in order to deny the father's visiting rights. My informant invited me to help her conduct the interview. Before the family arrived, my informant and I went through all of the police reports to pick out key words that might help us in the interview. Since it is illegal to "lead the witness" in a court of law, it was necessary to ask questions of this child that did not "put ideas into her head". When the family arrived (child, mother, grandmother), we interviewed the mother privately in order to obtain more details on information mentioned in the police report. After the interview we returned to the waiting room to find the child riding on a kiddy car and insisting that the car needed to "go with me to talk to these ladies". 
The interviewing room was small with the video camera and the operator in the room. The rest of the room was empty except for a carpeted floor and "the dolls" (these are anatomically correct dolls used for interviewing small children in sexual abuse cases). The case worker and I sat down on the floor and asked the child to join us. She immediately began giving the dolls names and undressing them. With some suggestion on our part, "Does this doll look like your daddy?" "Yes!" "What is your daddy's name?" "His name is Steve and this is a steve doll.", the child finally had all the dolls named for members of her family. After a period of watching her play, my informant proceeded to ask her questions: "Do you and your daddy play games?" "Yes." "What games do you and your daddy play?" The child began acting out, with the dolls. "One of the games we play is squishing our bodies in the shower", as she rubbed the two dolls together. All of a sudden she became highly anxious, running around the room and looking at herself in the video camera. After a few more attempts to get the child back to the questions, we invited her grandmother into the interview to see if the child would tell her story to the grandmother as she had done previously. The grandmother was very nuturing and supportive, telling the child how proud she was of her and how she loved her. The child calmed down but after a few references to her daddy, the child said adamantly, "I don't want to talk about it!" The caseworker signalled that we end the interview and after many praise statements to the child, "You played real good and we're proud of you", the interview was ended.

This interview is significant because, in order to use a video tape interview in a legal proceeding, it is necessary that two factors are present: 1) a child witness must be proven to be reliable, and 2) the incidents of the abuse must be specific and detailed. We had established the child's reliability at the beginning of the interview by asking her questions which proved that she knew the difference between reality and fantasy. ("That's a bear". "Is 
that a real bear?" "No, it's just a puppet!") However, we were unable to fulfill the latter requirement. The fact that the child continued to insist, "I don't want to talk about it!" instead of "that never happened" or "I don't know what you mean" would indicate that she knew what her grandmother was referring to and was affirming that it was true but was fearful to discuss it. My informant and I were very disappointed that we were unable to get the child to give us more conclusive information. However, after the interview we were assured by one of the assessors that getting a child that young to give concrete facts in that kind of environment (interview room) is very difficult. 1

E. Incest Treatment Program

The CPS Incest Treatment Program operates statewide from funds allocated by the State Legislature. The Incest Treatment program in Multnomah County consists of two full time incest treatment specialists who operate the program and provide the major portion of treatment.

The program is designed to provide group therapy for victims and non-offending spouses. Secondarily, its purpose is to provide group therapy for the offenders in order to protect the victim.

My informant differentiated between offender treatment and that provided for victims and non-offending spouses. 
In our therapy groups for victims and nonoffending spouses we use an insight oriented, humanistic approach with a feminist perspective. However, in the offender treatment groups we use a behavioral approach backed by legal sanctions, i.e., 'do this or go to jail'.

At the present time this CPS program offers the following groups: 1) offenders' group; 2) mother-daughter group; 3) mothers' group (for women planning not to reunite with their spouse); 4) male victim group (10-14 years); 5) pre-adolescent victim (girls) group (11-13 years); 6) teen victim (girls) group (14-18 years, there are three of these); and 7) AMAC (Adults Molested As Children).

The group leaders are called "therapists" and their responsibilities are to be sure that the group focuses on issues and tasks which have been designed to help the members work through their trauma. The therapists provide certain agendas which they feel are necessary to accomplish the goals of treatment. The therapist's role is to lead the discussion, present educational material and ecnourage the members to relive their experiences by sharing them with the group members. My informant added, "therapists also use gentle confrontation with victims and non-offending spouses, especially when they tend to become unrealistic or vacillate on facts they know to be true".

Members of the groups, on the other hand, are responsible to try to communicate more effectively, to share their feelings and learn more constructive ways of dealing 
with each other, learn to be more assertive, and bring crises to the group for resolution. My informant was quick to point out that while the group members do support each other and this is an important aspect of developing trust, it is not a major goal of the therapy group. Group members are referred through CSD caseworkers. Criteria for acceptance is as follows: "For victims there is very limited criteria". These include sexual abuse by a family member, not mentally retarded, and ability to communicate with peers. To accept the non-offending spouse into a therapeutic group she must be supporting the child at least minimally, the child must be in the home or returning to the home soon, the offender must be out of the home, the child and the offender must have a "no contact" order, and, the member must abide by the rules of the program.

All of the groups and criteria discussed are for victims and non-offending spouses. However, for the offender, the criteria and treatment approach are entirely different. For example, the offender must have a complete psychological evaluation before acceptance into the program. The results of the psychological evaluation must indicate that the offender is amenable to community treatment, i.e., not psychotic, not violent, and represents no high risk or danger to the community. My informant added, "any offender is a risk to re-offend but we need to determine if he is a 
'cruising' pedaphile". ${ }^{2}$ In addition to the psychological profile it is preferred that offenders be currently involved in the legal process and that there is an open CSD case, i.e., the case worker is involved with the family. Lastly, the offender must be in individual treatment in order to quality for this program.

My informant then described a typical offenders group session:

We meet in a psychologist's office who is my co-therapist. It is a square room and includes eight offenders and the two therapists. We begin the meeting by asking the men 'Who needs time?' If no one wants 'time' (this means an opportunity to bring up issues that are relevant to the group) we will either pick on someone who we have some business to deal with or if we do not have specific issues we will begin dealing with more general things like offender cycles or offender behavior. The group meets one and one half hours weekly. There are no evaluation sessions but the two therapists determine when each offender has completed the group.

As I mentioned earlier, the two Incest Treatment Specialists conduct most of the group therapy, as well as screening group members, and providing public relations and education. However, in the last year they have recruited volunteers who are trained at the Master's level for in the process of obtaining a master's degree) to act as therapists. These volunteers are either co-therapists with an Incest Treatment specialist or, in the case of those who have extensive group experience, conduct their groups in- 
dependently. The Incest Treatment Specialists provide training for the volunteer therapists.

"When does your job end?" I asked my informant. She stated,

Our job ends when we feel the family has completed treatment. This may not have anything to do with the situation of the offender. If the offender is not in the picture, victims and nonoffending spouses can be dismissed from treatment when it is felt that they are able to cope with their own life situations. However, when the offender is still considered a part of the family, the process of termination is more defined.

Ideally, therapists meet first with the probation officer, the case worker, and the offender's individual therapist. This team determines the time of visitation for the offender and eventually when the offender should be allowed to return to the home. This case management team concept is the ideal. It is merely in its inception and has not been formalized as yet.

CPS practitioners are a major link in the network. In many cases they are involved from first report through completion of treatment. And, in all cases, they are involved at some level to provide service to the incest family. One informant summed it up, "We must, we have no choice. Whether we have enough funds or staff doesn't matter, we are bound by law!" 


\section{TASK AREA II}

\section{PARENTS UNITED}

Parents United (PU) is the only task area in our network which deals solely with incest. It is defined by its parent organization in San Jose, California as:

A self help group formed by individuals and families who have experienced child sexual molestation. Its purpose is to provide assistance for families involved in child sexual abuse by enabling them to get help for their particular situation during the initial crisis period, by showing them they are not alone and that problems can be resolved with a positive attitude and by encouraging them to seek proper guidance and counseling. The program reduces the isolation which is intensified when the problem is uncovered by showing them this happens to other families in every social, economic level and ethnic group. The program gives back to the family responsibility for long range decisions about its future (Parents United 1976:2).

In contrast to the incest treatment program at CPS which is concerned with therapy, the Parents United chapters were developed for the purpose of providing self help and support to their members.

The Multnomah County chapter of PU has been in operation since 1978. It was established through a grant from the National Center on Child Abuse and Neglect.

At the present time there are approximately 145 adults and 60 children in the PU membership. All of these members are in PU groups. These groups are led by 
"facilitators" who are volunteers from the social service community. They are working professionals and trainees at the graduate educational level. The groups offered by PU include: open intake, closed intake, women's group, men's group, couples group, mixed support group, parenting group, anger group, stress management group, and human sexuality group. The children's groups include victims' groups of all ages for boys and girls as well as a group for non-victimized siblings.

In order to better understand the steps required for a PU member to complete the program, my informant described this process using a typical member as an illustration.

Sam began in the open intake group. In this group he found both couples and individuals who are members of an incest family. During the twelve weeks Sam was in this group, new people joined and the group became larger. At the end of twelve weeks, Sam moved into the closed intake group which consisted of eleven people, again both couples and individuals. This group retained the same eleven people for the next twelve weeks. From this group same went into orientation. He began in this group with his wife, but as both made progress Sam advanced to the men's group and his wife moved to the women's group. After twelve weeks in the men's group, Sam rejoined his wife in the couples' group. At the end of the couples' group, Sam and his wife were told by the staff that they had completed the required part of the program.

(At admission each member agrees to continue in the program until they complete the couples' group or have been in groups for one year.)

At this point sam and his wife had to make a decision whether or not they felt the need to continue in the program and if so, which groups they would like to join. Sam decided to join 
the human sexuality group since he was still sorting out conflicts regarding his own sexuality. His wife joined the anger group to deal with her anger over the incest.

During a facilitators meeting which I observed, there was an intense discussion about the role of facilitators and group members. Two volunteers had drawn up a recommended list of these responsibilities. They are listed in Table XIV. One informant explained to me that these are merely guidelines and that the responsibilities of the facilitators and members are dependent on the constellation of the particular group. She said,

When I begin a group I spend the first two sessions getting the members to express what each wants to get out of the group. I then keep these needs and expectations in front of me so that I can meet them during the remaining weeks.

The groups all meet on the same evening each week. Before the group members go to their individual groups, there is a general meeting. A description of one of those general meetings follows.

The meeting was held in a large auditorium in a community center. When I arrived at $7: 10$ p.m. there were only a few people there. They were relaxed and informal, leaning on the counter around the coffee pot chatting with each other. Another small group sat in the middle of this large room planning an activity. I learned later they were planning to participate in the opening of the I-205 bridge celebration. After a few minutes, more and more people joined the group and meandered around greeting one another and chatting. Some remained outside smoking until the meeting began. Very few stood alone or in twos. Most seemed well acquainted and anxious to get together. 
TABLE XIV

\section{RESPONSIBILITIES AT PARENTS UNITED}

A. What Facilitators Do:

Explain rules, boundaries and expectations

Encourage problem solving

Encourage group interaction and equal participation

Support the development of network of members outside the group

Model self disclosure

Raise issues where appropriate

Maintain group focus on incest, sexual issues and family communication

Validate feelings

B. What Members Do:

Share their story and take responsibility for their actions

Observe the rules of confidentiality

Commitment to attend

Listen with one talking at a time

Take reseponsibility for yourself in the group

Ask for time to talk

Keep the group on task, its your job!

Express concerns in groups and about group 
At promptly $7: 30 \mathrm{p} . \mathrm{m}$. the meeting began. There were about 50 to 60 people present, sitting in a semi-circle in front of a stage. Most were couples and there were no children.

\section{(My informant explained that the children cannot be invol-}

ved in the general meeting since there is, in most cases, a "no contact order" between the child and the offender.)

The president stood up and introduced himself. Then spontaneously each group member followed using first names only. The basket was passed and people contributed coins and dollars. ("This helps pay for the rental of the church where we have our groups!") The president then announced that this was the last session so there would be an evaluation in each of the individual groups. Announcements followed by the secretary: "1) There are some clothes donated for anyone who needs them, 2) There's a potluck next week which will replace group, all names $A$ to $\mathrm{L}$ bring salads, $L$ to $\mathrm{P}$ bring bread and $\mathrm{P}$ to $\mathrm{Z}$ bring desserts, 3) For you who have completed the couples group there is a "parenting for teens group" that you can sign up for. The first twelve people who sign will make up the class, 4) One of our kids, Sandy, will be on Town Hall Sunday night. She came in second for the greatest kid in Portland. Everyone watch!, 5) Two probation officers will be here next week to talk about issues and answer questions. If you don't know why you're on probation, you can ask them!" Laughter followed.

Then group assignments were given to the new people. Next, a young woman stood up and announced that she was going to take the summer off from group in order to decide if she wanted to return in the fall. One group member asked, "Have we done something to offend you or are you doing this for other reasons?" She answered that she had made so much progress that she needed time to think it over and decide where to go from here. She assured the group that no one had offended her. The group responded by giving her a hand for all her work and many individuals went up and hugged her.

The meeting ended with the election of officers. There were six people running for 
president and no one for vice-president so everyone was asked to vote for two. "Everyone is eligible to vote who has been here for a month or more." Voting was done by ballot after each candidate was introduced. The group then dispersed and many rushed out to have a cigarette before their individual groups began. At 8:00 p.m. everyone dispersed to go to their assigned groups which are held in the church be hind the community center.

It was obvious during this meeting and others that I attended, that these people had formed a community based on their common problem. Out of tragedy seemed to be developing a comradarie and a support system that would affect them the rest of their lives.

According to my informant, one of the most important goals of $\mathrm{PU}$ is the support network. They encourage members to exchange phone numbers, to plan social events, and to network for things they need, e.g., to borrow a truck or to use the food bank sponsored by PU.

Another critical part of this support network is sponsorship. The sponsorship program is the primary way that $P U$ members reach out to new members and bring them into their community. Sponsors are members who have been in groups for some time and now want to be a support to someone who is just beginning. Their duties may include making the new person aware of $\mathrm{PU}$, greeting them at meetings, introducing them to other members, spending time (on the phone or personally) when things are difficult, to talk over a problem or to give advice, or just to "be there" for 
them as they begin this long ordeal. The sponsorship program provides a dimension of the incest network that is not provided by other components, i.e., immediate peer support for an incest family. For example, immediately after the victim discloses the incest, many alleged offenders are afraid to admit the offense. Through the sponsorship program a former offender can help this new person to understand the procedure, to realize that it is better for her/ himself and for his family if s/he admits his guilt, and to sympathize with the new offender's fears because the PU member has "been there" her/himself. This concern, coupled with information from someone who has been through the process can be an invaluable support. In many cases this support from an experiential perspective can provide the impetus to carry the family through the total investigation and treatment process.

While the sponsorship program is a formal aspect of the PU program, it is a process carried out by the members themselves. Some sponsors are assigned, others come together through mutual concern on the part of the members. Who are members of PU? Because PU works with the entire incest family they are referred to the program by any of the investigatory agencies in the network, i.e., sheriff, police, CPS, CSD, juvenile court, etc. In many cases the offender, at least, may be mandated by court order to attend PU as part of his treatment program. Other families 
or individuals may solicit membership in $\mathrm{PU}$ on their own. However they find themselves at PU, each member is screened before being accepted into the program. According to my informant, they are required to screen out offenders who molest children outside of the family, have an extensive criminal history, are overtly psychotic, have had unsuccessful participation in previous incest treatment programs, or have a history of violent behavior. Each offender must also be in individual therapy to join PU.

The cost of each group is $\$ 2.00$ for adults and free for children. The success rate of the PU program is high. Success is based on "no received reports of re-offense for clients in the program or after having completed the program". Based on this definition, the success rate is $98 \%$. My inforamnt is quick to add that this is a very simplistic way to evaluate success but it is all they have since there is no formal evaluation component in the program. Funds do not provide for this type of research.

In addition to parents United there is also a counterpart for the children, i.e., Daughters and Sons United. In addition to the children's groups offered there is also a Youth Outreach Worker who organizes activities and does a great deal of preventative education in the schools. The young people also sponsor victims as part of the sponsorship program and co-lead some of the childrens' groups with an adult facilitator. For most of the children involved in 
PU there is a "no contact order" between themselves and the offender. Therefore, the Daughters and Sons United program must be separate in all aspects from that of the adults. It is, however, fairly obvious in observing their activities that they have formed their own sub-community and carry out many of the same activities and responsibilities as their adult counterparts do.

The entire PU program is carried out with only four paid staff members. This self help, support component is a valuable link in the network and critical to the success of any incest program. As one member stated, "It seems like we gain confidence in ourselves as we share problems, information and activities". 


\section{TASK AREA III}

\section{CRIMINAL JUSTICE SYSTEM}

The title "Criminal Justice System" (CJS) is, according to informants, the best cover term to include law enforcement, the District Attorney's (DA) office and the judicial office. All are components of the network involved in investigation and prosecution.

A. Special Services - Sheriff's Office

I spent one day observing the activities of the special Services Detail of the Multnomah County Sheriff. The Sheriff's office serves the entire population outside of the Portland city limits but within the confines of Multnomah county. My informant, a sergeant in the special services Detail, allowed me to accompany him on his calls during a typical day. The morale was low at this time because the division had been informed that budget cutbacks necessitated personnel layoffs and demotions. My informant, along with five other sergeants in the Sheriff's office were being demoted as of July 1, 1983.

The Special Services Detail is made up of four plainclothes officers. The division deals with all sex crimes with my informant and another officer dealing specifically with child physical abuse and sexual abuse. The two other 
officers deal with adult sex crimes. It was evident that the recent cutbacks were impacting negatively on the job responsibilities in this division. All of the officers were being forced to assume other responsibilities, e.g., one day a month each officer is assigned to the court to transport defendants from the jail to the court room for hearings .

When I arrived at his office, my informant was on the phone following up on a sex abuse report referred by a CSD worker. He then briefed me about the specific responsibilities of his division and the activities he would be involved in that day. Next he called back a witness on a sex abuse charge and tape recorded the conversation. The witness had been a babysitter in the home of the alleged abuse. The children had disclosed the occurrence of incest in a recent interview conducted by my informant. After several questions to the baby sitter, the sergeant asked her if she would be willing to testify in support of the children. She hesitantly agreed. He explained what the procedure for testifying would be, thanked her and hung up. I asked if he had to have permission to tape phone calls. He answered, "Legally, only one party has to agree to the taping of a phone call. I am one of the parties and I gave permission!"

We left the office to do an "in-home interview" of another alleged incest victim. In this instance the girl 
friends of the alleged victim had reported that they had seen her father "mess around with her" in the swimming pool and at other times.

In the car, on the way to the interview, my informant discussed his method of investigation of a sex offender. His major concern has been to develop a process which would not violate the offender's rights, while at the same time reducing trauma on the victim brought about by numerous interviews and court appearances. Table XV is the culture domain on "The Investigation of the offender" as developed by my informant. In this particular procedure, the victim may need to tell his/her story only once. My informant mentioned that in other systems the child may have to tell his/her story an average of six times before the proceedings are completed.

When we arrived at the aparatment complex of the teenage girl, two of her friends came out and took us to the alleged victim's apartment. An account of the interview follows.

The sergeant began by explaining who he was and that his job was "to help people who had problems". He asked questions of the teenagers in a very supportive, sensitive manner. At one point when the two friends became "giggly", he asked them to go upstairs and continued the interview with the alleged victim and her closest friend who had arrived after the interview was underway. The alleged victim continued to deny that her father had ever made any sexual advances toward her. Toward the end of the interview she became very anxious, especially when the sergeant asked her, "Why do you think your friends would report something like this?" She 
TABLE XV

THE INVESTIGATION OF THE OFFENDER

Sheriff's Office

Interview victim with CPS worker - use video tape.

Interview offender - tape statement of what he did.

Do not arrest but cite offender and order him to appear in court.

Allow him two weeks before the court hearing by which time he must have done the following:

Get a lawyer;

Start at Parents United; and

Remove himself from home of the victim.

Inform him that if he violates any of the above requirements he will go to jail.

Recommend he waive Grand Jury in order to protect the victim.

Encourage him to plead guilty which will also waive the preliminary hearing and a criminal trial.

Complete the investigation and submit report to the DA. 
answered, "I don't know, but nothing happened like that." Her friends began to vacillate in their story saying they hadn't actually seen everything they had reported but other friends had told them about it. As we left, the sergeant gave the girl his card and assured her that he would be available to help her if anything like this did happen to her or if she remembered something that she had forgotten in the interview.

The sergeant informed me later that the father had called him that evening. He was very concerned and assured my informant that he had never made any sexual advances toward his daughter. Based on the information received, my informant completed his report and classified the case as "unfounded". He explained that unless new information was reported in the future, the case would be closed.

The remainder of the day was spent in investigation interviews regarding an alleged physical abuse case. This was a time-consuming process involving a number of interviews in different locations, phone calls and paper work. The day concluded with the sergeant filing a report alleging physical abuse of an 18 month old child at the home of the babysitter. We also learned that the parents of the child were going to press charges.

In one of the interviews, the sergeant asked the alleged offender if she would be willing to take a polygraph test. Later, I asked my informant about his use of the polygraph (lie detector). He stated,"I can choose to use the polygraph when I feel it will be helpful to determine 
the truth of a case." He added that he uses it rather routinely and that it has a great deal of credibility in court.

After spending eight hours with my informant I was sufficiently impressed. He is a highly skilled investigator with a professional approach and a good understanding of all aspects of child sex abuse. Even though his demotion will mean a financial setback, he said, "I want to continue working in this position rather than transfer to another division even though my salary would be significantly higher." His investigative skills and his innovative work to improve the protocol (procedure for investigation and prosecution) are greatly needed in the incest network.

B. Special Services - Portland Police Bureau

The Special Services Detail is a section of the Detectives Division of the Portland Police Bureau. It is the counterpart in the metropolitan area to the special services Division of the Sheriff's Office described earlier. Like the Sheriff's office, this unit deals with all sex crimes, both child and adult. In contrast, however, they have eleven detectives and one sergeant and have suffered no layoffs or demotions due to cutbacks. In fact, according to my informant, there has been an increase in personnel in the past few years. 
The detectives in this unit deal with all types of sex crimes. There seems to be no specialization or assignment of specific sex crimes, e.g., incest, to particular individuals in the unit. My informant did say that over half of her cases are child related sex crimes. This unit also handles physical abuse. Although the uniformed officer (regular police) takes the first report in a physical abuse case, this unit does the follow up investigation. In cases of child sex abuse this unit handles the first report as well as the follow-up investigation. The investigatory process for child sex abuse is described by my informant as follows.

I need to begin by saying that every step of this process will have exceptions. We receive reports from CPS regarding incest, however, we also get calls direct from teachers, doctors, clergy and others. Once we have received the report, we interview the victim and often use the anatomically correct dolls. We may have CPS involved in the interview but the police officer does the interview. We are the ones that need to get the information for the report. If the child is in danger, we then take the child into custody. CPS becomes responsible to place the child in alternative care. After we have completed the interview with the child and made sure of his/her safety we then interview others involved in the case. This would include the offender, family members and people who have a close relationship with the victim. After we have compiled all the information, the case then goes to the DA.

After interviewing the offender we may arrest him. This depends on how long ago the abuse happened, the living situation, the nature of the offense and other things. The alleged offender, if arrested, will stay in jail until his preliminary hearing the following day unless he 'bails out'. At that hearing the judge can 
either release him or order him to remain in jail. He can also 'bail out'. On the other hand, the alleged offender may merely be cited at the time of the interview and allowed to remain free until his hearing. The preliminary hearing is the formal 'charging'. The detective may make recommendations to the DA regarding the case but at this point our responsibility ends.

My informant talked about attempts she had made in the past to gain "DA information". In these cases the information from the police report goes to the judge via the DA. The judge then makes a determination which may include waiving the hearing and carrying out direct sentencing. My informant felt this was preferable since it kept the child out of court.

I have done this procedure successfully in three cases but the judges don't like to do it. It is hard to continue to work on improving this procedure since faces change regularly and the new DAs and judges need to be educated and con vinced all over again.

She went on,

Protocol is dependent on personality. I have been here a long time and have seen dozens of CPS workers and DAs come and go. I have also worked on joint interviewing, trying to get a workable arrangement between us and CPS so that there need only be one interview. But I just get it established with someone who works well with us and then $s /$ he leaves. I don't do it anymore. In order to have smooth networking there must be a core of people who remain the same so that there isn't the constant change in stability.

My informant said that she would like to see all agencies in the network better coordinated and more specificaliy defined in their roles. 
We should look at the whole picture, see what the need is and then get representatives from each agency. This is the only way to establish con sistent protocol.

C. District Attorney - Juvenile Court

The responsibility of this department in the Juvenile Court is to prosecute cases of incest in which the offender is a juvenile (under 18 years of age) and to provide the legal sanctions to protect child vicitms. Through Juvenile Court jurisdiction, custody can be established for the juvenile offender and treatment or rehabilitation can be mandated and monitored by the court.

In protection cases for the victim, temporary custody can be established and supervision given to CPS so that alternative living or other means can be taken to insure the victim's safety from the offender, e.g., insist on removal of the offender from the home, a no contact order between the offender and victim until the investigation is completed.

The procedure for establishing court jurisdiction for the victim is through a pre-trial conference, which is set up to determine if there is a need for securing temporary custody. In this hearing the evidence needed is not as specific as that in the adult court. According to my informant, a protective custody hearing requires "proof by preponderence" which is not as severe as the "proof beyond a reasonable doubt" which is required in the adult court. 
The former proof means that "it is more likely to be true than not". The Juvenile court aiso has the authority to seek permanent custody of the child if the home situation does not improve and the child continues to be in danger of reoffense. In this case, parental rights are terminated and the child is eligible for adoption. My informant stressed that the value of the Juvenile court process in the network is that besides providing protection for the victim, it also provides immediate leverage to force the offender to take steps needed to complete the legal proces so that he can be reunited with his child. In the case of the juvenile offender, the Juvenile Court has full responsibility for the prosecution. In most of these cases the court takes jurisdiction of the offender and orders treatment in the community. In some cases it is determined that the juvenile cannot be treated in the community and $\mathrm{s} / \mathrm{he}$ is then ordered to a residential treatment facility or the state training school. However, one of the major problems in rehabilitation of the juvenile offender is the lack of programs in the community which provide treatment for juvenile sex offenders.

My informant stated that the critical issue in determining whether or not protective custody or jurisdiction by the court is needed, is the degree of risk involved if the person remains in the community, e.g., Is the perpetrator 
(offender) in the home? What is the age of the perpetrator?

\section{District Attorney -- Adult Court}

In order to view the legal process from a different perspective, I chose an informant who works with the Victims Assistance Program (VAP) in the DA's office. The Victims Assistance Program is designed to provide advocacy to victims of any crime. This program helps victims in their dealings with the Criminal Justice System. VAP has been in operation since November 1974 and originated out of a rape victim advocate program. While the present program is not specifically child oriented, my informant was clear that many of their advocacy roles concern children. Some of these duties include: 1) providing support for the child if there is a need for a medical examination; 2) being present and offering support for the child during the detectives' interview; 3 ) helping the child deal with the legal process including the Grand Jury, interviews with the DA and criminal trial; 4) preparing and giving information to the child in regard to the court proceedings; and 5) advocating for the child in dealing with the defense attorney. My informant stated that there are some distinctive problems that arise in providing victim assistance in incest cases. In contrast to rape, incest is not a one time only problem. It usually involves numerous acts over a 
period of time. Also, in many cases the report is not made until months or years after the offense. Many times the VAP is not involved until the victim is brought in by a detective or some other agency representative. By this time the support system for the victim has already been established. In these cases VAP usually defers to CPS who has the authority to deal with cases over a long term. VAP is short term. In some CPS case, VAP may be involved to help prepare the worker and the victim for the Grand Jury. My informant gave me the following account of a Grand Jury hearing.

Before a Grand Jury hearing we take the victim through the steps so that it will be less fearful to them. When you arrive at the Grand Jury room in the courthouse there is a waiting area. To the left of the waiting area is a door which leads to the Grand Jury room. Within the room there are seven members of the Jury who are selected from a pool of private citizens and serve for a month. Only witnesses and the district attorney are allowed into the Grand Jury room. Each case has an assigned time. As the case begins the DA announces to the Grand Jury the details of the case and the witnesses he will call. He then brings in witnesses one at a time. They are escorted by a deputy. The witness takes the stand and speaks into a microphone. The DA leads the witness through the process by asking $\mathrm{him} / \mathrm{her}$ questions. In the case of a very young child the anatomically correct dolls can be used. The questions have been discussed with the witness ahead of time. After the testimony is completed the jurors can ask the witness questions. Once they have completed their questions, the witness leaves and other witnesses may be called in. These witnesses may include the alleged victim, the detective who filed the report and others who have been specifically involved in the case. Once all witnesses have been heard, the DA leaves the room and the jurors are left to make a decision. They knock on the door when they have 
reached their decision and the DA returns to hear the outcome.

The Grand Jury hearings are held to establish whether or not the state has enough evidence to make a case which can be used in the prosecution of an offender. There is no cross examination or sentencing in the Grand Jury. If the decision of the jury is that there is enough evidence for a case, the DA then proceeds with the process.

In some cases the Grand Jury may recommend that some of the charges be dropped because of insufficient evidence or "in order to get a plea". My informant explained to me the process of plea negotiation. It consists of attempting to get the offender to plead guilty to the most severe charges in exchange for dropping other charges. As she pointed out,

Our major concern is the child. Sometimes the child can't make it through a trial and if the plea can be negotiated to everyone's satis faction, the child will not have to stand trial.

She gave an example of a plea negotiation.

If an alleged offender has been charged with two counts of rape and two counts of sodomy, the negotiation may revolve around urging him to plead guilty to one count of rape with the trade off that the state will drop the other charges. These are both Class A felgnies and would merge at the time of sentencing.

If the offender agrees to plead guilty to one Class A felony then the sentencing can take place without a trial. If however, the alleged offender insists that he is not guilty of any of the charges and will not negotiate, the 
victim will then be forced to face the offender and the defense attorney in a criminal trial.

Criminal trials for incest, according to my informant, produce the most populated courtrooms. The participants in the trial consist of a regular jury made up of citizens, the bailiff, the judge, the defense attorney (usually from the Public Defender's Office), the District Attorney, a secretary, a law clerk, and the pre-sentence investigator (PSI). The PSI has the responsibility to provide the background check on the offender as well as to present the "victim impact statement" which outlines the traumatic effect the action has had on the victim. The pre-sentence reporter also makes recommendations to the judge in terms of the outcome.

Early pleading of "not guilty" and plea negotiations have been very effective in sexual abuse cases and only about $3 \%$ of these cases ever go to trial. My informant summed up the interview by saying,

One of the goals of the Victims Assistance Program is to solicit the cooperation of all involved. Sexual crimes are recitivistic. If we can't get cooperation, we can't stop them.

The Criminal Justice system has made many advances in more effective networking in incest cases. At this point, both the DA at the juvenile court and adult court as well as the Portland Police Bureau and the Sheriff's Office all have specific units designated to deal with sex crimes or 
child sex abuse. Within each of these departments there are a number of people who are highly skilled in investigations and prosecution procedures. However, there still remains a long way to go. According to informants, the legal procedure itself does not allow its practitioners the tools to deal fairly, sensitively, and effectively with this particular crime. Legal procedures, and even laws, need to be changed. 


\section{TASK AREA IV}

\section{MULTNOMAH COUNTY CHILD ABUSE COALITION}

The Multnomah County Child Abuse Coalition (MCCAC) had its beginning in 1979 when a Child Abuse Interest Group (CAIG) was formed. 4 This group had as its purpose to implement change in the system dealing with child abuse in Multnomah County and to educate the community and professionals in the field as to available treatment resources. CAIG operated primarily as a support group of peole who were directly involved in the treatment of child abuse and provided them an opportunity to exchange ideas and receive information. At the time of its inception CAIG members included representatives from waverly Outreach, Parents Anonymous, Community Health Nurse, and Morrison Center Nursing Program.

In an early meeting on December 21, 1979, the group stated one of its goals: "We will brainstorm to determine the major areas of difficulty in coordinating services and in communicating between CPS and Community Service Representatives". In their pursuits they ran up against many instances of little or no coordination. One member stated on April 14, 1981, "It was discovered that there are three different groups in the portland area that are doing work for the schools on child abuse and these groups apparently 
are not aware of each other". In another meeting, "right now it looks like the CAIG will act as an executive advisory group to address the communication of services in the Portland area". And so, a coordinating body, committed to developing a network for child abuse, was born.

In June of 1981 the group concensus was that the CAIG "should form its own structure within the oregon Chapter of the National Council for the Prevention of Child Abuse (OCNCPCA) and join this group as a community coalition". On October 23, 1981 CAIG became the Multnomah County Child Abuse Coalition (MCCAC). Its statement of purpose read as follows.

The purpose of the Multnomah County Child Abuse Coalition is to address the issues of child abuse and neglect within the Multnomah County area. These issues include but are not 1 imited to: 1) coordination of treatment agencies to provide better services; 2) coordination of treatment agencies, Child protective Services and Children's Services Division and justice services to result in improved systems intervention and service to families; 3 ) identification and development of needed service components; such as crisis intervention assessment of family needs, comprehensive medically based teams, and effective, innovative outpatient services; 4) prevention; 5) community education and public awareness; 6) legislative lobbyjng; 7) liason with state and national Child Abuse Chapters; and 8) fund raising to meet the above goals. As these issues are addressed, it is expected that the system of child abuse intervention will be of higher quality and effectiveness, resulting ultimately in a reduction of the incidence of child abuse and neglect. (MCCAC Minutes 1981)

On February 26,1982 the goals of MCCAC were finalized and published (see Appendix B, Figure I). In April of 1982, 
MCCAC became incorporated and granted non-profit corporation status by the state of Oregon. Its members represent many of the major task areas in the network (see Appendix B, Figure III).

\section{A. Present Functions of MCCAC}

In my observations of MCCAC meetings it was apparent that this organization whose major goal is the improvement of networking in child abuse, is an important link in the incest network. It began with ambitious goals and high enthusiasm. However, in its five years of growth there have arisen some foreseen as well as unforeseen problems which have kept these goals from being realized. In Table XVI the "Problems of MCCAC" are presented in a culture domain. Although this is only a partial taxonomy, it does point out the present issues and concerns seen by the members. I have divided the list into "external" and "internal" problems. "External problems" related specifically to budget cuts and time issues. According to informants, these problems are actually two sides of the same coin, since it is the cutbacks which have caused the demands on time and other external problems which make it difficult for MCCAC members to bring their energy and creativity to MCCAC meetings. In some instances, members do not have the time to attend such meetings at all which is the reason for 
TABLE XVI

PROBLEMS OF MCCAC

\section{External}

No budget for projects

No money to hire staff

No time to sit down and write grants

Members' external probleins

Time demands outside too great

Everyone involved above their regular job

Low attendance at meetings

Delinquent board members
Internal

Too many distractions

Need to be energized

Gotten pretty "scattered"

Have not generated a broad enough base of participation

Tried to tackle too much

Need to consolidate

Need to determine what we can realistically do

Need to set some ground rules

We are identified with CPS

There is confusion about the role of CSARP

Who will be part of MCCAC

Spent too much time sur-

viving - not creating 
low general attendance and the delinquency of many board members.

The "internal problems", while strongly affected by the "external" ones are issues that the members of MCCAC can deal with directly. The two issues which seemed to produce the most concern among informants were: 1) not having generated a broad enough base of participation; and 2) "we are identified with CPS". According to members, though both of these issues have been dealt with superficially, they need to receive a specific resolution in the future. In my observations, it seemed that by generating a broader base of participation with representatives from all components of the network, the problem of "identification with CPS" would be eliminated. It would then be clear that CPS is only one link, although an important one, in the total network. The increase in membership which would result from broader participation would also impact positively on the low energy and lack of time problems facing the present members.

In the meeting which I observed on May 20, 1983 there was a discussion about discontinuing MCCAC for the summer months. All members felt that MCCAC had accomplished a great deal in the past year but that discontinuing for the summer was necessary. They vowed to start with renewed energy in september. According to one member, "we are at the low end of the trough, but when money comes back, MCCAC 
will be in a good position to impact on where the money is spent". Most core members of the Board are acutely aware of the problems and seem ready to tackle them when they return in the fall. As one informant stated, "We have built the house, now we must decide what to put in it!"

"Building the house" has included a number of subcommittees which are the "core" of the coalition. A discussion of these sub-committees will provide an inside look at MCCAC on the practical, experiential level.

\section{B. Child Sex Abuse Response Project}

The Child Sex Abuse Response Project (CSARP) is a major subcommitte of MCCAC. It is particularly relevant to this study since it deals directly with child sex abuse, and particularly incest. CSARP evolved separate, but parallel, to the development of MCCAC. It had its origin in the Incest Response Steering Committee (IRSC), which was developed in April of 1980 as a result of a workshop, sponsored by the City-County, on incest. At the end of the workshop, there was a call to organize and IRSC was formed. In January 1982, with mutual consent of both the IRSC and MCCAC, the former became a subcommitte of the latter. It was renamed the Child Sex Abuse Response Project and its statement of purpose is included in Appendix.B, Figure II. By september 28, 1982 CSARP had formed three subcommittees: Protocol, Curriculum and Public Information. 
The accomplishments of this subcommittee have been formidable. The following is a list of activities completed before May, 1982 .

1) Co-sponsoring with Portland State University a workshop on Child Sex Abuse.

2) Developing a resource directory of treatment agencies for child sex abuse and distributing it to all agencies.

3) Preparing printed information for victims, offenders and families about what happens to or for them when a report is made.

4) Planning a statewide workshop for educators to work in the area of prevention of child sex abuse.

5) Talking with TV stations about programming a series on child sex abuse this fall.

6) Working on the protocol of child sex abuse cases especially minimizing the number of times the child victim has to testify.

Unfortunately, energy levels are low on this committee as well and on January 31, 1983 there was a discussion concerning the future of CSARP and whether the committee felt they should continue or disband. The majority voted to retain the committee, but to focus on specific "do-able" tasks. 
Discussion then moved to the types of tasks that we might consider being involved in... The group voted to focus on the work being done by the Protocol Committee regarding drawing together resources in the community and having them work together more smoothly. (CSARP Minutes 1983)

Therefore, the Protocol committee of CSARP was the only subcommittee retained at that time. However, in October 1983, after low attendance and minimal interest, the Protocol Committee also voted to discontinue. As a result the CSARP is now defunct. This is a major setback both for the coalition and the network as a whole.

C. Child Abuse and Neglect Team

The Child Abuse and Neglect Team (CAN) came into existence in April of 1981. Since it shares many of the same goals of the CAIG, it was in some ways an outgrowth of that group. CAN is the direct service element of MCCAC. The goal of the CAN Team is "to develop and maintain multi-disciplinary expertise around child abuse and neglect cases in order to serve as consultants to the legal system and treatment agencies so that families receive effective intervention" (See Appendix B, Figure IV for complete explanation of goals and objectives)

In attending a CAN Team meeting on July 8, 1983, there was a different atmosphere than I had observed in other subcommittees. This group is more energized and active. The team includes a variety of highly knowledgeable experts in the field of child abuse who are working together to 
network at the grass roots level, i.e., the consultation and coordination of a specific case.

Each member signs a confidentiality statement before the meeting begins to insure the protection of information in each case presented.

On this particular day the case was presented by a CPS ongoing caseworker and a hotline operator. It involved a ten year old boy who was suspected of being a victim of both physical and sexual abuse. He is mentally retarded, autistic and has little speech. His parents have been uncooperative with CPS because they feel they are interfering with their parenting. Because of the reported abuse and the parents lack of cooperation it was necessary to place this child in alternative care. Because of his "special needs", i.e., autism and lack of speech, this had become a problem for CPS.

Once the facts had been given and the major issues established the CAN Team then offered recommendations to the CPS representatives. The discussions and recommendations brought together each individual's expertise which resulted in a very dynamic, supportive and informative approach to the problem being presented.

According to one informant from this group, the kinds of cases dealt with by the CAN Team are the extremely difficult ones; those involving death, severe physical or sexual abuse; or a situation which is cyclical or generational. The CAN Team reviews its cases annually and presents a summary to the MCCAC Board. 
D. Legislative Committee

The purpose of the legislative subcommittee is to review bills in the state Legislature which impact on child abuse directly or indirectly. Once the committee has received the information on each bill and reviewed it, they then make a recommendation to the MCCAC board whether the coalition should support or oppose a particular bill. In some cases where a bill is very critical, the decision might be made to lobby or send letters from the coalition to legislators.

In 1983 (a legislative year) this subcommittee was concerned with a number of bills. On March 10, 1983 the committee presented the major bills and discussed the action which should be taken on each:

Senate Bill 410 - anti pornography, child exploitation bill. The discussion focused on a tag on to the bill requiring photo processing labs to report under the child Abuse Reporting Law if they should see pornographic photos of children. Some members felt this was a good idea. Others contested it, stating that it would be an intrusion and a violation of the right to privacy. It was recommended that a letter be written supporting the bill and that individual concerns be expressed in individual letters.

House Bill 2771 - involves a $\$ 2.00$ fee on birth certificates to be donated to Child Abuse Prevention programs. It states, in consultation with the advisory council on the prevention of Child Abuse, the director may make grants to private non profit organizations providing parent education and support programs for the prevention of child abuse from funds available therefore under ORS $432.145^{\prime}$. It was felt by the committee that the bill should be supported. However, there was some question about where the funds would go once they were allocated. One of the 
members volunteered to attend the next meeting on the bill and report back.

House Bill 2779 - requires school personnel to sit in on child abuse investigation interviews on school property. The committee was unanimously opposed to this bill. They felt that it goes contrary to the work of the protocol committee which has been working to decrease the number of people that the child must tell his/her story to. This would add an additional witness which is unnecessary in an investigation and may in fact hinder it. One member agreed to write an oposition letter from MCCAC and send it to the legislators.

House Bill 2638 - creating open records to defense attorneys prior to court. The committee strongly opposed this bill since it would open all records (including CSD and police records) and would leave the victim and others open to interragation by the defense attorney before the court hearing. The members will write an opposition letter from MCCAC.

House Bill 2629 - a central registry for sex offenders. This bill brought a favorable response from many members since it would provide a monitoring system and immediate access to the previous sex offenses of an individual. According to one member, -it would act as a deterrent since many sex offenders skip from state to state to avoid a central registry. They come to oregon where there isn't a registry to maintain their anonymity. This presents a further threat to chilaren in our area.' There was an equal number of opponents for the bill as well. Therefore, the vote ended in a tie and no action was taken.

Since this committee is also concerned with legislative funding, one member presented to the committee the following information:

"I have received a letter from the children's Defense Fund opposing President Reagan's federal fund cuts. The 3.5 million dollar cut will result in a 418 cut of the budget for the National Center on Child Abuse and Neglect. This will impact on all of us!" 
Again there emerges that major external problem -cutbacks. It seems to be one of the negative elements that bind and constrain all four task areas. 


\section{CHAPTER V ENDNOTES}

\section{TASK AREAS}

$1_{\text {The informant reported much later that after four }}$ sessions of individual play therapy, the child did "tell her story" and at the time of this writing had successfully completed treatment. The case is still pending in court.

${ }^{2} \mathrm{~A}$ "cruising pedaphile" is an offender who is at high risk to abuse other children he comes into contact with.

${ }^{3}$ see "State vs. Garcia" in oregon court Proceedings for further details on plea bargaining.

${ }^{4} \mathrm{All}$ historical information obtained in this section was acquired through MCCAC minutes of past meetings from 1979 to the present. 


\section{CHAPTER VI}

THE TOTAL NETWORK

\section{Density in Networking}

A major aspect of network analysis concerns "density" or "the connectedness or completeness of a network". Density is "estimated by the ratio between the potential links in the system and the number that actually exist" (Mitchell 1969:37). Now that we have looked at the four task areas individually, we will observe how these areas interact with each other within the network and the degree of density of the network as a whole.

In order to determine how my informants viewed the network, I asked each of them to give me a "verbal map" of the "steps in networking in incest in Multnomah County" (see Figures 2 through 9). While the maps vary in degree of detail and format, all eight include what is specified in Figure 7 as "coordinating agencies," i.e., CPS, Police, DA. All reported cases of incest (i.e., a "307" is completed) go through at least three components. However, once these basic coordinating agencies have been specified, the maps then become much more diverse in emphasis as well as procedures utilized. The most detailed and extensive map is Figure 3 which traces the steps from the report through the sentencing. While Figures 3,5 , and 7 reflect 
Steps in Networking

Report $\longrightarrow$ Received by $\longrightarrow$ Report to Special Hotline Services Chill and parent

Report to CPS

Removal of Child Causes Change in Family Systern $\downarrow$

Information collected on

Case by CPS

and police
Determine Need out-of-Home Interview

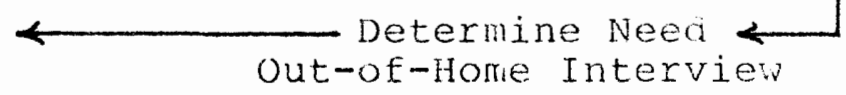

CPS Worker $\longrightarrow$ Needs
Assigned Assessinent

$\rightarrow$ CPS Worker
Assigned Hearing

Ongoing Counseling Individual / Gsous

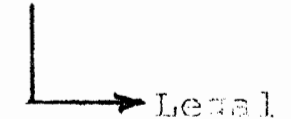

Trial and/or Mandated Counseling
Child or Offender Renovid

from ano

Victim/OEfender/Family Reaction to Treatment

Legal Deternination

CPS Determination<smiles>CN[Al](C)C</smiles>

Counseling source Determination

Individual's Reaction to events

Figure 2. \#1 - Hotline Informant. 


\section{Steps in Network}

Reporter Calls Police

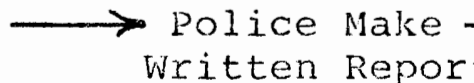

Written Report
Report Goes to
Special Services

(CPS contactec)
Interviewing of Victim/offender<smiles>[3H]C</smiles>

Results to DDA

Sex Crimes Unit
Special Services Conducts Investigation

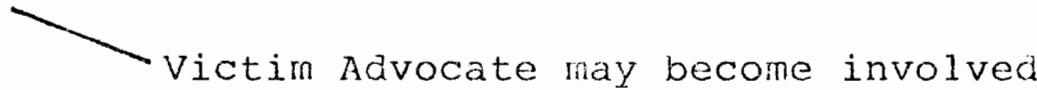

DDA Reviews Case Decide if have a case

Grand Jury interviews victin Charge offender if pleads to determine if enough evinot guilty to get lawyer dence for case

Arrest offender, re-arraign if already arrested If pleads guilty

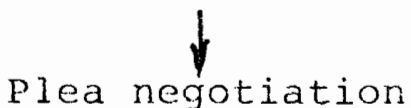
If pleads not guilty

Plea negotiation

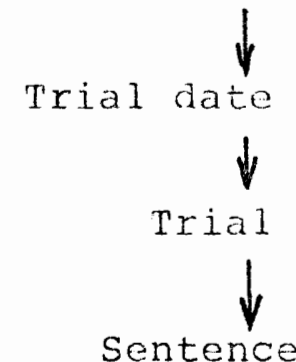

Eigure 3. \#2 - DA's office. 
Steps in Networking

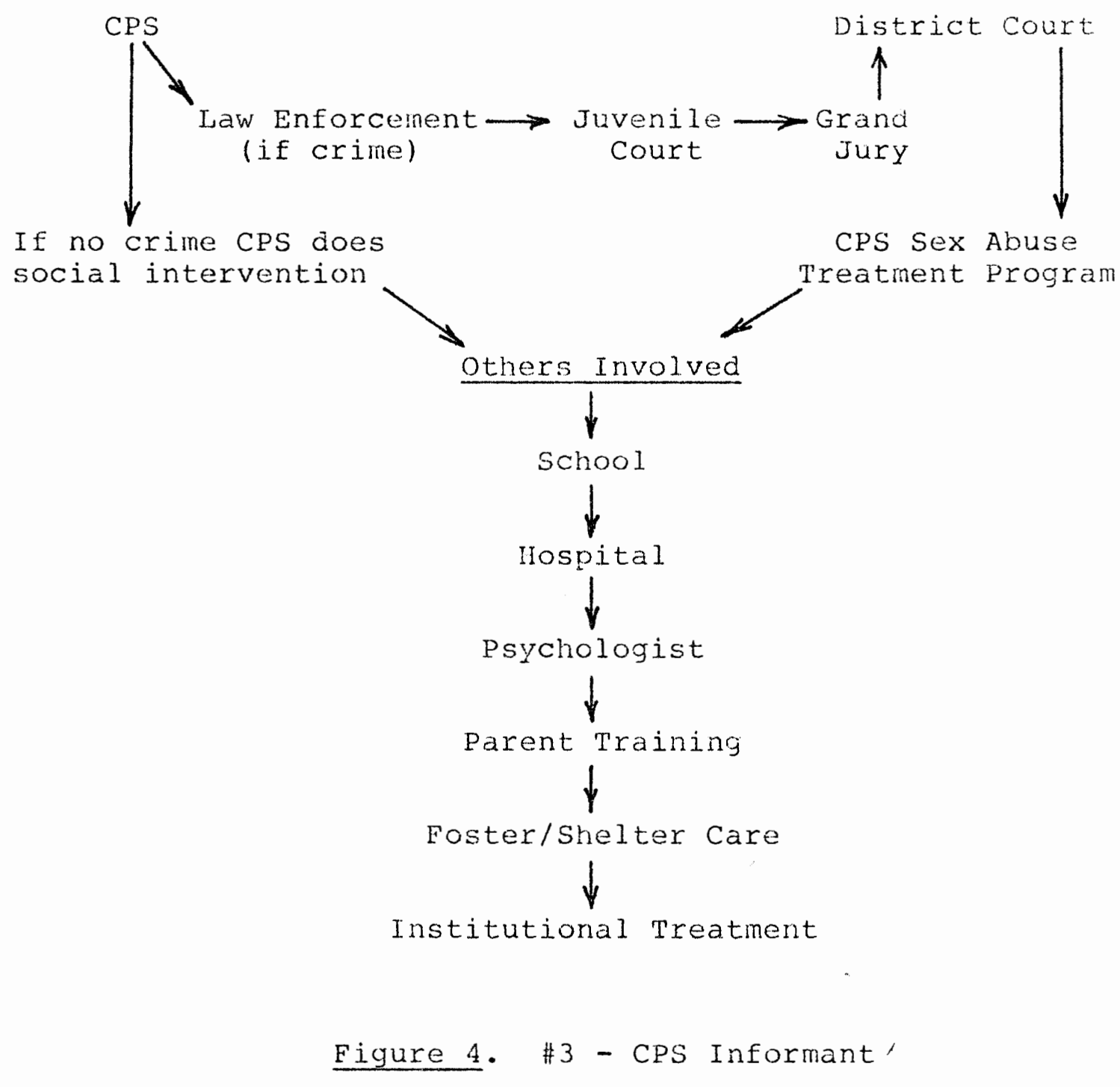


Steps in Networking

Infornation Police and/or CPS made public

Perpetrator informed of charge

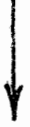

Intervien, questions/ lie detector, arrested
CPS works with social aspects

Juvenile court involved in custody proceedings for victin Grand Jury DA gets information and decides 4

Possible Trial or Guilty plea

Eigure 5. \#4-MCCAC Informant. 


\section{Steps in Networking}

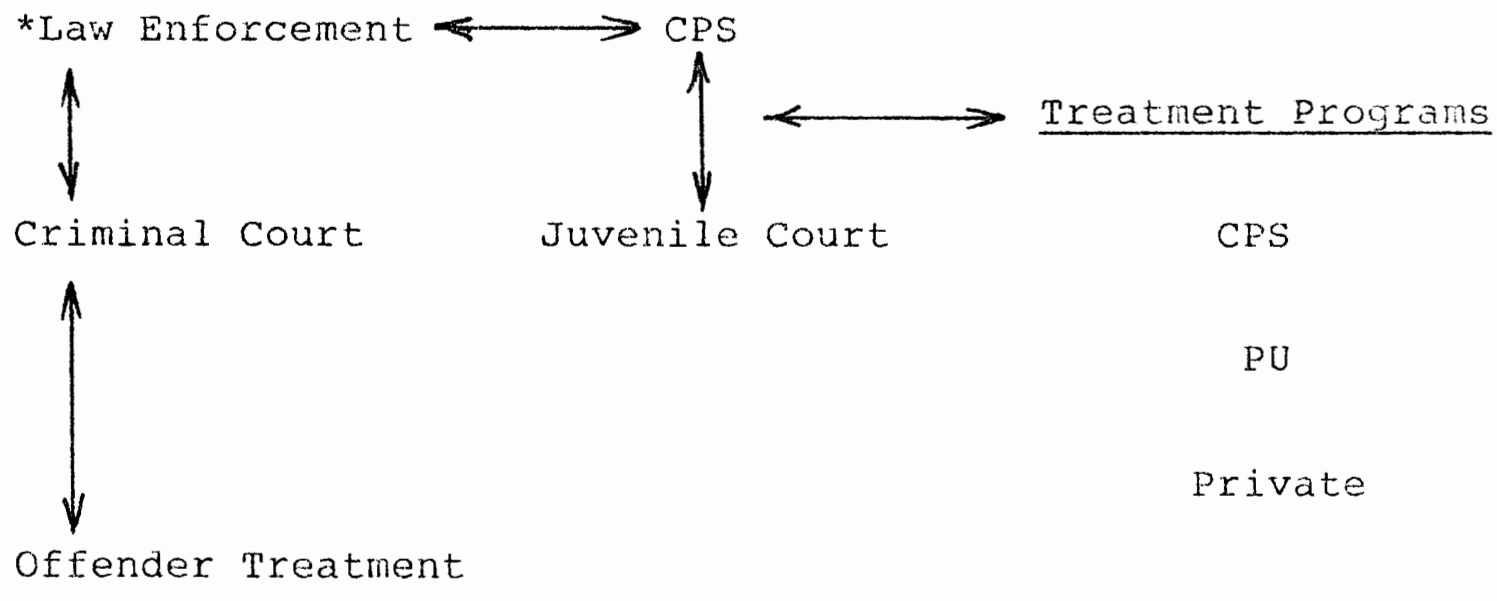

CPS and others

* May start with police, CPS or PU.

\section{Network at Case Management Level}

CSD/CPS or $\longrightarrow$ Mental Health Therapist Probation officer rents United

Meet every six months Others 
Steps in Networking

Coordinating Agencies

CPS $\leftrightarrow$ Police

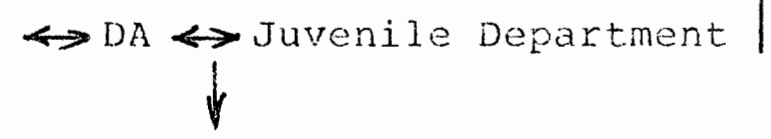

Service Agencies

PU

Private

If child is in danger:

Taken into
protective $\begin{gathered}\text { Placed in } \\ \text { Shelter }\end{gathered} \rightarrow \begin{aligned} & \text { Pretrial } \\ & \text { Next Day }\end{aligned}$

$\rightarrow$ If needed, temporary custody Detective with CSD supervising

May go home but court can issue 'No Contact' order other tools

Only need "proof of preponderance" to take custody

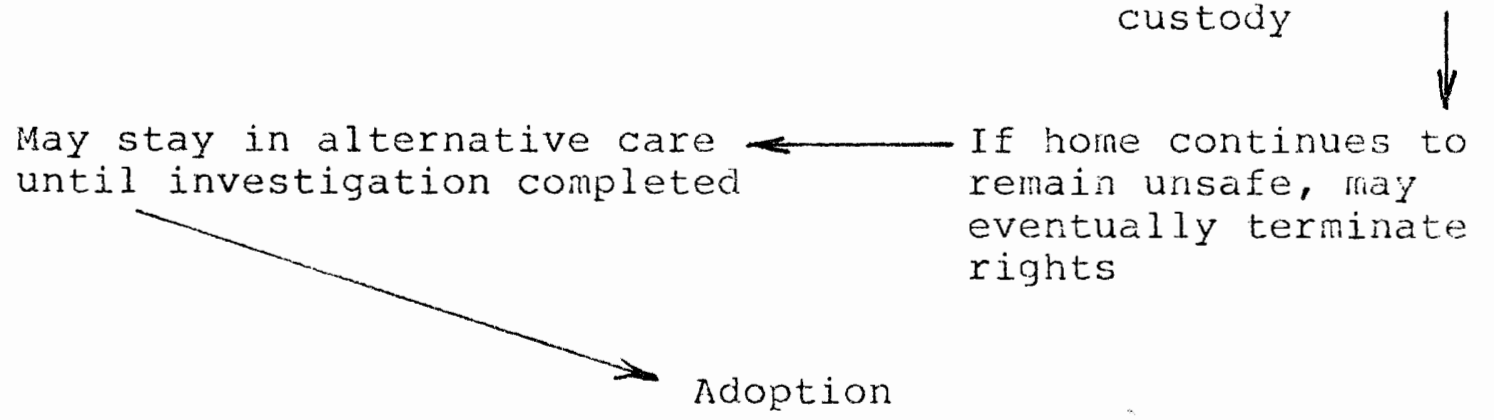

Eigure 7. \#6 - Juvenile court - DA Informant 
Steps in Networking

LEVEL ONE

Law Enforcement

PPB

Sheriff's - Outlying Areas

DA and courts

LEVEL TWO

Public Agencies

CPS

Mandated Reporters

Physicians

Lawyers

Private Therapists

LEVEL THREE

Private Providers

Waverly - Hotline and SC

Good Samaritan Ilospital

Private Service Groups -

Junior League

MCCAC

Metro Women

Downtown Business and Professional clubs

Exchange Club

First Interstate Bank

Service Delivery System

Figure 3. \#7 -CPS Management Informant 
Steps in Networking

Inception of case management team

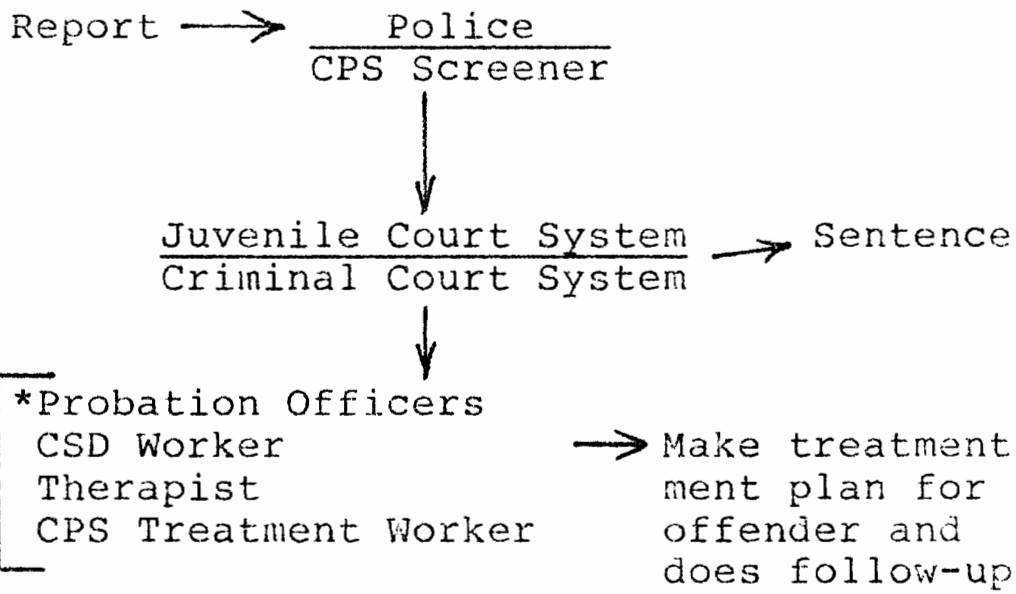

$\rightarrow$ Make treatment ment plan for offender and does follow-up

* Specialized Unit of probation officers

Figure 9. \#8 - CPS Treatment Informant 
the steps in networking from the prosecution perspective, Figures $3,5,6,78$, and 9 put more emphasis on case management (monitoring of individual cases) and treatment. There is a direct relationship between the informant's work focus and the emphasis shown in their particular map, e.g., PU informant places much more emphasis on treatment. All informants stated that while their map reflected the usual process, as they see it, there are exceptions in each step. For example, Figure 6 starts with law enforcement. However, my informant added that the report may begin with CPS or PU as well. This same informant also drew a map of networking at the case management level. This, she felt, was "a network within the larger network". In that same light, in Figure 9 the informant described a case management team which is being created at the present time but which was not mentioned by other informants. This case management team could add an important missing link to the network and address the concerns of those informants who felt that there was no consistency in the monitoring of cases from report through treatment. Lastly, some informants added agencies or groups not mentioned by others. Figures 6 and 9 include the probation office and Figure 8 adds private service groups.

What conclusions can be drawn to explain these differences? The following are possible reasons. 
1) Different informants deal with different components of the network in their daily routines.

2) There is both a criminal investigation and a social investigation involved and these lines of communication and responsibility overlap.

3) There is a lack of knowledge as to the specifics of each link or component in the network by other components.

\section{Problems in the Network}

This comparison of maps show that informants are in agreement about the major components of the network, but vary significantly in describing minor components and conditions of communication flow. Besides these inconsistencies, they also see other problems which weaken the linkage in the network and result in communication breakdown and duplication of efforts. The end results of a weakened network is further traumatization to the incest family. A "fictionalized" case study is presented below which will dramatize how problems in the network can impact negatively on the victim.

Tammy was 13 years old and had very few friends. She was afraid to get too close to anyone for fear they would learn her secret and then they would really know how awful she was! But things were getting worse at home. Her father was making more demands and she was scared.

One day she hung around in her last class not wanting to go home. The teacher asked Tammy if she wanted to help her put up a new bulletin board display. As they worked together and 
talked, Tammy felt a great deal of support from her teacher and eventually she haltingly "told her story". Her teacher assured her that her father's sexual advances were not Tammy's fault and that many other children had experienced the same problem. Tammy's teacher seemed anxious to help.

The next day a detective came to the school and Tammy had to tell her story again. Later that week CPS called and set up an appointment for Tammy and her mother. The worker said she was involved in the investigation but also wanted to talk about treatment resources. The CPS Assessor met with them and again Tammy told her story. A few days later there was a Juvenile Court hearing to determine if Tammy was safe in her own home since her father had moved out but continued to "drop in" unexpectedly. Again Tammy was asked to tell her story to the DA even though he had the police report. A "no contact" order was recommended and Tammy was allowed to remain at home with her mother.

A month later Tammy and her mother were subpoenaed to a Grand Jury hearing. This time Tammy told her story to seven jurors who she had never seen before. By this time Tammy felt like she was on trial and wished she had never mentioned it to her teacher in the first place. She was thinking seriously of telling everyone she had made it up and then maybe the family could get back to normal. Before didn't seem as bad as this...

The above account, while not untypical, combines the details of a number of cases in order to preserve confidentiality. It is not unusual for a child to be forced to tell her story a minimum of five or six times, and more when the offender does not plead guilty.

The duplication of reporting in Tammy's case is only one of the problems which informants see as weakening the network. Table XVII is a partial taxonomy listing the 
TABLE XVII

PROBLEMS IN NETWORKING

1) Budget Cuts

Five million dollar state deficit

Demotions and layoffs

Less salary due to no over time

No money for research

Legislature not sympathetic

2) Turf Issues

Confidentiality of clients necessary

More respect needed for work of CPS

Need better connection between CPS and police

Our large metro area with overlapping legal

jurisdictions and service responsibilities

Differences in treatment philosophies not res-

pected

3) Personnel

Low turnout at planning meetings

Low commitment of volunteers

New people in training

Untrained officers in investigation

Not enough people and time to take out peaks and valleys for collaborative agency networking 
TABLE XVII (continued)

3) Personnel (continued)

Not enough informed CSD, PO and judges on incest and treatment modalities

Not enough good offender treatment programs Protocol is dependent on personality

Constant changes in departments make consistency in protocol impossible

4) Other

Hesitancy in reporting

We are pioneers - no one knows what's treatable but we are afraid to say it!

Inconsistency in handing calls

We don't know how to network with incest behavior

Need more educaiton and prevention programs

Need juvenile offender programs

No well formulated case management team

Criminal process takes so long that families get

lost or get inadequate treatment

No way to order treatment until sentencing

Judges may order specific treatment without knowing what's best

"Everyone talks but no one does anything" 
"problems in networking". The classification can be separated into four categories: budget cuts, turf (territory) issues, personnel, and others. As stated in "Problems in MCCCAC" in Chapter $V$, the budget cuts impact directly on the personnel both in terms of number and energy output. Budget cuts also impact on burnout and high staff turnover. Most of the problems listed under "personnel" relate directly to one of these particular issues. "Turf (territory) issues", on the other hand, relate to procedures and philosophy. These problems, at least, are more within the control of those practitioners working in the network. Many of the specific concerns involve issues of protocol, poor communications or overlap in job responsibilities.

The last category "other" is a potpourrii of problems that are partially within the control of the network and partially influenced by funding and other external factors. The need for more education and prevention programs, plus the need for juvenile offender treatment are both projects which require additional funding. The remainder of the items mentioned in the category seems to evolve around informants' reactions to lack of efficiency in the network itself.

After studying these particular problems as related by informants, it appears that some are long range goals that may require the involvement of outside assistance, e.g., legislators, while others are short term goals which could 
be addressed from within the network, if a broad based group of representatives from each link of the network were willing to collaborate on such a project.

\section{This Network: Its Organizational Model}

We have analyzed the components of the network individually and examined the specific procedures and communication flow which determine its linkage. We are now in a position to evaluate the incest network in Multnomah County by comparing it to the five models of network systems of MacFarlane and Bulkley which were discussed in Chapter III.

In examining the maps of "steps in the network" we find, firstly, that all informants include the police, CPS and the DA as core components. All of these components are concerned with investigation and prosecution which places a strong emphasis on incest as a crime. However, most informants in these three task areas do not see incarceration of the offender as the sentence of choice. Rather, they see the criminal aspect and the prosecution process as the needed"motivation" for offenders to receive treatment.

secondly, the focus of these task areas is the family with specialized treatment for each member of the incest family (CPS Incest Treatment) as well as a self help component geared to the entire family (PU). Thirdly, one of the major goals of the members of the incest network in Multnomah County is to reduce trauma to the incest family 
by altering and hopefully improving the system. Altogether then, these three factors in this network are comparable to the philosophy, focus, and goal of the Systems Modification Model of MacFarlane and Bulkley (see Chapter III).

The remaining area of comparison is the "service component" aspect of the model. Since service to incest families is not provided solely by the specialized programs (CPS and PU), I also examined the more generalized private treatment programs in this county. Table XXVI includes a taxonomy of treatment resources with dimensions of contrast in: 1) type of treatment, 2) client focus, 3) cost, 4) treatment approach, 5) length of treatment sessions, 6) evaluation process, 7) program focus and 8) structural focus. Although the two specialized incest treatment programs are included in the taxonomy, I will concentrate only on the generalized private treatment programs since both CPS and PU were dealth with extensively in Chapter $V$.

The "type of treatment" is fairly evenly distributed with five programs providing "all of the above". It was surprising to me that in "client focus" many more programs focus on the victim and the entire family with only three focusing on the offender. In regard to "cost", most of the programs are competitive ( $\$ 35$ to $\$ 50$ an hour) although sex operate on a sliding scale (fee is geared to ability to pay). The variations in "treatment approach" were so vast that it indicates that the programs are attempting a 
TABLE XXIII

\section{INCEST TREATMENT PROGRAMS}

\section{PUBLIC}

CPS

Parents United

PRIVATE

Morrison Center - East

Morrison Center - West

Providence Day Treatment

Metropolitan Family Service

Good Samaritan Childrens Program

Clincal and Consulting Psych Association

Columbia Psychological Clinic

Portland Counseling and Psychological Association

Sylvan Psychological and Counseling Service University of Oregon Health Sciences Center Lutheran Family Service 
TABLE XIX

Dimensions of Contrast - Incest Treatment

1.0 Type of Treatment (Focus)

1.1 Group

1.2 Individual

1.3 Couple

1.4 All of above

2.0 Client (Focus) Services

2.1 Victim

2.2 Offender

2.3 Total family

2.4 Non-offending family members

2.5 Any of above

3.0 Cost

3.1 Free

3.2 sliding scale

3.3 Competitive

4.0 Treatment Approach

4.1 Insight oriented

4.2 Behavioral

4.3 Confrontative

4.4 Aversive 
TABLE XIX (continued)

4.5 Supportive

4.6 Education

4.7 Self help

4.8 Family Systems

4.9 Cognitive restructuring

5.0 Length of Treatment sessions

5.1 Six to eight weeks

5.2 Eight to twelve weeks

5.3 Twelve to fifteen weeks

5.4 Open ended

6.0 Evaluation process

6.1 Written

6.2 Verbal

6.3 Treatment team meeting

6.4 One to three months

6.5 Three to Six months

6.6 Testing

6.7 No evaluation component

6.8 Pre- and post-testing 
TABLE XIX (continued)

7.0 Program Focus

7.1 only incest treatment

7.2 Only sex abuse treatment

7.3 Incest treatment - one-half of cases

7.4 Incest treatment - one-fourth of cases

7.5 Incest treatment - minimal

8.0 Structural Focus

8.1 Specialized program

8.2 Part of multi-problem treatment 
TABLE XX

COMPONENTIAL DEFINITIONS OF INCEST TREATMENT

\begin{tabular}{|c|c|c|c|c|c|c|c|c|}
\hline Incest Treatment & 1.0 & 2.0 & 3.0 & 4.0 & 5.0 & 6.0 & 7.0 & 8.0 \\
\hline CPS Incest Treatment Program & 1.1 & $2.1,4$ & 3.1 & $\begin{array}{l}4 \cdot 1,2 \\
3,5,6\end{array}$ & 5.4 & $\begin{array}{l}6.1 \\
3\end{array}$ & 7.1 & 8.1 \\
\hline Parents United & 1.1 & 2.3 & 3.2 & $\begin{array}{r}4.5 \\
6,7\end{array}$ & 5.2 & $6.3,5$ & 7.1 & 8.1 \\
\hline Providence & $\begin{array}{c}1.1 \\
3\end{array}$ & 2.2 & 3.3 & $\begin{array}{c}4.1,2 \\
3,6\end{array}$ & 5.4 & 6.6 & 7.2 & 8.1 \\
\hline Morrison Center West & 1.4 & $2.1,3$ & 3.2 & $\begin{array}{l}4 \cdot 1,2 \\
3,5,6\end{array}$ & 5.4 & $6.1,8$ & 7.3 & 8.2 \\
\hline Morrison Center East & 1.4 & $2.1,3$ & 3.2 & $\begin{array}{c}4.3,5 \\
6,8\end{array}$ & 5.2 & $\begin{array}{l}6.1 \\
5,8\end{array}$ & 7.3 & 8.2 \\
\hline Metropolitan Family Service & 1.2 & 2.5 & 3.2 & 4.1 & 5.4 & 6.1 & 7.5 & 8.2 \\
\hline $\begin{array}{l}\text { Good Samaritan Childrens } \\
\text { Pragram }\end{array}$ & $\begin{array}{c}1.2 \\
3\end{array}$ & 2.5 & 3.3 & $\begin{array}{l}4.2 \\
5,6\end{array}$ & 5.2 & $\begin{array}{l}6.1 \\
3,8\end{array}$ & 7.5 & 8.2 \\
\hline $\begin{array}{l}\text { Chinical and Consulting } \\
\text { Psychology Association }\end{array}$ & 1.2 & 2.1 & 3.3 & $\begin{array}{l}4 \cdot 1,2 \\
3,4,5,6\end{array}$ & 5.4 & $\begin{array}{l}6.1 \\
3,8\end{array}$ & 7.5 & 8.2 \\
\hline Columbia Psychology Clinic & 1.2 & $\begin{array}{c}2.1 \\
2\end{array}$ & 3.3 & $\begin{array}{l}4.1,2 \\
3,4,5,6\end{array}$ & 5.4 & $\begin{array}{c}6.1 \\
6\end{array}$ & 7.2 & 8.1 \\
\hline $\begin{array}{l}\text { Portland Counseling and } \\
\text { Psychology Association }\end{array}$ & 1.4 & 2.5 & 3.3 & $\begin{array}{r}4.1 \\
8,9\end{array}$ & $5.4 !$ & 6.8 & 7.3 & 8.2 \\
\hline $\begin{array}{l}\text { Sylvan Psychology and } \\
\text { Counseling Service }\end{array}$ & 1.4 & 2.3 & 3.3 & $\begin{array}{r}4.1,2 \\
3,4,5,6\end{array}$ & 5.4 & 6.3 & 7.4 & 8.2 \\
\hline $\begin{array}{l}\text { University of Oregon } \\
\text { Mealth Sciences }\end{array}$ & 1.2 & 2.1 & 3.2 & 4.1 & 5.4 & 6.1 & 7.4 & 8.2 \\
\hline Lutheran Family Services & 1.4 & 2.3 & 3.2 & $\begin{array}{l}4.1,2 \\
3,5,6,7\end{array}$ & 5.4 & $-\cdots$ & 7.5 & B.2 \\
\hline
\end{tabular}


variety of treatment modalities either because all are effective or, more likely, to find what works best. Ten of the programs have "open ended" treatment sessions with only three providing short term treatment. Eight programs have a written evaluation with five providing pre- and posttreatment testing, two programs provide testing throughout treatment. The last two sections ("program" and "structural focus") are significant in that among private programs, none have "only incest treatment" as their focus, and only two focus on "only child sex abuse". Only four programs have specialized treatment to deal with child sex abuse while the others treat the problem as part of a "multi-problem" treatment approach.

The generalized private treatment programs expand the treatment aspect of the network and add a new dimension to the model. The specialized treatment programs (PU and CPS) provide the "service components" outlined in the systems Modification Model, i.e., they provide a family treatment approach treating family members individually (CPS) and combined (PU) and they offer a specialized sexual abuse program for the entire family. The generalized private treatment programs, however, do not offer specialized sexual abuse treatment but rather reflect the "service components" of the Independent Model. These programs use many different treatment techniques and in many cases operate parallel with the Criminal Justice system. Therefore, with 
the addition of the generalized private treatment programs, I assert that the child sex abuse network in Multnomah County combines the features of two models, i.e., the Systems Modification and Independent Model, and therefore, does not represent a "pure" model type.

This study in comparison has, I believe, provided an empirical description of the existing network; one that reflects the philosophy, focus, goal and service components of this network. It indicates that a linkage between the legal and the treatment components exists but shows the density in this linkage to be low, especially when including the generalized private treatment programs. The identification of this combined model provides the network in Multnomah County with a basis for comparison and evaluation and a conceptul framework from which to operate and build. 


\section{CHAPTER VII}

\section{SUMMARY RESULTS AND RECOMMENDATIONS}

The ethnographic analysis discussed in this study has concentrated on two areas: how incest is defined and the organizational format of the incest network.

\section{DEFINITION OF INCEST}

In Chapter II the nature of current working definitions of incest among practitioners in Multnomah County was explored. The formal defintions of incest used as the basis of comparison were the social defintion of incest by the National Council on Child Abuse and Neglect (NCCAN) and the legal definitions provided by the oregon statutes. While these definitions are well known, none of them seemed specific enough to prove functional for the daily tasks carried out by practitioners.

A common informal working definition of incest that all practitioners in Multnomah County agree upon was researched. In order for such a definition to be functional there must be agreement in fundamental areas. Currently, there is no agreement among practitioners concerning: who are to be categorized as incest offenders; the chronological age of a child victim; the specific sexual activities that constitute incest; and the difference between "incest" 
and "stranger molest", (see Chapter II). There also exists certain critical philosophical differences. While all practitioners agreed that incest is a crime, there were differing opinions as to whether it was also considered a family dysfunction, a mental illness, or both (see Chapter III). There was disagreement on whether incest is such only when it involves individuals with blood and marriage ties or if it also applies to those who have strong family identification through some special relationship, e.g., "live-in" boyfriend (see Chapter II). And lastly, some Multnomah County practitioners whom I interviewed questioned whether the term "incest" is a useful category at all under "kinds of sexual abuse" or whether it is not more practical to divide offenders into "known" and "unknown" assailants and ignore the incest distinction altogether (see Chapter II).

Thus, the only, consensus in regard to a working definition of incest among practitioners in Multnomah County is that it includes the words "sexual" and "family". However, even these two terms cannot be defined with uniformity. Summarily, there is no commonly agreed upon, explicit definition of incest among practitioners in Multnomah County.

Is such a common and uniform definition of incest absolutely necessary? Although all networks must have some level of common agreement in order to be functional, it is 
evident that a system can exist in which there are variations in definition among components of the network. The question is: how does this variation affect the performance of tasks?

In Chapter VI I discussed the "problems of the network". None of the practitioners listed "no common definition of incest" as a problem. Does this omission imply that practitioners in this network are not aware of the lack of a common definition of incest or that, in fact, it is not considered critical to them to have an explicit, uniformly held definition? Most of my informants were aware of dissimilarities in their concept of the component parts of the definition of incest. All felt that a formalized common definition of incest could be helpful, but no one saw this need as urgent.

To arrive at a common definition for a problem such as incest is very difficult because of its many situational aspects and variations. It is significant, J think, that there is no consensus on the definition of child sex abuse, in general, let alone incest in particular. In the 1981 report on "Child Sex Abuse" published by the U.S. Department of Health and Human Services, there is an extensive discussion on the difficulty in arriving at a common definition of child sexual abuse. The report states:

As with other forms of child abuse, there is generally agreement concerning the most extreme cases, but the operational definition of what specific behaviors constitute sexual abuse of 
children remains largely a matter of jurisdictional and individual interpretation. Many of the terms in the literature that differentiate types of child sexual abuse are used interchangeably by professionals and the public. As more has become known about this problem, even such unintentional behaviors as obscene language or accidental sexual stimulus have been discussed as possibly constituting sexual abuse. (U.S. Dept. of Health and Human Services 1981:4)

\section{CULtuRE THEMES - AN ALteRnative to DEFinition}

Let us assume for a moment that a common definition of incest is impossible to attain or is unnecessary for effective networking. What operational procedures or concepts could provide a basic format of agreement to allow for smooth communication throughout the network? Although I have shown the differences in practitioners' belief systems, I found, nevertheless, an underlying area of agreement which emerges as "culture themes". Culture themes may be defined as "cognitive principles either tacit or explicit recurrent in a number of domains and serving as a relationship among subsystems of cultural meaning" (Spradley 1979:186). These underlying themes permeate the entire network and appear to be generally accepted by all practitioners included in this study (see Table XXI). Although this list of culture themes is merely a beginning, it certainly could be used as a starting point to establish a basic agreement among practitioners working with incest. With further study using a more conclusive sample of 
TABLE XXI

\section{CULTURE THEMES AMONG PRACTITIONERS}

1. The offender is at fault for the incestuous act.

2. Victims do not ordinarily lie about incest.

3. Incest is a crime punishable by the law.

4. All victims, offenders and non offending family members need support and treatment.

5. Victims and offenders should be physically separated until the victims is no longer in danger of reabuse.

6. Incest offerders cannot solve the problem on their own. They must receive treatment.

7. Practitioners cannot be isolated. They must all work together in a functionally effectivew network in order to provide the greatest help to the incest family.

8. The victim is in danger as long as he/she is accessible in any way to the offender, until treatment is completed.

9. The goal of practitioners is to prevent re-offense of the victim or of other victims.

10. Incest is both "recidivistic" and "generational."

11. The non-offending spouse is the key family member in successful rehabilitation of the offender and the victims. 
12. Incest cases cross all religious, social, racial, and economic levels. 
practitioners, the list could be expanded and provide the framework for consensus within the incest network.

\section{NETWORK ANALYSIS}

The second area of concentration in this study was the incest network itself (see Chapters III and VI). These chapters dealt with such questions as: Does an effective network exist in Multnomah County that deals with the problem of incest? How does this network compare organizationally with other networking systems throughout the country?

In comparing the program models of MacFarlane and Bulkley (see Chapter III) I concluded that the incest network in Multnomah County most closely resembles the systems Modification Model in its philosophy, focus and goals; whereas, the Independent Model is more representative of the service components available in our private treatment programs (see Chapter VI).

The next question I examined was: How effective is the Systems Modification - Independent Model that we have developed in Multnomah County? The ethnographic analyses included many committed individuals who are carrying out their tasks in a highly professional manner. Further, all practitioners agree that the network is more effective than it was eight years ago. However, it is also obvious that many of these committed practitioners who have worked the past six to eight years trying to improve the network are 
now "burned out", laid off or have changed careers. Who will replace them and how effective will they be? Are there funds to replace them? Since the beginning of this research in June of 1983, the following major setbacks have occurred in the four task areas which threaten the functional effectiveness of the network.

1) The Special Services Detail of the Multnomah Sheriff's office suffered demotions and lay offs.

2) Parents United lost its major leadership and its funding source and is in a reorganization process.

3) The Multnomah County Child Abuse Coalition discontinued the Child Sex Abuse Response Project (i.e., the only committee directly concerned with child sex abuse) due to low energy and lack of energy.

4) Childrens Protective Services is threatened with more financial cutbacks and lay offs.

These disadvantageous conditions weaken the effectiveness of this current Systems Modification - Independent Model and suggest that changes in networking strategy and tactics are required. Suggestions as to how to improve network effectiveness in Multnomah County will conclude this study. 


\section{RECOMMENDATIONS}

Although the economic stresses outlined above have definitely had a negative impact on the incest network, they are also unavoidably a "sign of the times". In this period of cutbacks and elimination of social service programs, conditions of survival will depend heavily on personal creativity and commitment to common goals among the practitioners within each social program. In the Multnomah County incest network, human resources and energy are diminishing while the problems associated with incest are intensifying. How can this serious imbalance be rectified? The following are suggestions based on my research experiences.

1) Criminal Justice System. Conduct an efficiency study of the Special Services Detail of the Multnomah County Sheriff's, Office and the Portland Police Bureau. Based on the findings in the study, job responsibilities within the two departments could be combined and thus improve networking by fostering better communication among personnel and making maximum use of available human resources.

2) Criminal Justice System and Childrens Protective Services. Support and strengthen the case management team by developing a more effective liaison system between the Probation Office and the CPS Incest Treatment Program. This 
team will be instrumental in improving the monitoring of individual incest families, as well as providing information and education to the legal system as a whole.

3) Childrens Protective Services. Separate distinctly the dual (and often times conflictual roles) of investigation and treatment by giving CPS Incest Treatment specialists more autonomy from the investigatory process. This will provide them with the freedom to advocate therapeutically for their clients without producing the conflicting image of being both "detective" and therapist".

Another strategy I recommend is to provide more flexibility in separating the two roles of detective and therapist by having CPS contract with various private treatment agencies for services to incest families. This will eliminate the conflict of roles and at the same time provide more choices in treatment for incest families.

4) Parents United. Emphasize and expand the self help and support concepts of the program. The present groups need to be redesigned to provide more peer support and empowerment (giving victims control over their lives) among group members; thus leaving the therapeutic aspect to other specialized treatment programs. The self help aspect and the sponsorship programs are unique components of the network that are only offered by Parents United. These services are invaluable in the complex process of rehabilitation of incest families. 
I also recommend that the present sponsorship program of Parents United be recognized by the Criminal Justice System as a critical part of the process by incorporating it into the investigation process so that offenders and victims are automatically assigned PU sponsors at the time of disclosure. This will provide an early support system for the incest family and encourage more offenders to plead guilty; thus, lessening the trauma to the victim and the family as a whole.

5) Treatment Programs. Better understanding and respect (or at least a tolerance) for different treatment modalities within the network is needed. Combined effort among treatment agencies will provide information for comparative research and offer the best treatment options available to meet widely differing needs. The position that only one treatment approach can be effective should be relinquished unless (or until) research provides support for such a contention. If we don't know the cause of incest, how can we be sure of the cure?

6) Multnomah County Child Abuse Coalition. A grant proposal should be prepared which would financially subsidize a coordinator and part time secretary for MCCAC. These positions would make a broader base of participation in the network possible, as well as ensure the most effective utilization of members' time and expertise. 
7) Multnomah County Child Abuse Coalition. Reinstate the Child Sex Abuse response Project charged with the task of developing a consensus list of "culture themes" which could be formally promulgated and periodically evaluated. This service would provide the conceptual foundation for commonality of purpose and action which I believe is necessary in effective networking.

8) Multnomah County Child Abuse Coalition. In the area of protocol, pursue the task begun in this study of identifying further the type of networking system being used to work with incest in Multnomah County. Beginning with the Systems Modification - Independent Model, investigate alternative network types as well as the conceptual framework that all practitioners hold in common.

9) Multnomah County Child Abuse Coalition. Strengthen the Legislative Committee so that legislation can be developed and funds allocated to equip the network of practitioners with the tools and resources required to provide the most efficient and supportive protocol procedure for dealing with the incest family. A politician or legislative aide who understands and supports the need to work effectively with incest, should be included on the committee to provide a different perspective on policy issues and to act as a liaison between the committee and the State Legislature. 
10) Multnomah County Child Abuse Coalition. Develop a specific project designed to increase the understanding of judges and district attorneys on specific information and facts concerning incest, i.e., the early indicators, typical emotional reactions of family members, best treatment plans and the most effective protocol procedures.

Finally, each member of the network should set forth in writing its guidelines, philosophies, and procedures and distribute these to the agencies in the network. This sharing would improve awareness of what expertise each component of the network has to offer and how they can interface, collaborate and avoid duplication of effort. The end result will be an effective network which provides the best service possible to incest families in Multnomah County. 


\section{REFERENCES CITED}

Brommel, Bernard and Kathleen Galoin

1972 Family communication: Cohesion and Change. Scott Foresman, Illinois.

Burt, Ronald S.

1982 Toward a Structural Theory of Action: Network Models of Social Structure, Perception and Action. Academic Press, N. Y.

Giarretto, Henry

1976 Parents United Handbook 1976. San Jose, Ca. (unpublished).

MacFarlane, Kee and Josephine Bulkley

1982 Treating Child Sex Abuse: An Overview of Current Program Models, Journal of Social Work and Human Sexuality. 1:69-91.

Mazek, Patricia B. and C. Henry Kempe

1981 Sexually Abused Children and Their Families. Pergamon Press, Inc., N. Y.

Mead, Margaret

1968 Incest. Int. Journal of Social Sciences 115-121.

Merriam, G. and C. Merriam (eds.)

1978 Webster's New Ideal Dictionary. G. and C. Merriam Co., U.S.A.

Mitchell, J. C.

1969 Concept and use of Social Networks: Social Networking in Urban Situations, The Hague, Moutan.

Mitchell, J. Clyde

1974 Social Networks. Annual Review of Anthropology $3: 279-299$.

Oregon State Dept. of Human Resources

1980 "Child Abuse in Oregon: a 10 Year Overview" (unpublished).

Oregon Revised statutes

1983 Legislative Assembly Vol. I, State of Oregon. 
Rueveni, Uri

1979 Networking Families in Crisis. Human Sciences Press, New York.

Schultz, Leroy G.

1982 Child Sex Abuse in Historical Perspective. Journal of Social Work and Human Sexuality 1:21-33.

Spradley, James P.

1979 The Ethnographic Interview. Holt, Rinehart and Winston, N. Y.

Spradley, James P.

1980 Participant Observation. Holt, Rinehart and Winston, U.S.A.

U.S. Dept. of Health and Human Services

1974 Sexual Abuse of Children. National Center on Child Abuse and Neglect; Washington, D.C. (pamphlet).

U.S. Dept. of Health and Human Services

1981 Child Sexual Abuse: Incest, Assault and Sexual Exploitation. Office of Human Dev. Series, Washington, D.C. (document) 


\section{BIBLTOGRAPHY}

\section{INCEST -- THE ANTHROPOLOGICAL PERSPECTIVE}

Aberle, David F., et al.

1963 "The Incest Taboo and the Mating Patterns of Animals". American Anthropologist, New Series 65: 253-265.

Aldridge, Alfred 0 .

1951 "The Meaning of Incest From Hutcheson to Gibbon". Ethics 61: 309-313.

Bettelheim, Bruno

1954 Symbolic Wounds: Puberty Rites and the Envious Male. Free Press, Glencoe, Ill.

Cohen, Yehudi A.

1964 The Transition from Childhood to Adolescence: Cross-cultural Studies of Initiation Ceremonies, Legal Systems, and Incest Taboos. Aldine, Chicago.

Durkheim, Emile

1963 Incest: The Nature and Origin of the Taboo. Stewart, New York.

Fox, Robin

1967 Kinship and Marriage. C. Nichols and Co., Itd, Great Britain.

Frances, Vera and Allen

1976 "The Incest Taboo and Family structure". Family process, June, 1976.

Freud, sigmund

1918 Totem and Taboo. Random House, Inc., New York.

Kroeber, Alfred $L$.

1920 "Totem and Taboo: An Ethnologic Psychoanalysis". American Anthropologist, New York Seriers 22: 48-55.

Malinowski, Bronislaw

1929 The Sexual Life of Savages. Harcourt, Brace and World, New York. 
Mead, Margaret

1928 From the South Seas: Studies of Adolescence and Sex in Primitive Societies. William Morrow and Co., New York.

1968 Definition of Incest. International Journal of Social Sciences, pp. 115-121.

Murdock, George Peter

1949 Social Structure. Macmillan Company, New York.

Needham, Rodney, Ed.

1971 A Rethinking Kinship and Marriage. Tavistock Publications, London.

Reed, Evelyn

1975 Woman's Evolution. Pathfinder, New York.

Rush, Florence

1980 The BestKept Secret. McGraw-Hill Co., New York.

Schultz, Leroy G., Ed.

1980 The Sexual Victimology of Youth. Charles C. Thomas, springfield, Illinois.

Wallis, Wilson D.

19509 "The Origin of Incest Rules". American Anthropologist New S Series 52: 277-279.

Westermack, Edward

1981 The History of Human Marriage. Richard Clay and Sons, Suffolk, England.

White, Leslie $A$.

1948 "The Definition and Prohibition of Incest". American Anthropologist New Series 50: 416-435. 
APPENDIX A

\section{CHILD ABUSE REPORTING LAW}

The 1971 Oregon Legislative Assembly passed Oregon's first Child Abuse Reporting Law. It was amended by the 1975 and 1977 Legislative Assemblies.

The law defines "abuse" as:

A. Any physical injury to a child which has been caused by other than accidental means, including any injury which appears to be at variance with the explanation given of the injury.

B. Neglect which leads to physical harm. A child who in good faith is under treatment solely by spiritual means through prayer in accordance with the tenets and practices of a recongized church or religious denomination by a duly accredited practitioner thereof shall, for this reason alone, not be considered a neglected child within the meaning of ORS 418740 to 418.775 and 419.476 .

C. Sexual molestation.

Persons required to report are:

A. Physician, including any intern or resident.

B. Dentist.

C. School employe.

D. Licensed practical nurse or registered nurse. 
E. Employee of the Department of Human Resources, county health department, community mental health department, community mental health program, a county juvenile department, or a licensed childcaring agency.

F. Peace officer.

G. Psychologist.

H. Clergyman.

I. Social worker.

J. Optometrist.

K. Chiropractor.

L. Certified provider of day care, foster care, or an employe thereof.

M. Attorney.

When a person required to report has reasonable cause to believe that a child with whom they come into contact in their official capacity has suffered abuse, they must report the situtation to either a law enforcement agency or the local Children's Services Division (CSD). Upon receipt of an abuse report, the Children's Services Division must report to a law enforcement agency and vice versa.

The law enforcement agency or the local Children's Services Division must immediately cause an investigation to be made. If the law enforcement agency finds reasonable cause to believe that abuse has occurred, they must report the case to the local Children's Services Division. The 
local Children's Services Division must provide protective services (determine whether or not the child can remain in his own home, provide counseling to resolve the disposing problems and/or alleviate crisis that led to the abuse and provide supportive services such as day care, homemaker or medical services when indicated and available).

The local Children's Services Division must also report the case to the Child Abuse Central Registry which is maintained by the central office in Salem. Information in the Registry can be made available to physicians, law enforcement agencies, Children's Services Division personnel and abuse registries in other states. When making an investigation or diagnosis of child abuse, the above-named may contact the Central Registry to determine whether or not a previous report of child abuse has been filed on behalf of a child or another child in the same family. The law provides immunity from civil and/or criminal liability to anyone reporting in good faith.

Further information regarding child abuse/neglect can be obtained by contacting Mr. Alden "Bud" Powell, Manager, Protective Services, Salem, Oregon 97310, telephone number (503) 378-3016.

NOTE: Only psychiatrists, psychologists, clergymen, and attorneys retain their rights of privileged communication provided under ORS 40.225 to 40.295 , when counseling/ treating an adult or victim. 
TABLE XXII

SEXUAL MOLESTATION BY AGE AND PERPETRATOR

NUMBER

PERCENT

$\begin{array}{rrrrrrr}\text { Age } & 1980 & 1981 & 1982 & 1980 & 1981 & 1982 \\ 0-1 & 1 & 3 & 4 & 0 \% & 0 \% & 0 \% \\ 1-2 & 4 & 6 & 8 & 1 & 1 & 1 \\ 2-4 & 23 & 46 & 108 & 4 & 5 & 8 \\ 4-6 & 42 & 106 & 178 & 7 & 12 & 14 \\ 6-9 & 95 & 135 & 234 & 15 & 16 & 18 \\ 9-11 & 99 & 108 & 178 & 16 & 13 & 14 \\ 11-15 & 236 & 276 & 395 & 37 & 32 & 30 \\ 15-18 & 135 & 183 & 213 & 21 & 21 & 16 \\ \vdots & & & & & & 100 \%\end{array}$


TABLE XXII (continued)

\begin{tabular}{|c|c|c|c|c|c|c|}
\hline \multirow{3}{*}{ Perpetrator } & \multicolumn{3}{|c|}{ PERPETRATOR } & \multirow{2}{*}{\multicolumn{2}{|c|}{ Percent }} & \multirow[b]{3}{*}{1982} \\
\hline & \multicolumn{3}{|c|}{ Number } & & & \\
\hline & 1980 & 1981 & 1982 & 1980 & 1981 & \\
\hline Father & 204 & 258 & 308 & $32 \%$ & $30 \%$ & $23 \%$ \\
\hline Stepfather & 167 & 190 & 206 & 26 & 22 & 16 \\
\hline Relative & 59 & 91 & 151 & 9 & 11 & 11 \\
\hline Mother's boyfriend & 43 & 82 & 97 & 7 & 10 & 7 \\
\hline Babysitter & 18 & 30 & 69 & 3 & 3 & 5 \\
\hline Sibling & 28 & 30 & 94 & 4 & 5 & 7 \\
\hline Friend & 30 & 44 & 105 & 5 & 5 & 8 \\
\hline Neighbor & 30 & 53 & 90 & 5 & 6 & 7 \\
\hline Foster Father & 12 & 5 & 7 & 2 & 1 & 1 \\
\hline Foster Sibling & 3 & 4 & 7 & 0 & 0 & 1 \\
\hline Mother & 4 & 4 & 16 & 1 & 0 & 1 \\
\hline Stranger & 16 & 19 & 66 & 3 & 2 & 5 \\
\hline Babysitter's son & 0 & 1 & 8 & 0 & 0 & 0 \\
\hline Babysitter's husband & 1 & 3 & 3 & 0 & 0 & 0 \\
\hline Teacher & 0 & 2 & 9 & 0 & 0 & 1 \\
\hline
\end{tabular}


TABLE XXII (continued)

\section{PERPETRATOR}

Number Percent

\begin{tabular}{lrrrrrr}
\multicolumn{1}{c}{ Perpetrator } & 1980 & 1981 & 1982 & 1980 & 1981 & 1982 \\
\hline Landlord & 1 & 0 & 4 & 0 & 0 & 0 \\
Church personnel & 1 & 0 & 2 & 0 & 0 & 0 \\
Friend's father & 1 & 1 & 10 & 0 & 0 & 1 \\
Cult leader & 0 & 10 & 5 & 0 & 1 & 0 \\
Victim's boyfriend & 0 & 4 & 6 & 0 & 0 & 0 \\
& & & & & 1 & 1 \\
Unknown & 5 & 6 & 12 & 1 & 1 \\
Other & 12 & 16 & 43 & 2 & 2 & 3 \\
& & & & & $100 \%$ & $100 \%$
\end{tabular}

*A child may be molested by more than one perpetrator. 


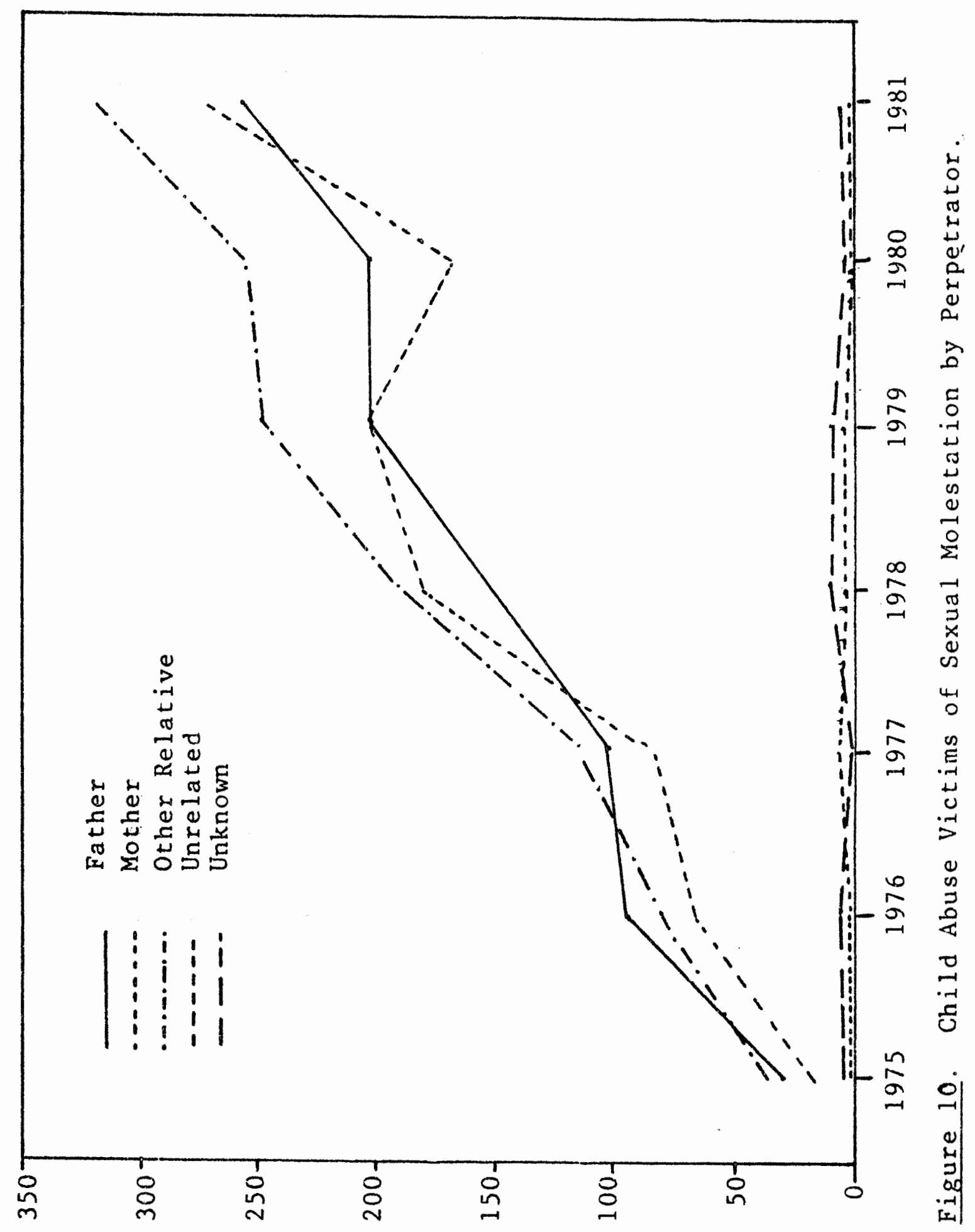




\section{APPENDIX B}

The purpose of the Multnomah County Child Abuse Coalition is to address the issues of child abuse and neglect within the Multnomah County area. These issues include but are not limited to: 1) coordination of treatment agencies to provide better services; 2) coordination of treatment agencies, Child Protective Services and Children's Services Division, and justice services to result in improved systems intervention and service to families; 3) identification and development of needed service components; such as crisis intervention, assessment of family needs, comprehensive medically based teams, and effective, innovative outpatient services; 4) prevention; 5) community education and public awareness; 6) legislative lobbying; 7) liaison with state and national Child Abuse Chapters; and 8) fund raising to meet the above goals. As these issues are addressed, it is expected that the system of child abuse intervention will be of higher quality and effectiveness, resulting ultimately in a reduction of the incidence of child abuse and neglect.

MCCAC GOALS/OBJECTIVES AND IDEANS

GOAL 1 Coordination of treatment agencies to provide better services. 
OBJECTIVES

1. Find out what treatment agencies there are (define who we are including).

2. Tell treatment agencies about us (beware of political backlash).

3. Identify gaps in our membership and try to fill them.

4. Identify gaps in service (see Goal III).

5. Do all of the above on an ongoing basis (it should get easier after we are better estabIished) .

GOAL II Coordination of treatment agencies, CPS, CSD and justice services to improve systems intervention and service to families.

\section{OBJECTIVES}

1. Identify gaps in our membership and try to fill them (more juv. ct.).

2. Develop a clear picture of the systems (like Terry's flow charts?).

3. Support pursuits like CAN Team and CSARP who are tackling this problem in the area of sex abuse.

4. Strengthen CAN Team and respond effectively to the issues they raise (they are a superb source for identifying systems problems). 
5. Develop an approach to people like judges and meet with them on a not crisis basis to tell them what we aredoing and ask their input.

6. Do the same for juvenile court personnel (Davene Cohen) •

7. Do the same wherever "weak links" are identified. GOAL III Identify gaps and develop needed service components, such as crisis intervention, assessment of family needs, comprehensive medically based teams, and effective innovative outpatient services.

OBJECTIVES

1. Use the CAN Team.

2. Develop another CAN Team lone at $U$ of 0 , one at Emanuel and one at Adventist?).

3. Look at who is falling through the cracks, ask why •

GOAL IV Prevention

OBJECTIVES

1. Find out who is doing what now (this is liable to be a big chore).

2. Have a meeting of all of the major people involved and anyone else who is interested, like the schools who are the target of so much of this effort.

3. Find other places besides school where there are kids (park system, especially in the summer). 
4. Try to get those already doing this to do it better, help them find resources and provide information, if possible, stay out of doing this directly.

GOAL V Community education and public awareness. OBJECTIVES

I. Same as all of IV, except perhaps 4 .

2. Possibly develop a speakers bureau or offer MCCAC resources in an existing service (library has a list of speaker agencies).

3. Get MCCAC into the papers, etc.

4. Continue to get article (human interest) in, perhaps some success stories of families or individuals who seem to have overcome.

5. Keep it slow and steady.

GOAL VI Legislative lobbying.

OBJECTIVES

1. Keep our eyes open for issues in advance of the legislative session.

2. Cultivate some friends--Gretchen Kafoury, Vera Katz, but stay out of any individuals' campaigns as an organization.

3. Keep informed as issues progress (Muriel Goldman probably best informed in town).

4. Be alert to problems which require legislative action. Be picky. 
5. Develop strategies--perhaps a committee.

GOAL VII Liaison with state and national Child Abuse Chapters.

OBJECTIVES

1. Affiliate membership.

2. Newsletter received if there is one.

3. Jack, monthly report.

GOAL VIII Fund raising to meet the above goals. OBJECTIVES

1. Get all of the above in place.

2. Decide what is needed and what it will cost.

3. Develop friends--Ned Look, Fred Meyer, Exchange Club, etc.

4. Call on your friends. 


\section{CHILD SEXUAL ABUSE RESPONSE PROJECT}

Statement of Purpose

The purpose of the Child Sexual Abuse Response Project is to establish in Multnomah County a consistent, coordinatea response to sexual abuse of children by their intimates. It is expected that such a response will increase the likelihood of offender rehabilitation; will minimize the insidious effects of exposing children to sexual exploitation by those they are taught to trust; will increase the likelihood that the children and their families will mature to lead healthy and productive lives and allow them experiences which will prevent the sexual abuse of the next generation of children.

To that end the Child Sexual Abuse Response Project has established the following goals:

I. A systematic and coordinated approach to victims as a unique group and to the alleviation of the crisis for victims and families.

II. Early and complete family assessment will determine strengths and weaknesses of each family member, assess health of the marriage, identify the family's natural support system and will result in coordinated case planning and management. Assessment of the offender 
would include criminal history and likely effects of offender remaining in or leaving the family.

III. Provision of information and specialized training for professionals whose work impacts directly or indirectly on offenders, child victims of sexual abuse, and their families.

IV. Increased community awareness of probiems of child sexual abuse and community involvement in the effort to eliminate those problems. 


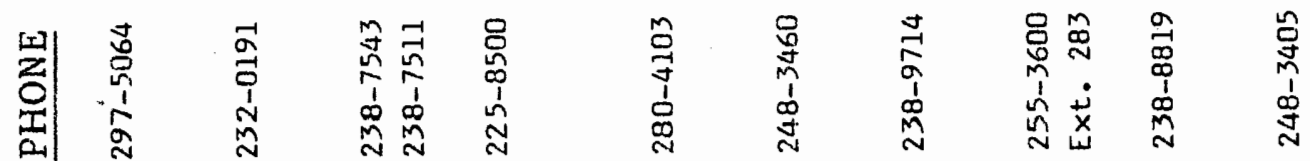

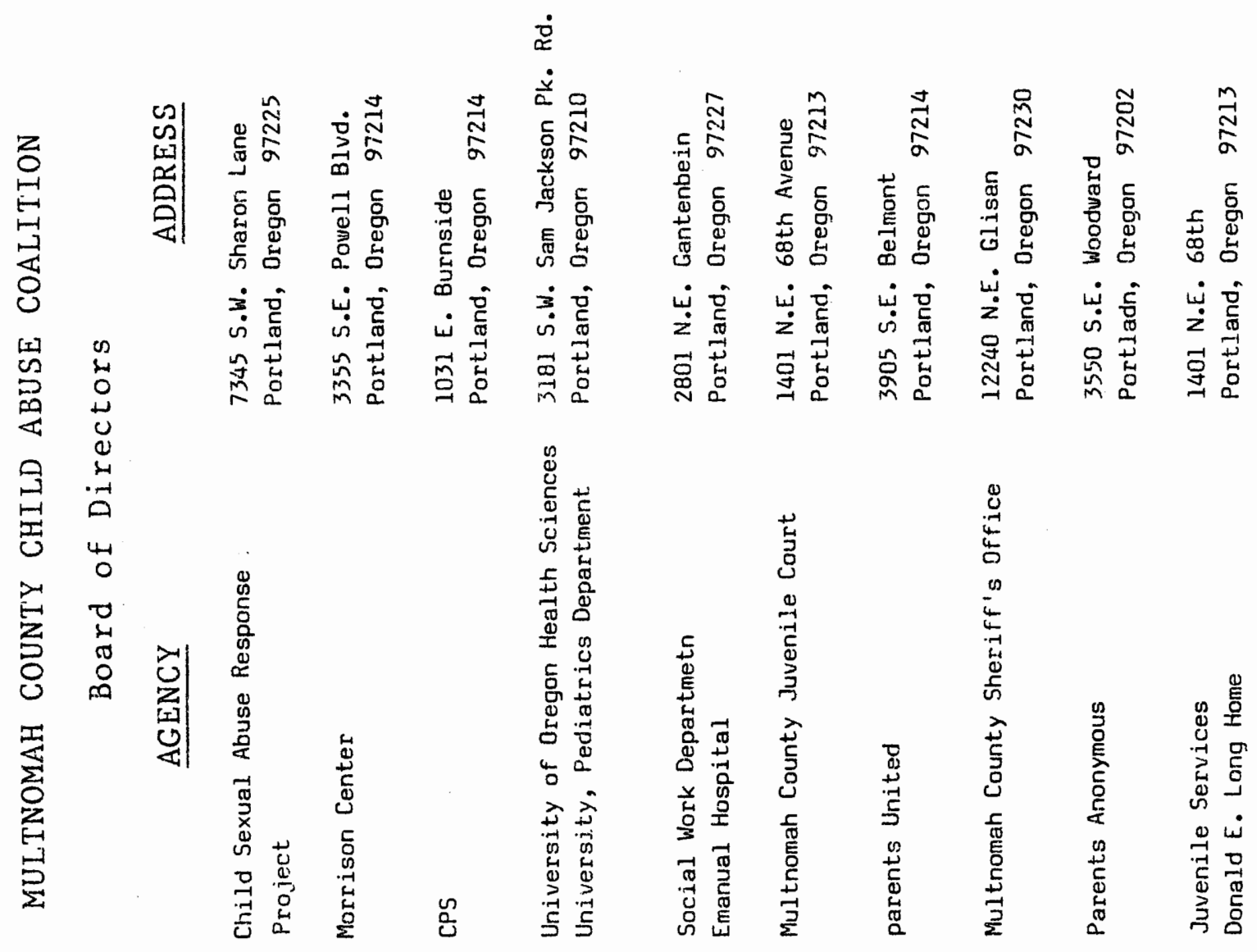

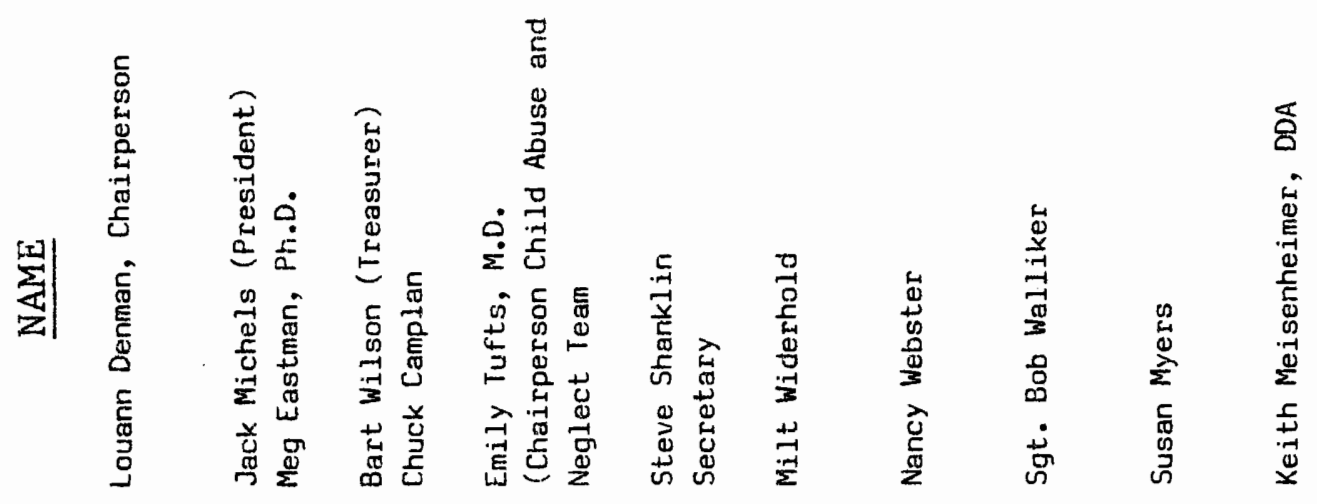




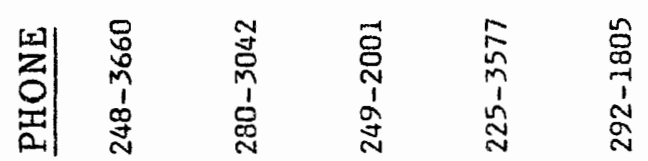

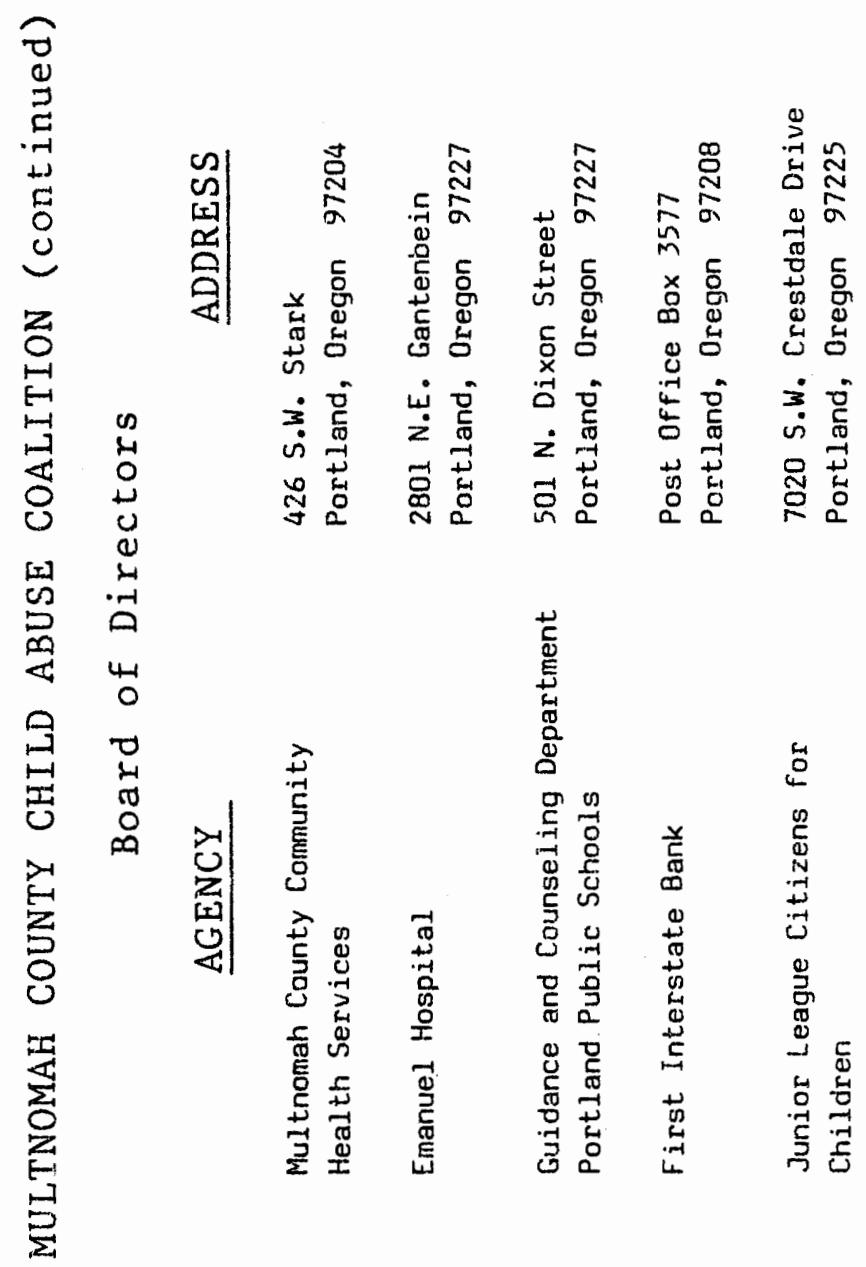

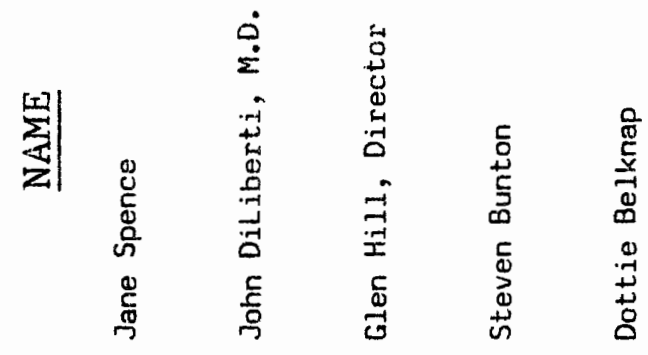


CAN TEAM GOAL AND OBJECTIVES

GOAL

To develop and maintain multidisciplinary expertise around Child Abuse and Neglect cases in order to serve as consultants to the legal system and treatment agencies so that families receive effective intervention.

\section{OBJECTIVES}

1. To serve as a resource for identifying and documenting examples of need and problems encountered in specific child abuse case management.

2. To serve as a quality team of independent professionals to consult regarding difficult CAN cases. a. To CPS in difficult case decisions and management.

b. To MCCAC regarding problem areas, community demands, ideal and realistic solutions.

c. To the legal system.

d. To community service agencies.

3. To critique new or existing programs through case reviews.

4. To identify, clarify, and attempt reconciliation of the differing goals of disciplines involved and needs of individual families. 
5. To develop realistic standards of practice and to advocate their acceptance.

6. To provide MCCAC with identified problem areas and suggestions for problem resolutions with the expectation that MCCAC will respond.

7. To support professionals in the legal and treatment disciplines. 